Portland State University

PDXScholar

\title{
Marital interaction and spousal health and well-being
}

Ralph Arthur Schmoldt

Portland State University

Follow this and additional works at: https://pdxscholar.library.pdx.edu/open_access_etds

Part of the Family, Life Course, and Society Commons

Let us know how access to this document benefits you.

\section{Recommended Citation}

Schmoldt, Ralph Arthur, "Marital interaction and spousal health and well-being" (1982). Dissertations and Theses. Paper 3232.

https://doi.org/10.15760/etd.3219

This Thesis is brought to you for free and open access. It has been accepted for inclusion in Dissertations and Theses by an authorized administrator of PDXScholar. Please contact us if we can make this document more accessible: pdxscholar@pdx.edu. 
AN ABSTRACT OF THE THESIS OF Ralph Arthur Schmoldt for the Master of Arts in Sociology presented June 21, 1982.

Title: Marital Interaction and Spousal Health and Well-Being.

APPROVED BY THE MEMBERS OF THE THESIS COMMITTEE:

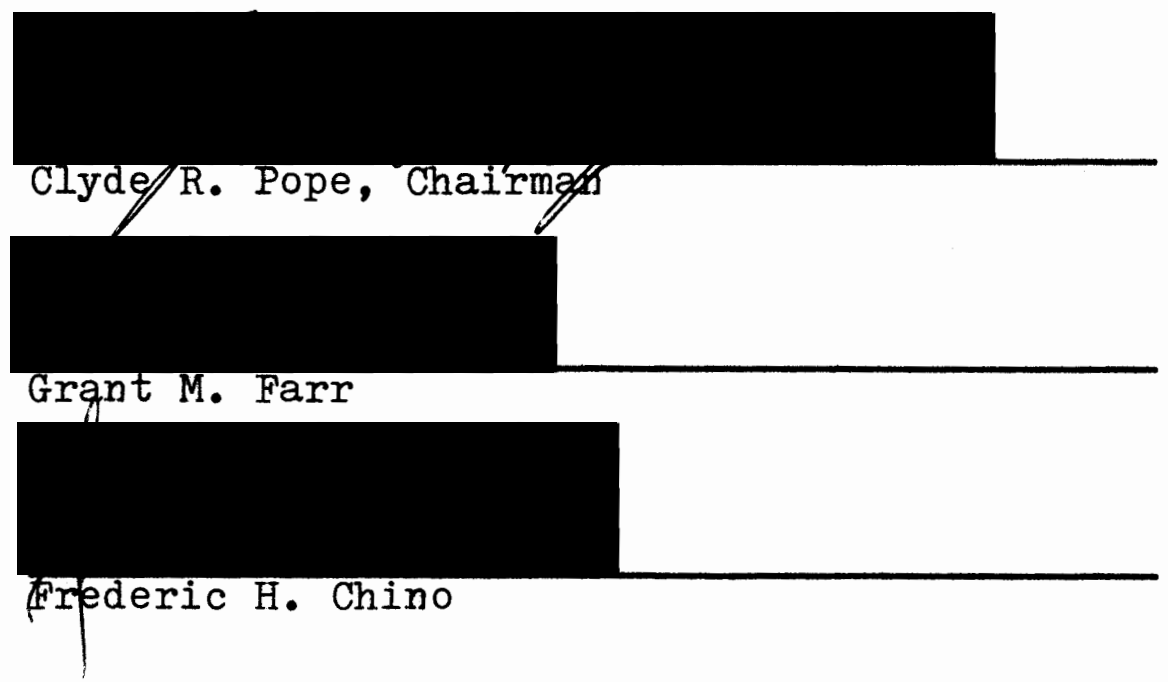

An attempt is made to determine whether marital interaction is related to the health and well-being of husbands and wives and, if such a relationship exists, to explore the nature of the relationship. The dimensions of marital interaction of interest include cohesion, companionship, cooperation, and consensus. Cohesion is manifest in the feelings a couple has about their relationship. Companionship and cooperation are seen in a couple's joint activities. A shared outlook on life represents consensus. 
A subset of a random sample of members of the Oregon Region of the Kaiser-Permanente Medical Care Program, including 988 legally married couples who represent a broad range of sociodemographic characteristics, provided the study population and data.

Two data sources were utilized: a household interview survey and an outpatient information system. The survey, which involved separate but simultaneous interviews with the husband and wife using two interviewers, was conducted under the supervision of the Kaiser-Permanente Health Services Research Center for a variety of research purposes. It elicited a wide range of demographic, health, behavioral, and attitudinal information. The marital interaction variables are measured by combining spouses' responses to various survey questions. Other survey questions were used to develop a measure of health (general health status), two measures of well-being (self-esteem, mental health status), and five control variables (socioeconomic status, education, age, childhood health, and duration of marriage). The outpatient information system records all medical care contacts (including doctor office visits, emergency room use, telephone calls, and correspondence) and associated diagnoses and treatments for each health plan member. Morbidity information from patient records is converted to a code in the Kaiser Clinical-Behavioral Classification System. Four disease classes within this classification system are used to provide additional measures of health (chronic disease, trauma, 
of health (chronic disease, trauma, acute disease, and emotion-related disease). The survey was conducted approximately in the middle of the period during which medical record data was collected for most of the respondents (ranging from two to seven years).

After examining interrelationships among the dependent, independent, and control variables using cross-tabulational and correlational analysis, a series of stepwise multiple regression analyses are performed to determine the relative importance of the marital interaction and control variables in explaining variance in the health and well-being measures.

Although the amount of variance explained is small, the findings provide some support for the hypothesis that better health is associated with higher levels of marital interaction, particularly cohesion. There is some suggestion that marital interaction has a greater influence on the health of husbands than wives, but the difference is slight. Measures of health and well-being which tend to be more emotion-sensitive (self-esteem, mental health status, trauma, and emotion-related disease) are those most likely to be influenced by the marital relationship. The effect of marital interaction on health and welz-being is also independent of the health status one brings to a marriage.

These results and the implications for family life education are discussed and suggestions for future research are made. 


\title{
MARITAL INTERACTION AND SPOUSAL \\ HEALTH AND WELL-BEING
}

by

RALPH ARTHUR SCHMOLDT

A thesis submitted in partial fulfillment of the requirements for the degree of

\author{
MASTER OF ARTS \\ in \\ SOCIOLOGY
}

Portland State University

1982 
TO THE OFFICE OF GRADUATE STUDIES AND RESEARCH:

The members of the Committee approve the thesis of Ralph Arthur Schmoldt presented June 21, 1982.
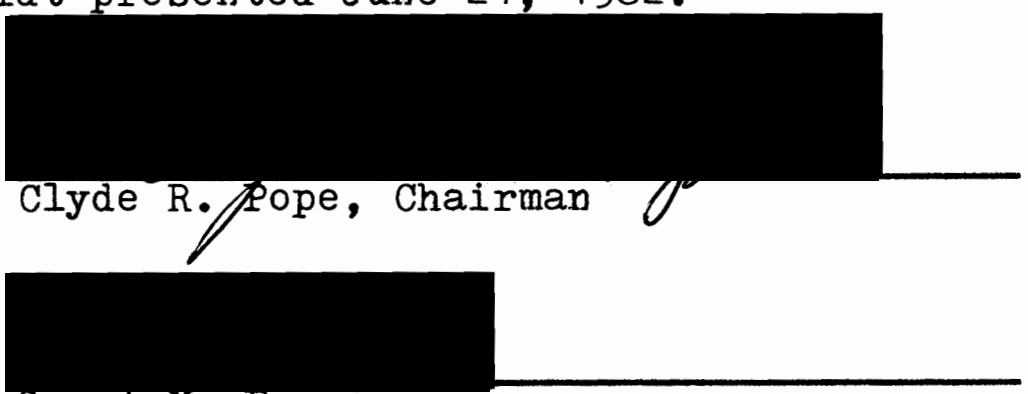

Grapt M. Farr

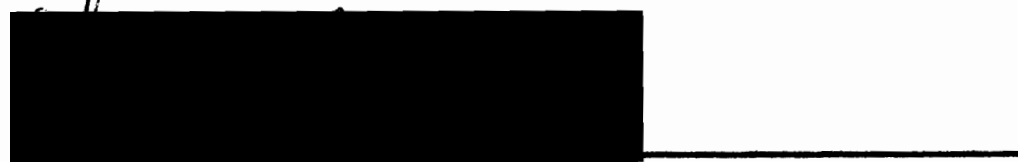

Arqaeric H. Chino

\section{APPROVED:}

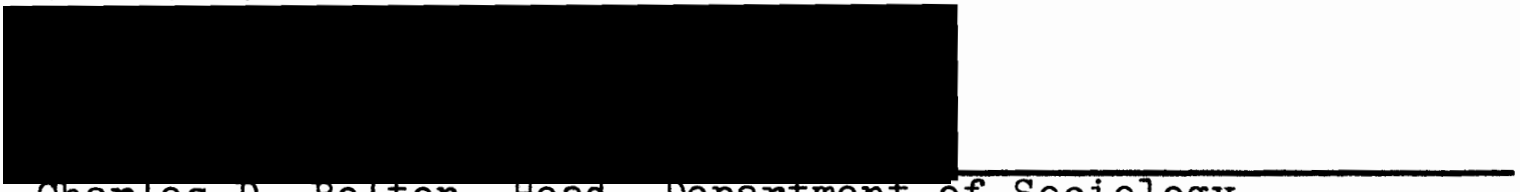

Charles D. Bolton, Head, Department of Sociology

Stanley E. Rauch, Dean of Graduate Studies and Research 


\section{ACKNOWLEDGMENTS}

Having access to the facilities and resources of the Kaiser Health Services Research Center not only enabled the smooth completion of this project but also provided a truly enjoyable and memorable research experience. Members of the Center's staff were especially helpful; Leslie Wycoff for bibliographic searching, Marilyn Drichas for computer processing, and Karen Stokes for manuscript editing. Dr. Clyde Pope, Senior Investigator at the Center, has been remarkably generous with his kindness, patience, and guidance; making this research venture a genuine apprenticeship opportunity with an excellent role model. It is the very satisfying and cohesive relationship with my wife Linda, however, that gave me the support I needed in order to invest myself in this project with enthusiasm even when time and energy for her were at a minimum. 
TABLE OF CONTENTS

PAGE

ACKNOWLEDGMENTS • • • • • • • . • • • • • • •

LIST OF TABLES

vi

LIST OF FIGURES

CHAPTER

I INTRODUCTION • • • . . . . . . • •

Theoretical Foundations . . . . .

The Social Factist Tradition

The Social Definitionist Tradition

II REVIEW OF THE LITERATURE . . . • . • .

The Marital Relationship . . . .

The Affective Dimension

The Affiliative Dimension

The Cognitive Dimension

Health and Well-Being . . . . .

Relationship to Socioeconomic Status

Relationship to Age, Sex, Religion

A Theoretical Model . . . . . .

The Marital Relationship and Health.

Marital Interaction and Health

Comparison of Husbands and Wives

Research Hypotheses . . . . . . 
Data Sources • • • . • . • • •

Household Interview Survey

Outpatient Information system

Measures . . . . . . . . . . .

The Marital Relationship

Health and Well-Being

Sociodemographic Variables

Form of the Analysis . . . . . . 68

Characteristics of Husbands and Wives . . . . . . . • . . •

Sociodemographic Characteristics

Health and Well-Being

Interrelationships Among Measures • •

Interrelationships Among Marital Interaction Measures

Interrelationships Among Sociodemographic, Health, and

Marital Interaction Measures

Research Hypotheses . . . . . .

Relationship of Marital

Interaction and Health

Comparison of Husbands and Wives with Respect to the Marriage -

Health Relationship

Comparative Effects of the Marital Relationship on the Health and Well-Being Measures

The Direction of the Marriage Health Relationship

V SUMMARY AND DISCUSSION • . • • . • • •

Suggestions for Future Research . . 


\section{LIST OF TABLES}

TABLE

PAGE

I Frequency Distributions for Survey Items Used in Marital Cohesion Index . . . . .

II Marriage Happiness Ratings Reported in Selected Studies (Percentage Distribution) . . .

II Correlations Among Husband and Wife Measures

Used in the Construction of Cohesion

Index (Zero-Order Pearson) . . . . . .

IV Loadings for Companionship, Cooperation, and

Cohesion Factors (Varimax Rotation) . .

V Marital Activities Engaged in as Perceived

by Husbands and Wives . . . . . . . .

VI Religious Affiliation of Husbands and Wives . .

VII Comparison of Means on Health and Well-being

Measures for Husbands and Wives . . . .

VIII Correlations Among the Marital Interaction

Measures (Zero-Order Pearson) . . . . .

IX Correlations Between the Sociodemographic

Variables and the Health and Well-Being

Variables (Zero-Order Pearson) . . . . . 
$\mathrm{x}$ Correlations Between the Marital Interaction

Measures and the Sociodemographic

Variables (Zero-order Pearson) . . . .

XI Correlations Between the Marital Interaction

Measures and the Health and Well-Being

Variables for Husbands (Zero-Order

Pearson) • . . . . . . . . . . . .

78

XII Correlations Between the Marital Interaction

Measures and the Health and Well-Being

Variables for Wives (Zero-Order Pearson) • .

XIII Stepwise Regression of Sociodemographic

Variables and Marital Interaction

Measures on Health and Well-Being

of Husbands and Wives . . . . . . . . .

81

XIV Stepwise Regression of Sociodemographic

Variables and Marital Integration Index

on Selected Health and Well-Being

Variables of Husbands and Wives . . . . .

XV Means on Health and Well-Being Measures for

Husbands and Wives by High and Low

Categories of the Marital Interaction

Measures • • . • . . . . . . • • . 
XVI Stepwise Regression of Sociodemographic

Variables and Wife's (Husband's)

Marital Interaction Measures on

Husband's (Wife's) Health and

Well-Being Variables . . . . . . .

XVII Stepwise Regression of Sociodemographic

Variables and Both Husband's and Wife's

Marital Interaction Measures on Health

and Well-Being of Husbands and Wives . .

XVIII Correlations Between Childhood Health and

the Marital Interaction Measures and

Health and Well-Being Measures for

Husbands and Wives . . . . . . .

XIX Stepwise Regression of Sociodemographic

Variables and Marital Interaction

Measures on Health and Well-Being of

Husbands and Wives After Forcing

Entry of Childhood Health . . . . .

XX Stepwise Regression of Sociodemographic

Variables and Marital Interaction

Measures on Health and Well-Being

of Husbands and Wives who Had

Excellent Health During Childhood . . 
TABLE

XXI Correlations Between Companionship and Cooperation and the Components of the Marital Cohesion Index (Zero-order Pearson) . . . . . . . . . • • 


\section{LIST OF FIGURES}

F IGURE

PAGE

1. Listing of Parallel and Joint

Leisure Activities . • . . • • • • •

2. Theoretical Model of the Social

Environment-Health Relationship . . . •

3. Comparison of Regression Analyses - • • • • 
CHAPTER I

\section{INTRODUCTION}

While many researchers have presumed that social support is important in the promotion of health and well-being, there is little strong empirical evidence to confirm the role it plays. In particular, the interactional aspects of marriage through which some of the most personally meaningful social support mechanisms operate have received almost no attention in the literature. This void is especially significant in view of the fact that an overwhelming proportion of men and women prefer marriage as a way of life (968 of the women and 928 of the men, the Roper Organization, 1974); the affectivity and emotionality of contemporary marriage imposes a tremendous burden on husbands and wives (Parsons and Fox, 1952); and, an expanding literature demonstrates the significance of the socioemotional environment for health (Insel and Moos, 1974).

Cohesion, companionship, cooperation, and consensus are the marital interaction dimensions of interest in this study. Cohesion is manifest in the feelings a couple has about their relationship. Companionship and cooperation are seen in a couple's joint activities, especially during 
leisure. A shared outlook on life represents consensus. Given these aspects of the marital relationship, this thesis will address the following questions:

--Are higher levels of marital cohesion, companionship, cooperation, and consensus related to higher levels of health and well-being? Which marital variable(s) appear(s) to be more important?

- Is the health and well-being of wives more likely to be affected by marital cohesion, companionship, cooperation, and consensus than the health and well-being of husbands?

--Are diseases with a high emotional content more likely to reflect variation in marital cohesion, companionship, cooperation, and consensus than other types of illness?

- Is the influence of marital cohesion, companionship, cooperation, and consensus on health and well-being independent of the effect of health and well-being on these marital variables?

Responses to these questions will define which elements of marriage might be strengthened for the greatest benefit to personal health and well-being.

The two major theoretical paradigms in sociology are reviewed first because they serve as the framework for the literature review and research design which follow. One of the paradigms, social factism, is important to the extent that it demonstrates the importance of marital interaction by noting the effect of its absence. The other, social definitionism, is more directly related to the research questions above. 
THEORETICAL FOUNDATIONS

The Social Factist Tradition

The social factist paradigm generally assumes that what sociology ought to study are phenomena that are external to individuals and have a coercive influence on the actions of individuals. Social facts include norms, roles, customs, rites, rates of various behaviors, and so forth. They are assumed to have a reality that is independent of any individual and can thus be studied in essentially the same fashion as material objects. Within this paradigm, the sociologist is supposed to relate social facts to one another, explaining the existence of any one with reference only to others, thereby avoiding psychological, biological, or other types of "reductionism", that is, explanations of social facts by reference to nonsocial phenomena. Stated another way, human collectivities are assumed to have a reality that is separate and distinct from individuals. They are capable of being studied independently and comprise the subject matter of sociology. (Chafetz, 1978:38)

The classic study in the social factist tradition is Durkheim's Suicide (1951). Of particular interest here is his work using marital status as a primary social fact to account for variation in suicide rates. Using data from a number of European countries, he discovered that married persons, both husbands and wives, had a lower rate of suicide in comparison to unmarried persons. Widowed persons had a higher rate of suicide than those who were married but a lower rate than both the divorced and the unmarried.

In explaining his findings Durkheim considered both a "selection" hypothesis and a "protection" hypothesis. On the basis of his data, he ruled out "selection" which 
claimed that those admitted to marriage and family life already have "considerable guarantees of physical and moral health" leaving the unmarried to form a class composed of "the human dregs of the country" (1951:180). According to this view, lower rates of suicide among the married would be expected.

The "protection" hypothesis, Durkheim's preference, claimed that there was something in domestic life that protected people from suicide. This something, in his view, was the social support that results when one is strongly integrated into a family group. In his words, hubands and wives,

...cling to life more resolutely when belonging to a group they love, so as not to betray interests they put before their own. The bond that unites them with the common cause attaches them to life and the lofty goal they envisage prevents their feeling personal troubles so deeply. There is, in short, in a cohesive and animated society a constant interchange of ideas and feelings from all to each and each to all, something like mutual moral support, which instead of throwing the individual on his own resources, leads him to share in the collective energy and supports his own when exhausted. (1951:209)

While marriage itself has a limited preservative effect for husbands, Durkheim demonstrates that it is primarily the wider family group which includes children that offers the greatest suicide protection for both husbands and wives. Moreover, "immunity" is shown to increase with increasing size of the family unit. 
Durkheim's findings have been supported and extended in recent studies using mortality and morbidity rates as well as suicide rates as the dependent variable. The mortality rate is lower for married persons than for divorced, widowed, or single persons of the same age and sex (Zalocar, 1960; Sheps, 1961; Berkson, 1962; Verbrugge, 1979). Newly widowed men are a particularly vulnerable group (Kraus and Lilienfeld, 1959), although remarriage appears to increase the widowed man's chances of living longer (Greenberg, 1981). In terms of morbidity rates, those who divorce are more likely than the happily married to report physical disability, chronic illness, neurosis, depression, and isolation (Renne, 1971; Pearlin and Johnson, 1977; Gove, 1972, 1973; Kobrin and Hendershot, 1977; Blumenthal, 1967; Lattorgue, 1960; Berkman, 1969). Divorced and separated people also have higher rates of acute and chronic conditions and disabilities in comparison to widowed people and single people (Verbrugge, 1979). Morbidity rates are higher for formerly married women (divorced, separated, widowed) than men (Verbrugge, 1979). Renne's findings (1971) indicate that marital status in itself does not necessarily protect one from illness. Rather, it is the quality of a marriage which may be more important. While many studies show that married people are happier than persons in any other marital status category (Bradburn, 1969; Glenn, 1975; Gurin et al., 1960), Renne 
found that unhappily married people are "worse off" than single, divorced, or separated people in terms of psychological and physical health.

Social factists stress the importance of marital status for the preservation of health. It is because of the importance of marital quality, however, that the perspective of the social definitionists must be considered.

The Social Definitionist Tradition

The social definitionist paradigm generally assumes that what sociology ought to study are human actions to which the individual actors attach subjective meaning and in which the individual takes into account the actions of other humans (whether or not they are present). The emphasis in this paradigm falls on the subjective states of interacting individuals, who are often viewed as creating their own social reality.... The questions raised thus tend to be those pertaining to how people perceive and interpret others and themselves in a social context.... (Chafetz, 1978:38-39)

Symbolic interactionism has emerged as a perspective within the social definitionist tradition. Instead of focusing on the individual and his or her personality characteristics, or how the social structure or social situation causes individual behavior, symbolic interactionism focuses on the nature of interaction. In doing so, a more active image of the human being is created which stands in definite contrast to the image of the passive, determined organism (Charon, 1979). 
Although not himself a symbolic interactionist, Max Weber is the classical figure in sociology who is considered to be the conceptual father of interactionist theory. It was Weber who argued that human action was, on the whole, "meaningful", involving interpretation, thinking and intention (Charon, 1979:23). For Weber, interaction meant that people's minds were actively involved in situations, interpreting each other, communicating with each other, controlling their own acts according to what they wish to communicate to others (Charon, 1979).

Because, as noted earlier, the quality of marital interaction has consequences for health and well-being, symbolic interactionism provides a highly suitable theoretical framework for examining this relationship. E.W. Burgess, one of the more significant contributors to early research on marriage and family life, in fact defined family unity in terms remarkably similar to those used by contemporary symbolic interactionists:

The family as a unit of communicating personalities involves the fitting together of reactions and attitudes of husband and wife which have a history reaching back to the early months and years of each person's life. These persisting attitudes and values act as a selective factor in sensitizing each person to pay attention to objects, values, and situations similar to those previously experienced. The basic principle, however, is that persons undergo modification in the process of communicative interaction within the family. Thus, through communication, particularly of the intimate type found in most families, there is an interpenetration and fusion of the attitudes of husband and wife and of parents and children, for in their 
reciprocal responses the members continually modify one another's behavior. (Burgess et al., 1963:267)

For Burgess, marital integration involved interaction that complemented each partner in order to provide mutual satisfaction and the achievement of common objectives. Such interaction involved intercommunication, interstimulation, and participation in common activities (Burgess et al., $1963)$.

That husband and wife both define their marital situation as satisfying or "happy" is extremely important to maintaining marriage as a system of interacting roles and communication networks. Given the fact that shifts in communication and/or role patterns are likely to influence an alteration in adjustment patterns and in perceived satisfaction in the marital relationship, common activities also become critical in maintaining the marriage system. It is during periods of joint activity, especially in leisure time, that husbands and wives are more free to redefine their situations and open themselves to new behavioral interpretations (Orthner, 1975). Both happiness (cohesion) and joint activity (companionship) as well as shared definitions (consensus) and cooperative interaction (cooperation) are included in this thesis as primary elements which affect the quality of marital interaction and which, in turn, influence spousal health and well-being. 
CHAPTER II

REVIEW OF THE LITERATURE

The literature is reviewed first from the perspective of the independent variable (marital interaction) with special emphasis on findings relevant to an interest in cohesion, companionship, cooperation, and consensus; and then from that of the dependent variable (health and well-being). A theoretical model of the relationship between the social environment and health is presented to provide a context for reviewing the evidence which links marital interaction to health. A great deal of attention is given to the effect of sociodemographic factors (primarily socioeconomic status, age, and sex) on both the marital relationship and health and well-being to determine the need for controlling these factors in this research. Finally, the research questions are rephrased in terms of anticipated results.

\section{THE MARITAL RELATIONSHIP}

Over the years a variety of terms have been used to describe the interactional character of the marital relationship. Burgess spoke of marital "success" and used eight criteria to define this concept: permanence, 
happiness, satisfaction, sexual adjustment, marital adjustment, integration, consensus, and companionship (1939:290). Locke (1951) used a similar combination of factors which, taken together, referred to marital "adjustment." In more recent studies adjustment and success have largely been supplanted by the term "satisfaction." Currently, marital "quality" is the concept which seems to be the preferred choice of marriage and family researchers. Each of these broad terms essentially refers to a similar set of specific marital variables. Among others, the set usually includes the marital variables of interest in this study; namely, companionship/cooperation ("common interests and activities"), consensus ("agreement and settlement of disagreements"), communication ("demonstration of affection and confiding"), and cohesion ("feelings of happiness and togetherness").

While it has been deemed inadequate by some to employ any one of these variables to represent the many facets of the marriage relationship, "happiness" has often been used as a single criterion of a successful marriage. Critics of this approach, while acknowledging that marital happiness does represent a subjective expression of affect which is culturally considered to be the result of a "good" marriage, indicate that happiness is not the only cultural goal of marriage. This observation notwithstanding, simple marital happiness measures have been shown to be positively 
correlated with more complex marital satisfaction scales (Luckey, 1964). This suggests that simple measures of self-rated marital happiness may be tapping the same phenomenon that many-itemed adjustment inventories or satisfaction scales do. Marital "happiness" might therefore be added to the list of general terms which describe the interactional character of a marriage.

General measures of marital satisfaction and happiness should not be confused with the use of these terms in evaluating very specific features of married life. Asking a person to rate the extent to which his/her marriage is happy is conceptually distinct from asking him/her to specify the specific sources of happiness in marriage (see, for example, Gurin, et al., 1960). Similarly, satisfaction with marriage is conceptually distinct from satisfaction with specific aspects of marriage such as sex life, amount of time spent in conversation, etc. (see, for example, Scanzoni, 1970). When either or both of these terms (happiness and satisfaction) have a specific referent, they may no longer be positively correlated. For example, there may be dissatisfaction with leisure activities even though the overall marriage is rated "extremely happy." Likewise, unhappiness with finances or dissatisfaction with the amount of affection shown may not necessarily detract from general marital satisfaction. Burgess (1939) was probably 
the first to make such a distinction beteen marital happiness and satisfaction.

Husbands and wives who are happy with marriage tend to stress aspects of their relationship rather than situational features of their marriage (home, children, social life, etc.) as the primary sources of their happiness. And, contrariwise, husbands and wives who are unhappy with their marriage tend to focus on situational sources of unhappiness (Gurin et al., 1960; Burke and Weir, 1977). To a considerable degree, then, happiness in marriage appears to imply happiness in the relationship. Higher levels of education and socioeconomic status are consistently associated with greater marital satisfaction and adjustment (Blood and Wolfe, 1960; Geismar, 1973; Winch, 1963; Luckey, 1966; Roth and Peck, 1951; Locke, 1951; Terman, 1938; Burgess and Cottrell, 1939). Relationships in which the status of husband and wife are approximately equal contribute to greater satisfaction than those in which the wife has a considerably higher or lower status (Blood and Wolfe, 1960; Roth and Peck, 1951).

As the length of marriage increases, the intimacy of the marriage relationship declines as does overall marital satisfaction (Feldman, 1964; Blood and Wolfe, 1960; Luckey, 1966). In terms of stages in the marital career, the drop in satisfaction is particularly evident following the birth of the first child (Blood and Wolfe, 1960; Pineo, 1961; 
Gurin et al., 1960; Paris and Luckey, 1966), although the timing of the decline is difficult to pinpoint. Burr (1970) sees the decline occurring when the oldest child is somewhere between age six and age twelve. Feldman (1964), in agreement with Burr, claims that this period is likely to produce the highest level of stress of any stage in marriage. Although childless couples also experience a decline in satisfaction over time, their stated marital satisfaction is higher than that of couples with children (Feldman, 1964). In the later years of marriage, satisfaction with the relationship makes something of a comeback; although the level of satisfaction is not nearly so high as it was in the honeymoon period (Feldman, 1964; Rollins and Cannon, 1974; Rollins and Feldman, 1970). Feldman offers this explanation of the "disenchantment" (term from Pineo, 1961:9) process:

...at the beginning of the marriage, reactivity, sexual relations and enchantment with knowing the other increases affectivity toward the other. The stress periods, near the middle of marriage, have a continuing high enchantment level but there is the beginning of disillusionment with the other as filling the romanticized ideal. Near the end of marriage the couple comes to grips with marriage and begins to accept the other more realistically. Companionship as a value begins to supercede the affective romantic orientation and satisfaction increases. (1964:126)

Regardless of how quickly the romanticized ideal fades, Jordan (1976) points to the fact that the middle stages of marriage present the developmental challenges of parenting (usually for wives) and career development (usually for 
husbands). These challenges strain a couple's ability to provide companionate interaction for one another. The experience of childbearing and childrearing has in fact been demonstrated to have a more negative impact upon the marital satisfaction of wives than husbands. The satisfaction level for husbands, on the other hand, is much more influenced by their occupational experiences (Rollins and Feldman, 1970)

Satisfaction with marriage is not simply dependent upon the degree of companionate interaction between spouses. It relates to the different meanings which marriage has for men and women. Marriage in our society, according to Bell,

...remains a key mechanism for validating personal adequacy, heterosexual normality and personal maturity. Since women are denied alternative areas for social validation (notably in careers) - marriage may be more often needed by them than by men. (1972:69)

Research seems to support this interpretation. Rollins and Feldman (1970) reviewed twelve studies of the decline in marital satisfaction over time and noted that the decline was more characteristic of wives than husbands. Hawkens (1968) showed that socioemotional factors are somewhat more crucial to the marital satisfaction of wives in comparison to husbands. Wives also place more emphasis on affective values, are more likely to feel more stress, and experience a wider range of emotionality in marriage (Feldman, 1964). Such differences may partially account for why correlations 
(ranging from .36 to .59) between marital happiness scores of husbands and wives are high but not too high (Terman, 1938; Terman and Oden, 1947; Burgess and Wallin, 1944; Locke, 1951).

Scanzoni's (1970) three demensions of primary interaction in marriage provide a basic framework for describing the marital variables to be used in this study. The affective dimension stresses the emotional involvement of the partners in all aspects of displaying love and affection and the vicarious experience of the feelings, thoughts, or attitudes of the other (1970:108). The affiliative dimension stresses "doing things together" during leisure time or engaging in joint activity (1970:26). The third, or cognitive, dimension focuses on mutual identification with "the verbal and intellectual elements inherent in the use of overt symbols of communication and understanding" (1970:26). Empathy, which includes the reciprocal skills of communication and understanding, is at the core of the cognitive dimension and is considered crucial to the solidarity of the conjugal unit. The three dimensions overlap but there is no necessary correlation between them. A review of the literature relevant to these dimensions follows. 
The Affective Dimension

Feelings of happiness and the nature of communication in marriage are considered here to closely reflect Scanzoni's affective dimension of interaction. Relationship of Happiness to Sociodemographic Variables. The relationship of marital happiness to social class and education parallels the findings for the relationship of marital satisfaction and marital adjustment, i.e., higher educational and social class levels are associated with greater happiness. Interestingly, the more highly educated not only report greater marital happiness but also more problems with marriage and a greater sense of inadequacy with the spousal role (Gurin et al., 1960). Education may not only make one more introspective, thereby increasing one's awareness of the intrinsic aspects of marriage, but may also increase one's expectations for what a marriage should be. Feelings of inadequacy may result when the expectations are unmet (Gurin et al., 1960).

Marital happiness declines along with marital satisfaction and marital adjustment the longer a couple is married (Terman, 1938; Dizard, 1968).

Husband-Wife Differences in Happiness. Women are somewhat unhappier and report more problems in their marriages than men (Gurin et al., 1960). Since the feminine role has been traditionally more associated with the maintenance of family cohesiveness, women may be more 
attuned to the socioemotional climate of marriage. Their standards for happiness may therefore be higher. In addition, women have greater permission in our culture to admit to difficulties. Men, in contrast, are less likely to experience and show feelings that indicate failure in coping with their environment (Gurin et al., 1960). Nevertheless, the real stresses of marriage encountered by women should not be underestimated.

\section{Relationship of Empathy to Marital Satisfaction. 1}

Another aspect of the affective dimension of marital interaction is empathy which includes communication and understanding. Athough "just plain talk" between husbands and wives occurs relatively infrequently (Bernard, 1964:33), it is one aspect of marriage that seems to improve over the years. The longer a marriage continues, the more satisfactory empathy becomes in the view of both sexes; a fact which appears to be true even when marital happiness wanes (Scanzoni, 1970). Communication and listening skills take years to develop and are something a couple can fall back on when leisure activities and physical affect lose their charm (Scanzoni, 1970). An

Iscanzoni's cognitive dimension of primary interaction, which emphasizes empathy, contains both affective and cognitive elements. The affective contributions of empathy seem especially relevant to the discussion at this point. The discussion of the cognitive dimension later will focus more narrowly on the intellectual and more purely cognitive characteristics of marital interaction. 
increase in verbal communication among older persons whose children have left home has been noted (Feldman, I964). On the average, middle and upper-class couples spend one and one-half hours per day in conversation, with the wife initiating discussions of most topics except for the husband's work. Although most topics seem to foster cohesion, the most cohesive effects result from conversations about intra-familial topics (personal feelings, sex, children's problems, etc., Feldman, 1964). The more time couples report that they spend talking with each other, the more likely they will also report a high level of marital interaction, marital satisfaction, and positive affect after discussions (Feldman, 1964). Couples expressing greater marital satisfaction disclosed their feelings to one another more, showed more sensitivity to one another's feelings, conveyed an understanding of one another's communications, and communicated on a wider range of subjects than those dissatisfied with their marriages (Burke and Weir, 1977).

\section{Relationship of Empathy of Sociodemographic}

Variables. Empathy increases with increasing social class and education. The higher the status of the husband's job, the greater the degree of communication with the wife regarding his job (Scanzoni, 1970). For less successful males, who seemingly have "a trained incapacity to share," "silence is golden" but their wives expect more 
communication (Scanzoni, 1970:120-121). Extremely educated persons (sixteen or more years of formal education) also talk less with their spouse (Scanzoni, 1970).

The Affiliative (Activity) Dimension

Companionship is the term which is most often used to refer to the affiliative or activity dimension of primary interaction. It has been ranked by husbands and wives as the most valued aspect of married life (Blood and wolfe, 1960; Feldman, 1964) and has been seen as the primary basis for marital satisfaction because of its tension management function (Hawkens, 1968). Wives rank companionship more highly than husband's employment and income in terms of its contribution to marital quality (Geismar, 1973).

Broadly defined, companionship describes contemporary marriage in which expressive behavior is emphasized in contrast to traditional marriage which placed more emphasis on instrumental functions (Bell, 1972; Burgess et al., 1963). The more limited focus here, however, will be on shared activity (both expressive and instrumental) which is the conventional way of operationalizing companionship in the literature.

Activity Classifications. Joint marital activity has been classified in various ways. Some researchers make a distinction between "companionship" and "sociability" (Orden and Bradburn, 1973). Companionship activities issue 
from the basic interpersonal relationship in marriage, are independent of activities with other people, and do not involve any expenditure of funds. Examples include: "did something the other appreciated", "drove or walked for pleasure", "had a good laugh", "was affectionate" and "spent evening chatting" (1973:718). Marriage "sociability", on the other hand, includes activities of a social nature which may or may not involve other people and the expenditure of funds. Items here include: "visited friends together", "went out to movie, etc.", "entertained friends", and "ate out in restaurant" (1973:718).

Another common activity division is that between joint, parallel, and individual activities:

Joint activities require a high degree of interaction for successful completion of the activity and tend to open communication and encourage role interchange.

Parallel activities are little more than individual activities in group settings and a minimum of interaction is allowed among the participants.

Individual activities require no communication with others and may actually discourage interaction. (Orthner 1975:95)

Figure 1 provides examples of parallel and joint leisure activities. The examples should not be considered rigid, however, inasmuch as there is evidence to suggest that some of the activities which are termed "parallel" may in fact be "joint" (Scheuch, 1960).

Carisse (1975) offers a four-part typology of preferred values for leisure activity. Couples who value 
Parallel Lelsure Activities

Shopping for pleasure
Going to library
Attending race tracks
Visiting museum or
gallery
Attending movle theater
Attending wrestling or
boxing matches
Attending athletic
events as spectator
Caring for pets
Studying nature
Collecting (stamps,
coins, etc.)
Gardening and yard
work for pleasure
Tinkering in workshop
Constructing models

Writing poems, stories
Fancy needlework
Art modeling, painting
Sewing for pleasure
Writing letters
Reading books, magazines,
newspapers
Playing musical
instruments
Listening to records or
tapes
Watching television
Listening to radio
(primary activity)
Skin or scuba diving
Roller skating
Ice skating
Bicycling for pleasure

Writing poems, stories

Fancy needlework

Sewing for pleasure

Writing letters

Reading books, magazines,

newspapers

laying musical

instruments

Listening to records or tapes

Watching television

ustening to radio

(primary activity)

Roller skating

Bicycling for pleasure
Fishing

Swimming

Hunting

Hiking

Playing pencil and paper games

Attending musical concerts

Attending lectures, debates

Attending plays or other drama

Taking college class

Attending church

Taking naps or just relaxing

Creatively cooking

(beyond meal prep.)

Joint Leisure Activities

Going to park or
playground
Visiting zoo
Attending drive-in
theater
Spending time in tavern,
nightclub, lounge
Visiting amusement parks
Attending parties
Picnicking away from home
Eating meals out
Visiting friends
Riding in auto for
pleasure
Playing billiards or pool
Playing basketball,
baseball, volleyball
Playing tennis
Water skilng
Snow skilng
Bowling
Salling

Motor boating

Flying for pleasure

Playing handball

Boxing, wrestling, judo

Attending organized camps

Going on hay ride

Playing badminton

Playing shuffleboard

Riding (horses)

Playing miniature golf

Playlng golf

Camping (organized area)

Camping (backwoods)

Playing backyard or lawn games

Dancing or attending dances

Playing football

Canoeing, rowing

Playing card games

Playing board games
Playing ping-pong

Taking part in: amateur dramatics, debates, discussion groups, community service work, parent-teacher activities, political activities

Attending: craft or adult ed. classes, fraternal organization meetings, community social events, church suppers, family or club reunions, other socials outside the home

Playing informally with the children

Engaging in affectional or sexual activity Casual conversation

\section{Source: Orthner (1976).}


"togetherness" have the same leisure interests and like to do things together as much as possible. Couples who value "similarity" have many interests in common but physical propinquity is not specifically sought. "Closeness" is valued by those for whom physical closeness is important but doing different things while together is considered normal. And "individuality" is valued by couples in which each partner has his/her own interests and pursues them according to his/her own time schedule.

Another companionship typology is presented by Blood and Wolfe (1960) which is based more on the content of an activity rather than on any underlying theoretical dimensions. Four types of companionship are described. The "organizational" type involves joint participation in formally organized groups outside the home. The "informational" type involves spousal communication about things which happen while a couple is apart. Couples who get together with the husband's work colleagues illustrate "collegial" companionship. The fourth type, "friendship," simply involves visiting with friends.

Relationship to Marital Satisfaction and Happiness. Companionship alone does not guarantee marital success, but it does explain a relatively large portion of the variation in marital satisfaction (.50 for husbands and .60 for wives; Hawkens, 1968; Blood and Wolfe, 1960; Jordan, 1976; Locke, 1951; Feldman, 1964). Although there is a common 
belief in our culture that a high rate of interaction in a leisure context produces more cohesion among individuals in a group (Carisse, 1975; Homans, 1950), it has been suggested that companionship is more likely the product of cohesion rather than its determinant (Orthner, 1976). The purpose here is only to note their relationship.

Using Orden and Bradburn's distinction (1973), "companionship" is more strongly related to marital happiness than "sociability", suggesting that the personal relationship between a husband and wife is more important in marriage than the social activities they enjoy together. Greater satisfaction in marriage is also more highly correlated with joint activities than with parallel activities, and there is a negative relationship with individual activities (Orthner, 1974). More important for satisfaction is the quality of activity (Williams, 1978), the variety of activities (Blood and Wolfe, 1960), and the meaning an activity has for the individual (Donald and Havighurst, 1959), rather than the number of activities shared (Gerson, 1960; Benson, 1952; Hawkins and Walters, 1952; Orthner, 1975 ).

Relationship to Sociodemographic Variables. The quantity and quality of shared participation in various activities is a result of the expectations a husband and wife bring to a marriage. These expectations are conditioned by various sociodemographic factors. older and 
less educated persons, for example, engage in more individual or separate activities than the younger and more educated (Komarovsky, 1962). There is more sex-segrated activity in blue-collar marriages while white-collar husbands are more likely to include wives in their leisure pursuits. Wives of husbands next-to-the-top in terms of occupational status and income are relatively dissatisfied with companionship (even though there may be a fair amount of joint activity) since the achievement orientation of their upwardly mobile husbands detracts from companionship quality (Blood and Wolfe, 1960). It appears as though education is a better predictor of companionship satisfaction than occupation, and occupation a better predictor than income (Scanzoni, 1970). A certain level of discretionary income is needed, however, for couples to participate together in many forms of social and recreational activities. This may be a reason why marital happiness and companionship do not necessarily decrease when the wife chooses to work outside the home (Orden and Bradburn, 1974). On weekdays leisure activity patterns remain basically the same for all socioeconomic groups (with the exception of the upper classes). It is on weekends where social class differences in activities, especially with respect to variety, are most pronounced (Scheuch, 1960). Leisure activities seem to be more significantly related to two stages in the marital career: when the 
marital dyad is initiated (from 0-5 years of marriage) and when it is reaffirmed as children are being launched (from 18 to 23 years of marriage, orthner, 1975). Participation in "joint" activities tends to decline and participation in individual activities tends to increase the longer a couple is married (Dentler and Pineo, 1960; Rollins and Feldman, 1970; Burgess et al., 1963; Komarovsky, 1962). The choice of leisure activities is more limited in families with children at home (Blood and Wolfe, 1960; Scheuch, 1960). Husband-Wife Differences in Companionship. Wives appear to benefit more from companionship and sociability than husbands (Orden and Bradburn, 1973). Individual activities increase over the marital career for both husbands and wives, but more so for wives who are therefore more likely than their husbands to indicate dissatisfaction with the marriage (Orthner, 1975; Hawkens, 1968; Orthner, 1974). The satisfaction level of husbands may be affected more by their attitudes toward leisure rather than by the quality and quantity of their actual leisure time activities (Gerson, 1960).

The Cognitive (Agreement) Dimension

The cognitive dimension of marital interaction is most often discussed in the literature with the use of such concepts as agreement or consensus. As with the other marital concepts, agreement or consensus may be defined more or less broadly. Handel (1967) broadly speaks of a 
"congruence of images" in family life. He refers to the tendency toward compatibility or consensus of the emotionally significant images which family members have of each other as individuals and as a group. A woman, for example. may have an image of her family as a group of dependents who need her and reward her or she may see them primarily as the group that enslaves her. Each of these images has different consequences for interaction within the family. An example of a more narrow definition of consensus is given by Feldman: "the extent of agreement by husband and wife about areas of concern as indexed by their overt statements about differences in value orientations" (1964:53). Both the research reviewed here and the design of the present study are more representative of the latter definition.

Relationship to Marital Satisfaction and Happiness. At the level of general theory about human groups, normative agreement and conformity is seen to produce approval and sentiments of liking among group members (Homans, 1950). Theorists of marriage and family life very early included consensus or "the degree of agreement or disagreement of a couple on the primary values or objectives of their marriage" as a criterion for marital success (Burgess et al., 1963:290).

Empirical demonstrations of the relationship of agreement to marital satisfaction have been offered by a 
number of researchers. Perceived consensus about the goals of marriage is significantly and positively related to marital satisfaction (Feldman, 1964). Levinger and Breedlove (1966) suggest that perceived consensus or assumed agreement between partners when it overestimates actual agreement is the result of positive feelings they already feel for one another. It is when agreement has instrumental value for furthering the goals of the marriage that it contributes most directly to marital satisfaction (Levinger and Breedlove, 1966). In another study value similarity and the ability to recognize behavior associated with one's spouse's values was directly related to satisfaction in marriage. The ability to simply recognize the values of one's spouse, however, was not (Nast, 1979). Reminiscent of Handel's (1967) "congruence of images," satisfaction has also been shown to be related to the congruency of the husband's self-image with the image of him held by his wife. It was not, however, related to the congruency of the wife's self-image with the image of her held by her husband (Luckey, 1959).

Relationship to Length of Marriage. Burgess et al. (1963) reported that consensus decreased between the early and middle years of marriage. In the later marital stages, however, at least from the perspective of wives, perceived consensus again prevails (Blood and Wolfe, 1960). In general, value consensus follows the same pattern as the other 
marital interaction variables which have been reviewed, i.e., it declines the longer a couple is married, with some evidence of a partial comeback in the later years of marriage (Udry and Nelson, 1961; Levinger and Breedlove, $1966)$.

HEALTH AND WELL-BEING

"Health" has been broadly described as the absence of any disease or impairment, whether physical or mental, real or imaged (McEwan, 1974:489). Given a social system reference, health is "the state of optimum capacity of an individual for the effective performance of the roles and tasks for which he has been socialized" (Parsons, 1972: 110). Illness in contrast involves "taking the role of the sick person" (Parsons, 1972:109). "Any activity undertaken by a person who feels ill, for the purpose of defining the state of his health and of discovering suitable remedy" is referred to as "illness behavior" (Kasl and Cobb, 1966: 246).

"Well-being" is often included within the definitions of health. By itself, it is generally regarded as positive psychological or mental health (see, for example, Raymond, 1980). It is very closely related to Antonovsky's "sense of coherence" which refers to:

...a global orientation that expresses the extent to which one has a pervasive, enduring though dynamic feeling of confidence that one's internal and external environments are predictable and that 
there is a high probability that things will work out as well as can reasonably be expected (1979:127)

Given the relationship of socioemotional factors in the etiology of disease, the distinction made between health and well-being is admittedly based more upon a need to distinguish between the extremes of a continuum than to describe two distinctly different realitities. In this paper, unless the context indicates otherwise, health will usually refer more narrowly to physical well-ness, thereby reserving psychological well-ness as the referent for "well-being".

These health and illness definitions circumscribe the dependent variable of the present study. Mauksch's view of health and illness in relationship to the family which he describes as both the "process and the product of continuously interacting forces within the unit, among its members..." is particularly relevant to this study (1974:526). Indeed, illness behavior may serve a wide variety of interactional purposes (Mechanic, 1966). To name a few--it may be one way of seeking reassurance and support; it may be a way of providing an acceptable reason for social failure; it may help to avoid embarrassment and social difficulties (Mechanic, 1966).

Relationship to Socioeconomic Status

Although it is a generalization with a number of qualifications, it can be said that lower status persons 
are "sicker" both physically and mentally than higher status persons, and ironically, use fewer health services despite this difference (Richardson, 1972; Gurin et al., 1960; Lerner, 1969).

As one moves from the lowest to the highest income categories, there is a steady decline in the proportion of persons experiencing chronic illness with activity limitations. Chronic illness which does not restrict activity, on the other hand, may be more characteristic of higher income persons (Richardson, 1972). It may be that some low-income persons with an activity limiting chronic condition have become low-income because of their illness (Lawrence, 1948). Income differentials, however, do not show such a pronounced relationship to acute disease (Richardson, 1972).

Heart-related diseases are ambiguously related to socioeconomic status. Some studies report higher rates of coronary disease in lower rather than higher socioeconomic levels (Lehman, 1967). Other studies while acknowledging greater prevalence of hypertension in the lowest in comparison to the highest social class, report that higher class levels experience more coronary disease (Graham, 1963). In a study conducted by Lilienfeld (1956), the lowest socioeconomic group experienced higher mortality rates due to myocardial degeneration and hypertensive 
disease in comparison to higher social classes but there was no difference for coronary artery disease.

Similar to physical health, there is a social class gradient in relationship to mental health. In this case, however, the relationship is more pronounced. A number of studies have concluded that there is greater total prevalence of mental illness in the lower classes, with more psychoses relative to neuroses, and more schizophrenia relative to manic depressive psychoses (Leighton, 1957; Hollingshead and Redlich, 1953; Fried, 1969). In the Midtown Manhattan Study the lowest class level in comparison to the highest class level had more organic, psychotic, and psychosomatic personality types and a greater number of alcoholic, asocial, depressed, hostile, schizoid, and schizophrenic symptoms. The highest class had more psychoneurotic types who were characterized by aggressiveness (Langner and Michael, 1963; Rennie et al., 1957).

While these findings with respect to the relationship of mental illness to social class are consistent, there are methodological grounds for criticism. Many of these studies (the Midtown Study excluded) are based upon treatment rather than true prevalence data. One of the biases in the use of treatment data is that upper-class clients tend to be selected for psychotherapeutic treatment more often than lower-class clients who may be left untreated until they become chronic psychotics consigned to custodial 
care (Meyers and Schaffer, 1954). Another problem relates to the suggestion that lower-class persons are more likely to express psychological distress in physiological terms, thereby confounding psychiatric rates with physical illness (Crandell and Dohrenwend, 1967).

In spite of the higher rates of illness, persons from lower socioeconomic groups underutilize health services. Physician visits are most frequent in higher status groups and least frequent among nonwhites for every age and income category (Richardson, 1972; Rosenstock, 1966). When physician visits do occur for low-income groups, they are more than twice as likely than other groups to see a physician in a hospital clinic or emergency room. Upper income persons, in contrast, not only use physicians more but also are more likely to use medical specialists for every specialty (Richardson, 1972). One explanation that has been offered for this difference in utilization is that upper class persons are more likely than lower class persons to view themselves as ill when they have particular symptoms and, when questioned about these symptoms, are more likely to report that they would seek a doctor's advice (Koos, 1954). Lower class persons also perceive less support from their significant others for assuming the sick role in comparison to those in other income groups (Petroni, 1969). 
A study which is especially relevant to the topic of this thesis showed greater prevalence of psychiatric disturbance among English working class women compared to women in higher social classes (Brown et al.. 1975). This class difference was due not to the greater frequency of difficulties and troubles among working class women but to the much greater likelihood that working class women would break down after the onset of problems. The primary intervening variable in determining whether a breakdown would occur was the degree to which a woman had an intimate and confiding relationship with a husband or male friend. Interestingly, confidants other than a husband or male friend appeared to play no protective role at all. The amount of emotional support and the level of satisfaction derived from the marital relationship, which is generally lower in lower class marriages, are critical to psychological health.

An excellent review of how lower class people view their bodies, medical treatment, and medical institutions has been presented by Lee Rainwater (1968).

Relationship to Age, Sex, and Religion

Chronic illness increases dramatically with age (Trussell and Elinson, 1959; Richardson, 1972; Downes, 1947). In terms of an overall rate for psychiatric disorders or a tendency to report symptoms of psychological anxiety, there is little relationship to age (Dohrenwend 
and Dohrenwend, 1965; Gurin et al., 1960). The Midtown Study, however, showed more mental health impairment with advancing age (Srole et al., 1978).

Women tend to report more health problems than men (measured by the Cornell Medical Health Index, Aved, 1976) and wives utilize health services significantly more often than their husbands (Chien and Schneiderman, 1975). This is true even though wives may be more instrumental in influencing the illness behavior of their husbands than viceversa (Petroni, 1969). Males, however, may experience higher morbidity rates when specific diseases are examined, e.g., arteriosclerotic heart disease and myocardial degeneration (Lilienfeld, 1956). While it is often claimed that women suffer more often from neurotic depression than men (Wright, 1972), some important studies do not support this conclusion (Srole et al., 1978).

Evidence from the Midtown Study showed no difference in mental health between Protestants and Catholics. Jews, however, significantly differed from these groups, having more members in the middle range of the mental health continuum rather than at either extreme (Srole et al., 1978).

A THEORETICAL MODEL

The theoretical model which provides the context for the present study is presented in Figure 2. It derives from the work of Aaron Antonovsky (1979). 


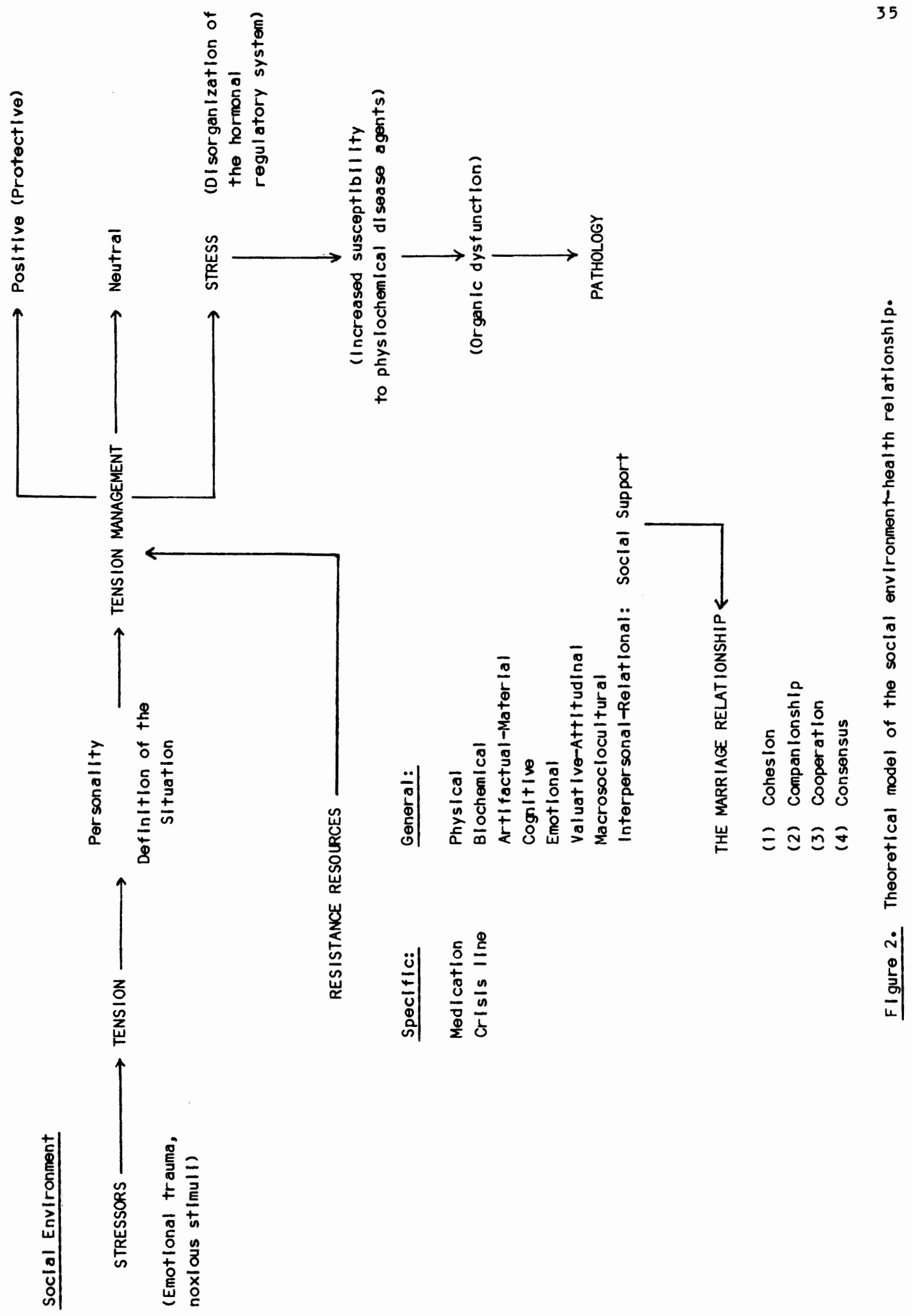


The social environment is composed of the total array of social situations, structures, and relationships which impinge on a person. Any one of these situations, structures, or relationships has the potential to become a stressor when it has negatively charged emotional significance or meaning for an individual. Marital conflict eventuating in divorce, for example, is an intensely traumatic experience. Such a situation involving the loss of a significant relationship creates a tension in the human organism which must somehow be managed. Whether the state of the tension has a positive, negative, or neutral effect on a person is determined by the tension management process. If the effect is negative, it is referred to as stress and is evidenced by a clinically observable disorganization of the body's hormonal regulatory system. The nature, duration and intensity of the hormonal imbalance determines whether one's susceptibility to physiochemical or microbiologic disease agents (which are directly implicated in the causation of disease) is increased. Increased susceptibility may result in organic dysfunction which manifests itself pathologically in the form of some specific disease entity.

Whether the tension management process is successful in avoiding stress is determined by the resistance resources of an individual. These resources, according to Antonovsky (1979), are of two types: specific and general. 
Specific resistance resources intervene very directly in managing tension. Examples of these resources are taking medication or using a crisis phone hotline. General resistance resources help to facilitate the use of specific resources and fall within the following categories:

a) physical

b) biochemical

c) artifactual-material: access to money, physical strength, food, clothing, shelter, etc.

d) cognitive: knowledge, intelligence, information, etc.

e) emotional: ego identity, etc.

f) valuative-attitudinal: coping styles, rationality, flexibility, farsightedness, etc.

g) interpersonal-relational: power, status, etc.

h) macrosociocultural: greater pain tolerance due to differential socialization, etc.

Of special interest here are the interpersonalrelational resources. A significant part of these resources is an individual's system of social supports. Kaplan et al. (1977), in a fine review article, presents evidence from both animal and human studies of the protective effect of social supports in the face of psychosocial stressor factors (see also Pilisuk and Froland, 1978).

The marriage relationship, of course, is a particularly significant social support resource because it is through this relationship that many support mechanisms 
operate. The support mechanisms of "normative fit" (consensus), "group solidarity" (cohesion), and "intimacy opportunities" (companionship, cooperation) are particularly relevant since they are used as the independent variables in the present study (Kaplan, 1977:58).2

Although the model depicts the psychosocial process through which physiological malfunctioning occurs, it is not difficult to see the appropriateness of the model for mental illness as well. A neuroendocrine imbalance, for example, may alter mental process in addition to organic structure and thereby create a psychological sense of ill-being.

Sociologists who are sympathetic with symbolic interactionism, the definitionists, believe that stressors affect people differently depending upon individual personality differences and individual definitions of the situation. According to this view, persons interpret and react to their life situations in terms of the meaning these have for them. It would therefore be incorrect to classify a set of social situations or relationships as inherently stressful. Other sociologists, the factists, without denying the validity of the interactionist framework, would note the possibility and desirability of identifying a class of stressors at a more general level which

2The marriage relationship itself may, of course, be a stressor in addition to being a source of social support. 
consistently evoke major neuroendocrinal changes in people. If attributes of this class of stressors could be identified, it may well be seen that the same relationships or social circumstances within a given culture (or perhaps subculture) regularly function as stressors. At the same time, given the model, it should be recognized that no stressor or set of stressors is etiologically specific for any given disease. In this sense, there is no subset of clinical entities known as stress diseases since all diseases can, at least in part, be due to the psychosocial processes which have been described (Cassel, 1976).

\section{THE MARITAL RELATIONSHIP AND HEALTH}

Given the practical importance of the subject, the relative abundance of marital satisfaction studies, and the well-defined link between the social environment and health, it is remarkable that so few studies directly bear on the relationship between marital interaction and health. Pratt, for example, could find no direct studies of the relationship of marital companionship and spousal health before her own work in this area was published in 1972. A review article by Spanier and Lewis (1980) which summarized marital quality research of the 1970's indicated that, although little research had been conducted linking marital interaction and health, there was a developing interest in using marital quality as an independent variable in 
predicting personal outcomes in the area of health and well-being.

The few sociological or social-psychological studies which do appear in the literature rely almost exclusively on self-evaluated health and well-being (with an emphasis on well-being) rather than on medical record data. Another prevalent characteristic of these studies is the use of general measures of marital happiness, adjustment, or satisfaction. Only infrequently do specific components of marital interaction (e.g., companionship) receive attention in relationship to health. In most of these studies there is also no attempt to establish the causal direction of the marriage-health relationship, i.e., "does poor health make a marriage unhappy or does an unhappy marriage damage health?"

Marital Interaction and Health

Marital satisfaction is positively related to indices of general morale or "happiness", psychological well-being, attitudes towards one's own health, and negatively associated with feelings of isolation and depression (Renne, 1970). Marital happiness is positively related to good health and good health practices (Geismar, 1973). Socially healthy persons who are happily married are also physically healthier and more likely to assess their health in positive terms than those experiencing lower levels of social health (Renne, 1974). These relationships also exist among 
Chicano couples (Raymond et al., 1980), older couples (Mancini, 1979; Stinnett et al., 1972), childless couples (Glick, 1976), happily married couples (in comparison to unhappily married, Renne, 1971), and among couples enjoying stable marriages (in comparison to those seeking marital counseling, Rogers et al., 1970).

In one of the few marriage studies using stepwise regression analysis with physical health status as the dependent variable, marital satisfaction was the first variable to be entered in the regression equation for husbands and the third variable to be entered in the equation for wives. Joint activities at home was the third variable entered for husbands and the sixth variable entered for wives. Total variance explained was 40 percent for husbands and 60 percent for wives. Other variables in both equations included: depression, yearly medical visits, years lived in a large city, age, education, activities in the community without spouse, years married, activities at home without spouse, and activities in the community with spouse (Aved, 1976).

It is important to look beyond general measures of marital satisfaction to the specific elements of interaction in marriage, since these elements may continue to influence health even when the level of satisfaction is controlled. For example, among couples satisfied with their marriage, there is a significant association between 
rheumatoid arthritis in the wife and peptic ulcer in the husband. The key variable here is marital hostility which contributes to the wife's arthritis via resentment and depression and to the husband's ulcer via unmet needs for emotional support (Cobb, 1969).

Another reason for examining specific interactional characteristics of marriage is that there is continuing disagreement as to the extent to which some of these characteristics are really correlates of marital satisfaction. Cuber and Haroff (1964) in their study of affluent couples found that the companionship of shared activities was not always necessary for marriage partners to feel that their marriage was good. The point here is that specific features of marital interaction will contribute additional information to our understanding of the marriage-health realtionship.

The companionship of shared activities has been examined in relationship to health and well-being. Pratt (1972) measured companionship by means of an index composed of eleven types of activities husbands and wives often do together. She found the index to be significantly related to a variety of health indices for both husbands and wives. In a later study, using regression analysis, (Pratt, 1976) the index helped to explain the extent of health problems for husbands but not for wives. A number of items in a similar index showed a positive relationship with positive 
affect and a slight negative relationship with negative affect in a study by Orden and Bradburn (1973).

An important class of variables intervening between marital satisfaction and mental and physical well-being may be referred to as the "husband-wife helping relationship" variables. Burke and Weir (1977) included the following variables in this class: informing one's spouse when tense and why, being satisfied with one's spouse as confidante, taking specific actions to help one's spouse, feeling helpful to one's spouse, defining behaviors spouse could carry out or change to be more helpful, being satisfied with the help received from one's spouse, and being the first person turned to for help. Nearly all of these variables were positively related to the mental and physical health indices used in the work of these researchers (Burke and Weir, 1977).

Comparison of Husbands and Wives

A common denominator in research assessing the effects of psychosocial processes on health is that the member of the family system (or marital dyad) who is most involved in the emotional structure of the family (or relationship) is most likely to be affected (Meissner, 1966). Especially since Parsons and Bales popularized the notion that the woman is the socioemotional specialist in the family (Parsons and Bales, 1955), it has been easy to assume that this member is the wife/mother. In agreement 
with this assumption are studies which suggest that marriage is more psychologically stressful for wives (Bernard, 1972; Gove, 1972; Kreitman, 1964). As an example of this type of finding, correlations of self-esteem with the Locke-Wallace Marital Adjustment Test are significantly higher for wives than husbands (Barnett and Nietzel, 1979). The same study shows a significant positive correlation between self-esteem and frequency of activities engaged in with spouse for wives, but not for husbands.

In another study by Weiss and Aved (1978), a greater proportion of variance in physical health status is explained for wives (60\%) than for husbands (40\%) by a set of predictors which include marital satisfaction. However, this study also suggests that marital dissatisfaction and depression are more likely to be found together for husbands than for wives, although the magnitude of the correlation is small. Other findings support this greater apparent influence of marriage on husbands (Glenn, 1975; Radloff, 1975). Perhaps it is only the earlier stages of marriage which husbands find most stressful (Campbell et al., 1975). In general, one senses from the literature that the health and well-being of wives tends to be somewhat more affected by marriage but more research is needed to determine the circumstances under which this generalization appears to hold. 
The following hypotheses derive from the review of the literature:

--Higher levels of marital cohesion, companionship, cooperation, and consensus will be related to higher levels of health and well-being;

--The health and well-being of wives will more likely be affected by marital cohesion, companionship, cooperation, and consensus than that of husbands;

--Diseases with a higher emotional component will more likely reflect variation in marital cohesion, companionship, cooperation, and consensus than other types of illness;

--Marital cohesion, companionship, cooperation, and consensus will influence health and well-being independent of the effect of health and well-being on these marital variables. 
CHAPTER III

METHODOLOGY

The population and data for this thesis derive from the Oregon Region of the Kaiser-Permanente Medical Care Program (KPMCP), a federally certified health maintenance organization. Established in 1943, this prepaid medical plan now enrolls approximately 250,000 members, or about 20 percent of the population of the Portland, Oregon metropolitan area. This clientele is a broadly based population group with demogaphic and sociographic characteristics that correspond very closely to the metropolitan population as a whole (Kaiser-Permanente Health Services Research Center, 1980). The health status of this population and tendency to seek medical care is also not unlike that of the population enrolled in provider-sponsored plans (Blue Cross and Oregon Physicians Service) or commercial plans (Freeborn and Pope, 1981).

Medical personnel, practicing full-time in an integrated hospital-ambulatory care system, provide comprehensive medical services within the context of group practice. Health plan members are encouraged to choose a personal physician and to return to that same physician when the need for medical care arises. The focal point for medical 
care is the physician's office, where most patients are seen by appointment, although provisions are made for seeing walk-in patients as well. Emergency services are available at all hours, and house calls are provided for patients when medically indicated.

The medical care system maintains a single, central medical record for each member. Every contact an individual makes with the system is recorded in his/her unit chart. These medical records provide highly reliable indicators of utilization, because it has been shown that the membership receives essentially all its medical care within the system (Pope et al., 1972). In 1966 a five percent random sample of health plan subscribers was selected by the Kaiser-Permanente Health Services Research Center for utilization and other health-related research purposes. The sample continues to be updated monthly.

\section{STUDY POPULATION}

A subset of the Health Services Research Center five percent research sample provided the population for the present investigation. This subset includes those subscriber units (families) that were continuously enrolled in the KPMCP from January 1, 1969, through December 31, 1970. This population has 2,502 adult members, including 1,004 married couples. After eliminating sixteen couples who were still legally married but no longer living together, 
988 couples remained to provide the study population for this project.

\section{DATA SOURCES}

There are two sources of data for this study: a personal interview survey and patient medical records.

\section{Household Interview Survey}

Interviewed in the survey were 2,502 adult members, of 1,529 subscriber units (families) included in the sample, representing 92 percent of the total sample. The survey elicited three different types of data:

(1) objective or factual information, such as the demographic characteristics of the individuals and families in the study;

(2) information about behaviors of individual family members as well as the family as a whole, including actions directed toward health and medical care and interaction within the family, on the job, etc.; and

(3) perceptual or attitudinal data, including a wide variety of beliefs, opinions, and perceptions about things related to medicine, medical care, the self, one's personal situation, and life in general.

Separate but simultaneous interviews with the husband and wife were conducted when both were health plan members. 
This made it possible to develop a special "couple" data file which linked information for husband and wife as a unit. The present study represents the first use of this unique data file.

\section{Outpatient Information System}

All medical care contacts, including doctor office visits, emergency room use, telephone calls, and correspondence, are recorded for each health plan member on a "Medical Service Record Form" (see Appendix, pp. 138, 139). Presenting morbidities are coded on ths form in accord with the most current edition of the International Classification of Diseases, Adapted (ICDA). This information, along with the other data collected by the form, is transferred to a continuously updated computer file.

After a patient's medical record form is completed, the morbidity information is converted to a code in the Kaiser Clinical-Behavioral Classification System (see Appendix, p. 140, Hurtado and Greenlick, 1971). This system was developed to group diseases according to the special needs of investigators and can be adapted to solving both clinical and behavioral research questions. Ten disease classes are identified within the system based upon the likelihood that each condition within a class will produce similar medical care utilization responses among persons of similar background characteristics. 
The survey described above was conducted approximately in the middle of the period during which medical record data was collected for most of the respondents in this study, i.e., some utilization information pre-dates and some post-dates the household interview survey. The assumption is made that the cross-sectional survey data would not be significantly different had it been collected in a two to four year period either preceding or following the actual survey.

\section{MEASURES}

The marital relationship measures will be described at some length because they have been developed to achieve the primary aims of this research project. The measures of cohesion, companionship, and cooperation are constructed for husband's and wive's separately before being combined to create a joint measure representing the "couple." Consensus, however, is designed only to represent the couple. Each of these measures, both individual and joint, are at the ordinal level of measurement.

The remaining measures, both of health and well-being and the sociodemographic characteristics, have been widely used in previous studies and will therefore be more succinctly discussed. 
The Marital Relationship

Four marital interaction variables are developed. These are: cohesion, a measure of affect; companionship and cooperation, measures of activity; and consensus, a measure of agreement. All of these variables are measured by combining spouses' responses to various questions from the Household Interview Survey.

Cohesion (Affect). Cohesion refers to a sense of attachment, togetherness, we-ness, or bonding between marriage partners which is revealed in the feelings which one spouse has about the other or about the marriage relationship itself. It is closely related to Scanzoni's affective dimension of primary interaction (1970). It is measured by an index combining four items from the survey questionnaire. Two of these are taken from a list of activities which married couples often do together. Specifically, respondents were asked to indicate whether they had "spent an hour or two just chatting with each other" and whether they had "had a good laugh together or shared a joke" within the past few weeks (yes/no).3 The other two items are trichotomies. One inquires about the extent to which a husband or wife is worried about "getting along with

${ }^{3}$ Studies have demonstrated the importance of asking respondents to consider a limited (current) time span rather than to "average" their feelings over the duration of their marriage. How a respondent evaluates previous marital interaction is strongly influenced by the current state of interaction (Hawkens, 1968). 
his/her spouse" (no, not worried; yes, extremely worried; yes, somewhat worried). The other asks respondents to rate the happiness of his/her marriage (extremely happy, pretty happy, not especially happy) .4

Table I presents the distribution of responses for husbands and wives as separate groups (i.e., specific husbands and wives are not linked) to the four questionnaire items which compose the cohesion index. It reveals that similar proportions of husbands and wives responded to each of the categories of the four items. Only the item on "worry" about the spousal relationship shows a difference greater than a few percentage points. Wives tend to worry about their relationship with their husbands somewhat more than husbands worry about their relationship with their wives. Most of the husbands and wives, however, chat, laugh, describe their marriage as extremely or pretty happy, and are not worried about their relationship with their spouse. These findings are consistent with previous studies (Orden and Bradburn, 1973; Langner and Michael, 1963). Table II, for example, shows marriage happiness ratings reported in selected studies.

The first step in constructing the cohesion index was to create a "communication" measure by combining the "chat" and "laugh" items. Those husbands or wives (a separate

4This question is identical to that used by the National Opinion Research Center in its General Social Survey (Glenn, 1975). 
TABLE I

FREQUENCY DISTRIBUTIONS FOR SURVEY ITEMS USED

IN MARITAL COHESION INDEX

Husbands

Wives

"Spent an hour or two

just chatting"
(a) Yes
(b) No
$92.1 \%$
7.9
$93.2 \%$
6.8
$(n=965)$
$(n=980)$

"Had a good laugh together or shared a joke"
(a) Yes
97.0
96.7
(b) No
3.0
3.3
$(n=963)$
$(n=980)$

"Worried about getting along with spouse"
(a) No, not worried
91.3
85.7
(b) Yes, somewhat worried
7.5
11.5
(c) Yes, extremely worried
1.2
2.8
$(n=961)$
$(n=979)$

"How happy is marriage"
(a) Extremely happy
51.4
52.5
47.5
45.3
(c) Not especially happy
1.1
2.2
$(n=960)$
$(n=983)$

Note: Numbers in parentheses differ because of missing data. 
TABLE II

MARRIAGE HAPPINESS RATINGS REPORTED IN SELECTED STUDIES

(PERCENTAGE DISTRIBUTION)

Marriage Happiness Rating Total

Study

Very Pretty Not Too

Orden and Bradburn

(1973)

Happy

Happy

Happy

$\underline{\mathrm{N}}$

60

26

3

99

1738

Bradburn and

Caplovitz (1965)

76

23

1

100

363

Gurin, Veroff, and

Feld (1960)

68

29

3

$100 \quad 1875$

Landis (1953)

83

16

1

100

409

Burgess and Cottrell (1939)

63

14

22

99

526

Terman (1938)

85

9

5

99

792

Source: Orden and Bradburn (1973).

Note: In the present study, pre-test data using response categories similar to these produced similar results. In the final survey, however, "extremely happy" is used in place of "very happy" to produce a more equitable distribution of responses across categories. This explains why the happiness ratings in Table I differ from the ratings depicted here. 
"communication" measure was created for each spouse) who both chat and laugh or do neither form the two extreme categories. Those who do one or the other, but not both, form the middle category. The categories of the "communication" measure and the remaining two measures to be included in the cohesion index ("worry about relationship with spouse" and "extent of marital happiness") are then examined for consistency of direction in order to insure an ordinal level of measurement.

Combining these three measures results in an ordinal-level cohesion index for each spouse. A similar combinatory process, this time adding the husband and wife cohesion indices, creates a multi-category cohesion index representing the "couple." The final step is to collapse the categories approximately into thirds (high, medium and low)

Table III shows the correlations among the husband and wife measures which are used to construct the couple cohesion index. With the exception of the correlations involving marital communication and spousal worry, all items are significantly related. These items are appropriate for inclusion in an index of cohesion since they are interrelated strongly enough to suggest that they are measuring different aspects of a broader construct but not so strongly as to be redundant. Examining the correlation matrix in this way provides a method of assessing the 
discriminant and convergent validity of the cohesion index. Discriminant validation refers to the fact that when measurements correlate highly with each other, they may be

\section{TABLE III}

CORRELATIONS AMONG HUSBAND AND WIFE MEASURES USED IN THE CONSTRUCTION OF COHESION INDEX (ZERO-ORDER PEARSON)

Wife's Measures

Husband's Measures

Happiness

Worry

Communication
Happiness

$$
.385 * * *
$$$$
.216 * \star *
$$$$
.080 * *
$$

Worry

Communication

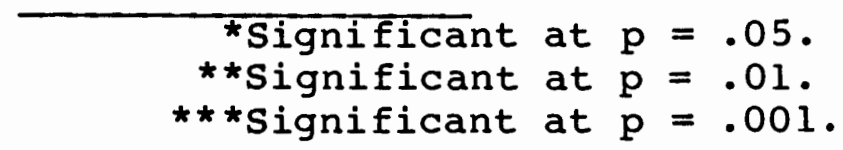

measuring the same rather than different constructs. In contrast, convergent validation means that if measurements correlate lowly, they may be measuring a different rather than the same construct (Campbell and Fiske, 1959). Companionship and Cooperation (Activity). Companionship is defined here as joint activity undertaken by a husband and wife for the benefit of the shared experience. Such activity produces a sense of pleasure in doing something together. In contrast, cooperation, although also a joint activity, has an instrumental purpose. It is activity which requires contributions from both partners to achieve a desired outcome for one or both of them. 
Although companionship receives more attention in the literature, cooperation is as important as companionship for understanding the character of the couple's interaction. Support for this view is provided by Blood and Wolfe (1960) who claim that marital satisfaction is enhanced when a husband helps his wife to solve the problems she faces (an example of a cooperative activity). Similarly, Burke and Weir (1977) report that greater marital satisfaction is associated with the performance of a greater number of helping activities between husbands and wives. The same study also indicates that better mental and physical health is related to partners selecting each other as first choice of helper, viewing themselves as good helpers, and expressing greater satisfaction with the helping interaction between them. For these reasons both cooperative and companionable activities will be examined in this thesis. Both of these concepts reflect the nature of Scanzoni's affiliative dimension of primary interaction (1970).

The companionship and cooperation measures will be considered together because they are both the result of a factor analysis ${ }^{5}$ of a set of survey items which assess

${ }^{5}$ Kim (1980:457) describes factor analysis as a "multivariate exploratory and analytical procedure used primarily to reduce the information contained in a set of variables to a smaller set of composite variables called factors." It offers the opportunity to view parsimoniously a large number of variables or indices in terms of a limited number of conceptual dimensions. An excellent introductory review of this statistical technique is given by Rummel (1967). 
(yes/no) recent participation in various activities married couples often do together. The utility of a marital activity list for the measurement of companionship is illustrated in a study by Pratt (1972). The significant positive relationship between companionship and health inthis study indicates that such a companionship measure has some construct validity. 6

Table IV presents the rotated loadings, using varimax rotation, for the various factors identified for husbands and wives respectively. Clusters of highly intercorrelated survey items which contain the highest loadings in each column (designated by the "boxed" areas) represent the factors.

Given the definition of cooperation, factor two, for both husbands and wives, is considered to represent this concept. Factor two for husbands contains "visited" and "entertained" friends, "helped spouse solve problem" and "worked on household project"; while factor two for wives contains the latter two items in addition to "done something spouse appreciated". This means that cooperation will be measured somewhat differently for husbands and wives.

Factors one and three provide the content for the companionship measure. This combination of factors validity.

6see Smith (1975) for a discussion of construct 
TABLE IV

LOADINGS FOR COMPANIONSHIP, COOPERATION, AND COHESION FACTORS

(VARIMAX ROTATION)

Factor $1 \quad$ Factor 2 Factor $3 \quad$ Factor 4 (Companionship) (Cooperation) (Compantonship) (Cohesion)

\begin{tabular}{|c|c|c|c|c|}
\hline Gone out & .727 & .094 & -.019 & .041 \\
\hline Eaten out & .665 & .042 & .253 & .060 \\
\hline Entertained friends & .135 & .732 & -.050 & .099 \\
\hline Visited friends & .480 & .601 & -.147 & .031 \\
\hline Helped spouse with & & & & \\
\hline problem & -.503 & .511 & .303 & .161 \\
\hline Worked on project & .034 & .457 & .397 & -.021 \\
\hline Gone shopping & -.051 & .049 & .706 & -.070 \\
\hline Taken drive or walk & .266 & -.072 & .604 & .081 \\
\hline Done something & & & & \\
\hline appreciated & .011 & .163 & .429 & .419 \\
\hline Chatted & -.080 & .005 & -.031 & .788 \\
\hline Laughed & .185 & .093 & .017 & .687 \\
\hline & \multicolumn{4}{|c|}{ (For Wives) } \\
\hline Visited friends & .800 & -.020 & .104 & .073 \\
\hline Entertained friends & .725 & .116 & -.075 & .173 \\
\hline Gone out & .475 & .211 & .333 & -.233 \\
\hline \multicolumn{5}{|l|}{ Helped spouse with } \\
\hline problem & -.050 & .772 & .016 & .090 \\
\hline Done something & & & & \\
\hline appreciated & .215 & .627 & -.004 & .123 \\
\hline Worked on project & .057 & .550 & .255 & .054 \\
\hline Gone shopping & -.118 & .153 & .714 & .085 \\
\hline Taken drive or walk & .077 & -.060 & .637 & .273 \\
\hline Eaten out & .332 & .148 & .554 & -.051 \\
\hline Chatted & .002 & .047 & .132 & .814 \\
\hline Laughed & .163 & .284 & .104 & .707 \\
\hline
\end{tabular}

Note: "Boxed" areas represent factors. 
contains the following items for both husbands and wives: "gone shopping", "taken drive or walk", "gone out for entertainment", and "eaten out." Husbands add "done something spouse appreciated" and wives add "visited" and "entertained" friends to this list. This means that companionship will be measured differently for husbands and wives. 7

The companionship and cooperation measures are constructed by summing the number of positive responses to the items contained within the factor(s) which is (are) associated with each concept. Simple summation is used because there is no theoretical basis for weighting any of the items. In each case the result is an ordinal-level measure of companionship and cooperation for each spouse. Combining husband and wife companionship measures creates an ordinal companionship measure representing the "couple." The final step involves collapsing the distribution to produce six categories. The same process is used in constructing an ordinal "couple" measure of cooperation with five categories.

Table $\mathrm{V}$ shows how individual activities are perceived by husbands and wives as separate groups (i.e., specific husbands and wives are not linked). In general, their perceptions are quite similar, differing at most by only three

7Factor four for both husbands and wives consists of items (chatted and laughed) used in the construction of the cohesion index described earlier. 


\section{TABLE V}

MARITAL ACTIVITIES ENGAGED IN AS PERCEIVED BY HUSBANDS AND WIVES

\begin{tabular}{|c|c|c|c|c|}
\hline & $\begin{array}{l}\text { Husbands } \\
\text { (\% Yes) }\end{array}$ & & $\begin{array}{l}\text { Wives } \\
(\% \text { Yes) }\end{array}$ & \\
\hline Visited friends & 80.3 & $(n=966)$ & 79.5 & $(n=980)$ \\
\hline Gone out for entertalnment & 62.9 & $(n=966)$ & 60.1 & $(n=980)$ \\
\hline Chatted for an hour or two & 92.1 & $(n=965)$ & 93.2 & $(n=980)$ \\
\hline Worked on household project & 69.9 & $(n=964)$ & 68.9 & $(n=980)$ \\
\hline Entertained friends at home & 76.4 & $(n=965)$ & 73.4 & $(n=980)$ \\
\hline Gone shopping & 77.8 & $(n=965)$ & 74.1 & $(n=980)$ \\
\hline Had good laugh & 97.0 & $(n=963)$ & 96.7 & $(n=980)$ \\
\hline Eaten out & 78.3 & $(n=965)$ & 75.7 & $(n=980)$ \\
\hline Taken drive or walk & 75.3 & $(n=961)$ & 75.2 & $(n=980)$ \\
\hline $\begin{array}{l}\text { Done something spouse } \\
\text { appreciated }\end{array}$ & 82.0 & $(n=955)$ & 86.2 & $(n=976)$ \\
\hline Helped spouse solve problem & 75.7 & $(n=963)$ & 70.8 & $(n=979)$ \\
\hline
\end{tabular}

Note: Nubers in parentheses differ because of missing data. 
to five percentage points and usually by only one or two. The most commonly engaged in activities, outside of "chatting" and "laughing" which were used in the construction of the cohesion index, are "visited friends" and "done something spouse appreciated." The least frequent activities are "gone out for entertainment" and "worked on a household project"; activities which may require more time or money than some of the others. Approximately two-thirds of each group, however, indicate that they had done these things within the past few weeks. These findings are consistent with previous studies (Orden and Bradburn, 1973).

Consensus (Agreement). Consensus represents agreement between husband and wife on the basic norms, beliefs, attitudes, and values which comprise their shared world view or outlook on life. It relates, in part, as explained earlier, to Scanzoni's cognitive dimension of primary interaction (1970).

The consensus measure is developed by comparing husbands' and wives' religious affiliations or preference. Of interest are not the affiliations or preferences themselves but rather whether or not spouses have identical, similar, or different affiliations or preferences. Most religious groups have a vested interest in the socialization of their adherents. Ordinarily, such socialization goes beyond inculating the fine points of doctrine to providing a general framework which includes appropriate 
values, norms, and attitudes for relating to the world. Comparing the religious affiliation of marriage partners would therefore seem to be a fitting measure of consensus. Specifically, two survey questions are used in the construction of the consensus meausre. One asks the respondent for his/her religion (Protestant, Catholic, Jewish, Eastern orthodox, Asian religion, or no affiliation). The other asks the respondent to designate a specific denomination if he/she is Protestant. These questions are the basis for constructing the final ordinal consensus measure which represents the couple. The categories of this measure include, in order of lesser to greater consensus: (a) husband and wife of different religions (in terms of outlook on life, "no religion" is interpreted in these categories as if it were a religion); (b) husband and wife both Protestant but of quite different denominations (in terms of outlook on life, "no specific denomination" is interpreted in these categories as if it were a religion); (c) husband and wife both Protestant and of closely related (i.e., theologically similar) denominations; and (4) husband and wife of the same religion and, if Protestant, the identical denomination.

Table VI compares the religious affiliation of husbands as a group with wives as a group. More wives than husbands are Protestant. More husbands than wives have no religious affiliation. When specific couples are compared, 
TABLE VI

RELIGIOUS AFFILIATION OF HUSBANDS AND WIVES

Husbands

PROTESTANT

Congregational, Unitarian

Disciples of Christ, Mennonite, Reformed, Quakers

Christian, Methodist (UCC), Presbyterian, Evangelical United Brethren

Baptist, Church of Christ, Free Methodist, Wesleyan Methodist, Covenant, Salvation Army

Church of God, Nazarene, Other Holiness

Assembly of God, Apostollc Faith, Other Pentecostal

Christian Scientist, Mormon, Seventh Day Adventists, Jehovah's Witnesses

Episcopalian, Lutheran

No specific denomination

No answer

CATHOLIC

JEWISH

EASTERN ORTHODOX

ASIAN

NONE
212

233

$661 \quad(66.3 \%)$

23

10

13

Wives

$755 \quad(75.2 \%)$

31

3

111

30

21

50

168

105

94

6

4

\begin{tabular}{|c|c|c|c|}
\hline 146 & $(14.6)$ & 155 & $(15.4)$ \\
\hline 8 & $(0.8)$ & 7 & $(0.7)$ \\
\hline 3 & $(0.3)$ & 2 & $(0.2)$ \\
\hline 4 & $(0.4)$ & 2 & $(0.2)$ \\
\hline 175 & $(17.6)$ & 83 & $(8.3)$ \\
\hline 997 & 100.0 & 1004 & 100.0 \\
\hline
\end{tabular}


77 percent are identically affiliated by religion and, of those who are Protestant, 58 percent are identically affiliated by denomination.

Health and Well-Being

In this analysis, health is measured by the mean annual rate of medical care contacts based upon two to seven years of utilization data. Four different disease classes (chronic, acute, trauma, and emotion-related) are measured in this way. In addition, a measure of selfevaluated general health status is included. Well-being is assessed by means of the Langer 22-Item Mental Health Index, and a measure of self-esteem. Both well-being measures and the measure of general health status are derived from the Household Interview Survey. Medical care contact data are obtained from patients' medical records. The survey measures will be described first before discussing the utilization measures. 8

Self-Esteem. A single question asking respondents to describe their feelings in terms of how much they would like to change themselves measures self-esteem. Three choices are given: change completely, change many things, or stay the same.

8The data source included other health and well-being measures: an Affect-Balance Scale, a Physical Symptoms Index, and a Worries Scale. Correlations of our health measures with these additional measures were sufficiently high so that using these additional measures seemed unnecessary. 
General Health Status. This measure is based on responses to the survey question, "Would you say your health in general is excellent, good, fair, or poor?" It is intended to reflect an individual's own perception of his or her general or composite health status.

Mental Health Status. This measure is the 22-item scale developed in the Midtown Manhattan Study. Information regarding the instrument's validity is given by Langner (1962). Although it was developed as a general measure of mental health, it is primarily a measure of psychophysiological symptomology and general malaise (Seiler, 1973). Conventional scoring, i.e., assigning a value of one to each "pathological" answer for the 22 items and summing across items, is followed. While the possible range of scores is 0 to 22 , the actual range is 0 to 15 (Freeborn, 1977).

The remaining health measures represent rate of total contacts for four of the disease classes from the tencategory Kaiser Clinical-Behavioral Classification System. As explained above, total contacts for this study includes all ambulatory contacts with health providers in the system as well as contacts with medical care personnel through telephone calls and letters.

Chronic Disease with Treatable Symptoms. Chronic disease includes impairments or disabilities which may require rehabilitative training and/or a long period of 
supervision, observation, etc. Excluded here are permanent impairments or disabilities for which treatment is not helpful in eliminating manifestations of the illness. Acute Disease. Acute disease includes disease produced by microorganisms such as viruses or bacteria or complications resulting from other illnesses or from surgical and medical procedures.

Trauma and Related Conditions. Trauma refers to illness or injury caused by external agents. Burns, chemical poisoning, fractured bones, and adverse reactions to medication are examples.

Emotion-Related Disease. Emotion-related diseases are more likely than other diseases to be produced or aggravated by emotions or by a disorganized social or psychological environment. Also included are emotional disorders without organic manifestations such as psychoses, neuroses, and psychophysiological disorders.

Sociodemographic (Control) Variables

Since the literature shows socioeconomic status, education, and age, to significantly influence both marriage and health, they are included in the analysis as control variables.9 Self-reported childhood health status and duration of marriage are also included as

${ }^{9}$ Since a large proportion of the study population (75.5\%) had been married only once, it was considered unnecessary to control for number of marriages. 
control variables. All of these variables are obtained by means of the Household Interview Survey.

Socioeconomic status is measured by the Duncan Socioeconomic Index. Education, age, and duration of marriage are simply measured in years. Childhood health status is based on the respondent's rating of his or her own health in childhood as excellent, good, fair, or poor.

\section{FORM OF THE ANALYSIS}

Each of the dependent, independent, and control variables is examined in relationship to each other. While this first involves cross-tabulational analysis in order to visualize the shape of the various relationships, only the results of a correlational analysis will be presented here. 10

The core of the analysis revolves around the use of the stepwise multiple regression procedure to address the questions posed in this study. In each regression the marital interaction and control variables are regressed on each of the health and well-being variables to determine the relative importance of the marital interaction and

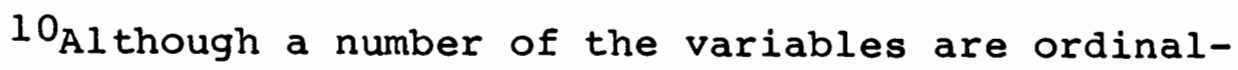
level, they are treated as if they were interval-level. This violation of assumptions for correlational statistics has become something of a convention in sociological research and is not considered serious here since the intent is merely to discover the existence of relationships and not to determine specific or absolute values of the correlations. 
control variables. This regression procedure is used here solely to determine the relative contributions of the independent variables in "explaining"ll variance in the various dependent variables. The predictive utility of multiple regression based on the absolute value of the regression coefficients is not of concern here.

The theoretical model presented earlier in this thesis simply provides a context for answering the questions of interest in the present research. It is not the purpose of this analysis to test the model itself.

11 When the term "explain" is used in presenting the findings of the various regression analyses, it should be understood that it is being used only in a statistical sense and not in terms of any cause-and-effect model. 


\section{CHAPTER IV}

\section{FINDINGS}

A summary of the sociodemographic and health characteristics of the husband and wife groups will be presented first in order to provide some familiarity with the study population. The relationship of the sociodemographic variables to the health and well-being variables is then described as a justification for the use of the sociodemographic variables as control variables in further analyses. Finally, data from a series of stepwise regression analyses is utilized to answer each of the research questions posed early in the thesis.

\section{CHARACTERISTICS OF HUSBANDS AND WIVES}

\section{Sociodemographic Characteristics}

At the time of the analysis the data available for education and socioeconomic status consisted of household information only, i.e., information about the male head. A broad range of educational and socioeconomic levels is represented among the households in the study population. Approximately one-third have completed less than high school, one-third have completed high school, and another third have at least some college education. Seventeen 
percent of the households are coded in the lowest socioeconomic category (Duncan Index), 18 percent in the highest category, and the remaining 65 percent are apportioned among the middle categories.

Age and number of years married are also broadly distributed among respondents. For both husbands and wives (as separate groups), nearly two-thirds are under age 50 and have been married for 25 years or less. The youngest quarter of the husband group and the youngest third of the wife group are under age 35. A third of both groups have been married for ten years or less.

\section{Health and Well-Being}

Wives are consistently more likely to score lower than their husbands on every health and well-being measure except one (See Table VII). Husbands experience more trauma, possibly because their occupational environment and/or male role behavior is more likely to increase their risk of accident or injury.

In terms of mental health status, more than twice as many husbands as wives are in the "symptom-free" category (38 percent compared to 18 percent). Wives also have lower self-esteem than husbands, being nearly twice as likely to want to "change many things" about themselves (42 percent compared to 25 percent).

The rate of contacts for medical care for wives is 16 percent higher than husbands for chronic disease, 38 
TABLE VII

COMPARISON OF MEANS ON THE HEALTH AND WELL-BEING MEASURES FOR HUSBANDS AND WIVES

\begin{tabular}{|c|c|c|}
\hline Husbands & Wives & $\begin{array}{c}\text { Signtficance } \\
\text { of } \\
\text { Difference }\end{array}$ \\
\hline & & \\
\hline
\end{tabular}

\section{Survey Measures}

Self-esteem

General Health Status (current)

Mental Health Status

Utilization Measures

Chronic Disease

Trauma

Acute Disease

Emotion-Related Disease

$$
2.73(n=973) \quad 2.57 \quad(n=989) \quad .000
$$

$$
\begin{array}{lllll}
1.83(n=977) & 1.84 \quad(n=996) & .767 \\
1.49 \quad(n=904) & 2.66 \quad(n=915) & .000
\end{array}
$$

$\begin{array}{rrrrr}1.37 \quad(n=1001) & 1.59 \quad(n=1001) & .020 \\ .68 \quad(n=1001) & .52 \quad(n=1001) & .001 \\ .84 \quad(n=1001) & 1.17 \quad(n=1001) & .000 \\ .75 \quad(n=1001) & 1.19 \quad(n=1001) & .000\end{array}$

Note: For all health and well-being measures except "self-esteem", the smaller the mean, the greater the health and well-being. For "self-esteem", the smaller the mean, the lower the "self-esteem." illnesses.

Utilization measures represent number of contacts per year for specific

The significance of difference in means was determined with the $\underline{t}$ test. 
percent higher than husbands for acute disease, and 59 percent higher than husbands for emotion-related disease. On self-evaluated health, both in childhood and currently, husbands and wives compare more closely. With respect to current health status, 38 percent of the husbands and 34 percent of the wives rate their health as excellent, 45 percent of the husbands and 49 percent of the wives rate their health good, 15 percent of the husbands and 14 percent of the wives state that they are in fair health, and about 3 percent of both husbands and wives report their health to be poor.

Very similar findings obtain in relation to childhood health. Forty-seven percent of the husbands and 45 percent of the wives evaluate their childhood health as excellent, 42 percent of the husbands compared to 39 percent of the wives rate their childhood health as good, 8 percent of the husbands and 11 percent of the wives rate their health in childhood fair, and about 4 percent of both husbands and wives report their health as a child as being poor.

\section{INTERRELATIONSHIPS AMONG MEASURES}

Interrelationships Among Marital Interaction Measures

Table VIII displays the zero-order Pearson correlations among the marital interaction measures. Companionship, cooperation, and cohesion are significantly, strongly, and positively intercorrelated. Consensus is 
weakly but positively related to cohesion and companionship, but is unrelated to cooperation.

\section{TABLE VIII}

CORRELATIONS AMONG THE MARITAL INTERACTION MEASURES

(ZERO-ORDER PEARSON)

$\begin{array}{lccc} & \text { Cohesion } & \text { Companionship } & \text { Cooperation } \\ \text { Companionship } & .179 * * * & & \\ \text { Cooperation } & .249 * * * & .406 * * * & \\ \text { Consensus } & .061 * & .059 * & .032\end{array}$

\footnotetext{
*Significant at $\mathrm{p}=.05$. **Significant at $\mathrm{p}=.01$. $\star * *$ Significant at $\mathrm{p}=.001$.
}

Interrelationships Among Sociodemographic, Health, and Marital Interaction Measures

Correlations between the sociodemographic variables and the health and well-being measures are given in Table IX and correlations between the marital interaction measures and the sociodemographic variables in Table $\mathrm{X}$. As Table IX indicates, the sociodemographic variables are significantly related to many of the health and well-being measures for both husbands and wives. Hence, their inclusion as control variables is important for the analysis.

All correlations in Table $\mathrm{X}$ involving cooperation and companionship are statistically significant. Education is significantly related to each of the interaction measures 
TABLE IX

CORRELATIONS BETWEEN THE SOCIODEMOGRAPHIC VARIABLES AND THE HEALTH AND WELL-BEING VARIABLES

(ZERO-ORDER PEARSON)

Sociodemographic Variables

Age Education SES Length of Marriage

A. For Husbands

Health and Wel1-Being Variables (Survey)

General Health Status

$-.271 * \star * \quad .231 * \star * \quad .125 * \star * \quad-.214 * \star *$

Self-Esteem

$-.103 * * * \quad-.047$

$.070 *$

Mental Health Status

.019

$.060 *$

.012

.024

Health Variables

(Utilization)

Chronic Disease

Trauma

Acute Disease

$.327 * * * \quad-.117 * \star * \quad-.018$

$.226 * \star \star$

Emotion-Related Disease

$-.134 * * * \quad-.043 \quad-.143 * \star *$

$-.108 * * *$

$.098 * * * \quad-.065 * \quad-.069 *$

$.077 * \star$

$.116 * * * \quad-.038$

$-.009$

$.092 * \star$

B. For Wives

Health and Well-Being Variables (Survey)

General Health Status

$-.291 * * *$

$.257 * \star \star$

$.161 * \star \star$

$-.244 * * *$

Self-Esteem

$.060 *$

$-.031$

$-.007$

$.058 *$

Mental Health Status

.013

$.106 * * *$

$.096 * \star$

.020

Health Variables (Utilization)

Chronic Disease

Trauma

$.229 * \star \star \quad-.006$

.025

$.186 * * \star$

Acute Disease

.017

$-.093 * *$

$-.073 *$

$-.029$

Emotion-Related Disease

$$
.061 *
$$

$-.011$

$-.039$

$.058 *$

$-.034$

.030

.029

$-.049$

*Significant at $p=.05$.

$\star *$ Significant at $p=.01$.

$\star * \star S i g n i f i c a n t$ at $\mathrm{p}=.00 \mathrm{i}$. 
TABLE X

CORRELATIONS BETWEEN THE MARITAL INTERACTION MEASURES

AND THE SOCIODEMOGRAPHIC VARIABLES

(ZERO-ORDER PEARSON)

Marital Interaction Measures

Cooperation Companionship Cohesion Consensus

Sociodemographic

\section{Variables}

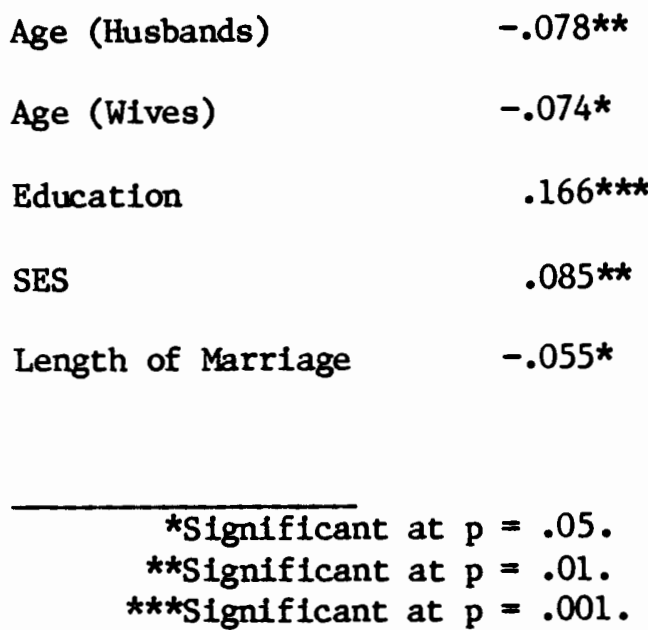

$\begin{array}{lll}-.084 * * & -.033 & .010 \\ -.059 * & -.041 & .005 \\ .127 * * * & .059 * & .110 * * * \\ .080 * * & .050 & .090 * * \\ -.064 * & -.017 & .077 * *\end{array}$


and SES to all except cohesion. Length of marriage and age are significantly but negatively related to cooperation, companionship and cohesion. Consensus, however, is directly related to the length of marriage though it is unrelated to age.

\section{RESEARCH HYPOTHESES}

Relationship of Marital Interaction and Health

Are higher levels of marital cohesion, companionship, cooperation, and consensus related to higher levels of health and well-being? Which marital variable(s) appear(s) to be more strongly and significantly related to health and well-being?

Table XI presents the correlations between the marital interaction measures and the health and well-being variables for husbands, and Table XII for wives. Most striking is the fact that significant relationships between marital interaction and health occur more frequently when health is measured by means of self-reported and survey data than by rates of medical utilization for the several disease categories. In fact, for wives there are no significant relationships between marital interaction and the utilization of medical services. For husbands, only four of the sixteen correlations are significant (each at the .05 level). The more cooperative and cohesive the marital relationship the less likely that husbands will 
TABLE XI

CORRELATIONS BETWEEN THE MARITAL INTERACTION MEASURES AND THE HEALTH AND WELL-BEING VARIABLES FOR HUSBANDS

(ZERO-ORDER PEARSON)

\section{Marital Interaction Measures}

Cooperation Companionship Cohesion Consensus

Health and We11-Being

Variables (Survey)

Current Health

$.112 \star * \star$

$.125 * * *$

$.165 * * \star \quad-.002$

Self-Esteem

$.073 *$

$.070 *$

$.144 \star \star \star \quad-.036$

Mental Health Status

$.085 * \star$

$.105 * * *$

$.120 * * * \quad-.002$

Health Variables
(Utilization)

Chronic Disease

(Treatable)

$-.022$

$-.027$

.006

$.064 *$

Trauma (Injuries, etc.)

$-.022$

.022

$-.064 *$

$-.035$

Acute Disease

.034

.028

$-.031$

.027

Emotion-Related Disease

$-.056 *$

$-.026$

$-.071 *$

.050

\footnotetext{
*Significant at $\mathrm{p}=.05$.

**Significant at $p=.01$.

$* * * S i g n i f i c a n t$ at $p=.001$.
} 
TABLE XII

CORRELATIONS BETWEEN THE MARITAL INTERACTION MEASURES AND THE HEALTH AND WELL-BEING VARIABLES FOR WIVES

(ZERO-ORDER PEARSON)

Marital Interaction Measures

Cooperation Companionship Cohesion Consensus

Health and Well-Being

Varlables (Survey)

Current Health

$.114 * \star \star$

$.128 * \star \star *$

$.162 * \star \star \quad .038$

Self-Esteen

$-.096 * *$

.015

$.144 * \star \star \quad .048$

Mental Health Status

$.114 * * *$

$.057 *$

$.167 * \star \star$

$.080 * *$

Health Variables

(Utilization)

Chronic Disease

(Treatable Symptoms)

$$
-.047
$$

$-.044$

$-.034$

.043

Trauma (Injuries, etc.)

.015

.037

$-.044$

$-.003$

Acute Disease

$-.033$

$-.013$

$-.000$

.007

Emotion-Related Disease

$-.026$

.001

$-.041$

$-.042$

*Significant at $p=.05$.

**Significant at $\mathrm{p}=.01$.

$\star * \star$ Significant at $p=.001$. 
have used services for emotion-related diseases. For husbands, higher cohesion also relates to using fewer services for trauma and related conditions. In contrast, the use of services for chronic diseases is more likely for husbands among couples higher in consensus.

The relationships between self-reported health and well-being and marital interaction are similar for husbands and wives. For both spouses, more highly cohesive, cooperative and companionable marriages are related to better current health and well-being except in the case of wives' self-esteem. For wives there is no relationship between self-esteem and companionship and consensus and the relationship to cooperation is negative rather than positive. For husbands, consensus bears no relationship to health and well-being, though for wives, consensus is positively related to mental health status.

The results of the stepwise regressions of sociodemographic and marital interaction variables on the various measures of health and well-being are displayed in Table XIII. Marital interaction, especially its cohesion dimension, plays a prominent role in explaining self-esteem, and both general and mental health status. As indicated in Table XIII-A, cohesion enters the regressions first for both husbands and wives when self-esteem is the dependent variable. This is followed by education for husbands and by age, cooperation, and childhood health for wives. Those 
TABLE XIII

STEPWISE REGRESSION OF SOCIODEMOGRAPHIC VARIABLES AND MARITAL INTERACTION MEASURES ON HEALTH AND WELL-BEING OF HUSBANDS AND WIVES

$\underline{\text { Regression Analysis }}$

Multiple R Rsq. Rsq. change Sig. Beta $\underline{\text { Sig. }}$

I. Health and Well-Being

Variables (Survey)

A. Self-Esteem

For Husbands

Cohesion

Education

.144

.0208

.0208

.000

.151

.000

or Wives

Cohesion
Age

.182

$.0332 \quad .0124$

$\begin{array}{lll}.001 & -.111 \quad .001\end{array}$

Cooperation

.144

.0206

.0206

.000

$.125 \quad .000$

Childhood Health

.158

.0250

.0043

.042

$.075 \quad .021$

.172

.0295

.0045

$.038 \quad .069 \quad .038$

.184

.0339

.0044

$.039 \quad .067$

.039

B. General Health Status

For Husbands

Age

.270

Childhood Health

Cohesion

Education

For Wives

Age

Childhood Health

Education

Cohesion

Companionship
.368

.394

.408

.291

.359

.393

.414

.419
.0733

.0733

.1355

.0622

.1550

.0196

.1668

.0118

.0846

.129

.1542

.1709

.1753

.0846

.0445

$\begin{array}{rrr}.000 & -.204 & .000 \\ .000 & .232 & .000 \\ .000 & .135 & .000 \\ .000 & .118 & .000\end{array}$

.000

$-.210 \quad .000$

$\begin{array}{lll}.000 & -.200 \quad .000\end{array}$

$.000 \quad .156 \quad .000$

$.000 \quad .118 \quad .000$

$\begin{array}{lll}.027 & .067 \quad .027\end{array}$

C. Mental Health Status

For Husbands

$\begin{array}{lllllll}\text { Childhood Health } & .154 & .0236 & .0236 & .000 & .140 & .000 \\ \text { Cohesion } & .189 & .0356 & .0120 & .001 & .097 & .004 \\ \text { Compantonship } & .202 & .0409 & .0053 & .029 & .074 & .029\end{array}$


TABLE XIII, CONTINUED

Regression Analysis

C. Mental Health

Multiple R Rsq. Rsq. change Sig. Beta Sig.

Status Cont.

$\frac{\text { For Wives }}{\text { Cohesion }}$

$.167 \quad .0278 \quad .0278$

$.000 \quad .000$
.009

Childhood Health

$.212 \quad .0451$

.0173

$.000 \quad .133 \quad .000$

Education

.231

.0536

.0084

$.006 \quad .118 \quad .001$

Age

.241

$.0581 \quad .0045$

$\begin{array}{lll}.042 & -.072 \quad .042\end{array}$

II. Health Variables (Utilization)

A. Chronic Disease

For Husbands

$\begin{array}{lllllll}\text { Age } & .327 & .1072 & .1072 & .000 & .446 & .000 \\ \text { Length of Marriage } & .336 & .1128 & .0056 & .016 & -.146 & .007 \\ \begin{array}{l}\text { Consensus } \\ \text { For Wives }\end{array} & .343 & .1177 & .0049 & .023 & .071 & .023 \\ \text { Age } & .229 & .0523 & .0523 & .000 & .256 & .000 \\ \text { Education } & .244 & .0594 & .0071 & .008 & .092 & .007 \\ \text { Childhood Health } & .258 & .0663 & .0069 & .009 & -.083 & .009\end{array}$

B. Trauma

For Husbands

$\begin{array}{lllllll}\text { SES } & .143 & .0205 & .0205 & .000 & -.163 & .000 \\ \text { Age } & .210 & .0442 & .0237 & .000 & -.155 & .000 \\ \begin{array}{l}\text { For Wives } \\ \text { Childhood Health }\end{array} & .102 & .0104 & .0104 & .002 & -.103 & .002 \\ \text { Education } & .136 & .0184 & .0080 & .006 & -.113 & .001 \\ \text { Length of Marriage } & .152 & .0232 & .0048 & .033 & -.073 & .033\end{array}$

C. Acute Disease

For Husbands

$\begin{array}{lllllll}\text { Age } & .098 & .0096 & .0096 & .003 & .098 & .003\end{array}$

For Wives

$\begin{array}{lllllllll}\text { Childhood Health } & .101 & .0103 & .0103 & .002 & -.101 & .002\end{array}$ 
TABLE XIII, CONTINUED

Regression Analysis

Multiple R Rsq. Rsq. change Sig. Beta Sig.

D. Emotion-Related Disease

For Husbands

\begin{tabular}{lrrrrrr} 
Age & .116 & .0134 & .0134 & .000 & .114 & .000 \\
$\begin{array}{l}\text { Cohesion } \\
\text { For Wives }\end{array}$ & .134 & .0179 & .0045 & .039 & -.067 & .039 \\
\hline Childhood Health & .091 & .0084 & .0084 & .005 & -.091 & .005
\end{tabular}


most likely to have greater self-esteem are husbands and wives higher in marital cohesion, husbands who are less educated, wives who are older, wives from couples higher in cooperation, and wives with better childhood health.

Cohesion also enters the regression first for wives and second, after childhood health, for husbands when mental health status is the dependent variable (see Table XIII-C). Cohesion is followed by childhood health, education, and age for wives and by companionship for husbands. Those most likely to enjoy better mental health are husbands and wives who had better health in childhood, husbands and wives who have more cohesive relationships, husbands among couples higher in companionship, and wives who are younger and more highly educated.

Table XIII-B presents the regressions on general health status. Cohesion, although included in the equations, is the third variable to be entered behind age, childhood health, and education for wives. It is the second variable to be entered behind age and childhood health for husbands. Education is also included in the regression for husbands and companionship in the regression for wives. Better general health status is more characteristic of husbands and wives who are younger, more highly educated, and more cohesive in their spousal relationship. Better general health status is also more characteristic of husbands who had better health during childhood, wives who 
had poorer health during childhood, and wives among couples higher in companionship.

Length of marriage, SES, and consensus fail to enter any of the above regression equations based on survey data. Tables XIII-D through XIII-G demonstrate that the dimensions of marital interaction are conspicuously uninvolved in explaining health as measured by utilization behavior. Marital interaction variables appear only twice and only in the equations for husbands' utilization. Consensus is the third variable to enter the regression when utilization for chronic disease by husbands is the dependent variable. Its influence, however, is opposite that expected, i.e., higher consensus is more highly related to the use of services for chronic disease. Cohesion enters as the second varible when use of services for emotionrelated disease by husbands is the dependent variable. Here the relationship is in the expected direction, i.e., higher cohesion is associated with less utilization of services for emotion-related disease. In both instances, the marital interaction variables contribute only a very small $R$ square change.

For husbands, age is usually the first and certainly the most frequently appearing explanatory variable in the regression equations on utilization for each of the four disease categories. For wives, health status in childhood has this distinction. 
older husbands use more services for chronic, acute, and emotion-related disease. It is the younger and lower SES husbands, however, who use more services for trauma and related disorders. Similarly, wives with less education and shorter length of marriage use more services for trauma and related disorders. Wives with better childhood health are less likely to use services for any of the four disease categories. But older and more educated wives, just as older husbands (and husbands with shorter length of marriage), are more likely to use services for chronic disease.

Neither cooperation nor companionship enters any of the regression equations (for either husbands or wives) for the utilization variables.

For the sake of parsimony, an attempt was made to develop an index of marital integration by combining all four of the marital interaction variables.12 This index was then used in a sample set of regressions similar to those in Table XIII (See Table XIV). In nearly every regression performed, marital integration enters the equation precisely at the point where one of its components had entered in Table XIII. Instead of improving the explanatory power of the marital variables, the index

12 The number of categories within each marital variable was either increased or decreased so that each variable would have an equal number (4). This procedure, in effect, weighted each variable equally when they were combined in the index. 
TABIE XIV

STEPWISE REGRESSION OF SOCIODEMOGRAPHIC VARIABLES AND MARITAL INTEGRATION INDEX ON SELECTED HEALTH AND WELL-BEING VARIABLES

OF HUSBANDS AND WIVES

Regression Analysis

Multiple R Rsq. Rsq. change Sig. Beta Sig.

A. Self-Esteem

For Husbands

\begin{tabular}{lllllll} 
Integration & .116 & .0133 & .0133 & .000 & .139 & .000 \\
$\begin{array}{l}\text { Education } \\
\text { For Wives }\end{array}$ & .171 & .0292 & .0159 & .000 & -.128 & .000 \\
\hline Integration & .139 & .0192 & .0192 & .000 & .139 & .000
\end{tabular}

B. General Health Status

For Husbands

Age

Childhood Health

.271

$.0733 \quad .0733$

$\begin{array}{lll}.000 & -.211 \quad .000\end{array}$

Integration

.1355

.0622

$.000 \quad .235 \quad .000$

Education

$.1498 \quad .0143$

$\begin{array}{lll}.000 \quad .001 & .02\end{array}$

.387

$.1587 \quad .0089$

$.002 \quad .105 \quad .002$

For Wives

Age

.398

.0846

$.000 \quad-.220 \quad .000$

Childhood Health

.291

.0846

.0846

$.000 \quad .200 \quad .000$

Education

.1291

.0445

.000

.147 .000

Integration

.393

.1542

.0251

.000

$.114 \quad .000$

C. Mental Health Status

For Husbands

Childhood Health

.154

$$
.0236
$$

.0236

.000

$.145 \quad .000$

Integration

.198

.0390

.0154

$.000 \quad .124 \quad .000$

For Wives

Integration
Childhood Health

.185

.0342

.0342

.000

$.161 \quad .000$

.225

.0505

.0163

.000

$.126 \quad .000$

Education

.235

.0554

.0049

.036

$.071 \quad .036$

D. Emotion-Related

For Husbands

Age

For Wives

Childhood Health

.116

.0134

.0134

.000

$.116 \quad .000$

.091

$.0084 \quad .0084$

$\begin{array}{lll}.005 & -.091 \quad .005\end{array}$ 
actually weakens their overall effect by diluting the influence of the strongest components (mainly cohesion). The index was therefore not utilized in further analyses. Means for the health measures are compared for husbands and wives in the upper and lower halves of the distribution for each marital variable in Table XV. A procedure which compares at the extremes of a distribution on the independent variable enables mean differences in the dependent variable to more readily emerge and gives one an opportunity to examine the magnitude of these differences both within and between the husband and wife groups. The findings reported in Table $\mathrm{XV}$ are essentially the same as those reported in Table XIII. In Table XV, however, cooperation accounts for differences in all three surveyrelated health measures in comparison to its influence only in relationship to self-esteem for wives in Table XIII. Also, there are significant differences in trauma between high and low groups of husbands and wives on cohesion in Table XV, while cohesion did not appear to be related to trauma in Table XIII.

In short, higher levels of the marital interaction variables are related to selected measures of health and well-being. Cohesion is more strongly and significantly related to more of the health and well-being measures than the other marital interaction variables. 
TABLE XV

MEANS ON HEALTH AND WELL-BEING MEASURES FOR HUSBANDS AND WIVES BY HIGH AND LOW CATEGORIES OF THE MARITAL INTERACTION MEASURES

\begin{tabular}{|c|c|c|c|c|c|c|c|c|}
\hline \multirow{4}{*}{ Cohesion } & \multicolumn{8}{|c|}{ Survey Measures } \\
\hline & \multicolumn{2}{|c|}{ Self-Esteem } & \multicolumn{3}{|c|}{$\begin{array}{c}\text { General Health } \\
\text { Status }\end{array}$} & \multicolumn{3}{|c|}{$\begin{array}{c}\text { Mental Health } \\
\text { status }\end{array}$} \\
\hline & Husbands & WIves & & tusbands & WI ves & & Husbands & WIves \\
\hline & 2.79 & $\overline{2.62}$ & & 1.75 & $\overline{1.77}$ & & 1.33 & $\overline{2.32}$ \\
\hline Low Group & 2.65 & 2.48 & & 1.94 & 1.96 & & 1.77 & 3.15 \\
\hline \multirow[t]{4}{*}{ SIgnifleance } & $(.000)$ & $(.000)$ & & $(.000)$ & $(.000)$ & & $(.001)$ & $(.000)$ \\
\hline & \multicolumn{8}{|c|}{ Utill zation Measures } \\
\hline & \multicolumn{2}{|c|}{ Chronle } & \multicolumn{2}{|c|}{ Trauma } & \multicolumn{2}{|l|}{ Acute } & \multicolumn{2}{|c|}{ EmotIon-Related } \\
\hline & Husbands & Wives & Husbands & WIves & Husbands & Wives & Husbands & Wives \\
\hline HIgh Group & 1.38 & $\overline{1.59}$ & .60 & $\overline{.47}$ & .80 & $\overline{1.19}$ & .67 & $\overline{1.16}$ \\
\hline Low Group & 1.35 & 1.59 & .80 & .59 & .90 & 1.16 & .85 & 1.23 \\
\hline SIgniflcance & (NS) & (NS) & $(.007)$ & $(.053)$ & (NS) & (NS) & $(.036)$ & (NS) \\
\hline
\end{tabular}

\begin{tabular}{|c|c|c|c|c|c|c|}
\hline \multirow[b]{3}{*}{ Companlonship } & \multicolumn{6}{|c|}{ Survey Measures } \\
\hline & \multicolumn{2}{|c|}{ Self-Esteem } & \multicolumn{2}{|c|}{$\begin{array}{c}\text { General Health } \\
\text { status }\end{array}$} & \multicolumn{2}{|c|}{$\begin{array}{c}\text { Mental Health } \\
\text { status }\end{array}$} \\
\hline & Husbands & Wives & Husbands & Wives & Husbands & Wives \\
\hline HIgh Group & 2.75 & 2.57 & 1.76 & $\overline{1.77}$ & 1.32 & 2.53 \\
\hline Low Group & 2.72 & 2.56 & 1.89 & 1.90 & 1.69 & 2.78 \\
\hline $\operatorname{sign}|f| \operatorname{cance}$ & (NS) & (NS) & $(.010)$ & $(.004)$ & $(.004)$ & (NS) \\
\hline
\end{tabular}

Utllization Measures

\begin{tabular}{|c|c|c|c|c|c|c|c|}
\hline \multicolumn{2}{|c|}{ Chronlc } & \multicolumn{2}{|c|}{ Trauma } & \multicolumn{2}{|c|}{ Acute } & \multicolumn{2}{|c|}{ EmotIon-Rel ated } \\
\hline Husbands & WIves & Husbands & WI ves & Husbands & Wives & Husbands & WIves \\
\hline 1.30 & 1.51 & .69 & .53 & .86 & $\overline{1.12}$ & .69 & 1.16 \\
\hline 1.40 & 1.65 & .68 & .50 & .79 & 1.19 & .79 & 1.22 \\
\hline (NS) & (NS) & (NS) & (NS) & (NS) & (NS) & (NS) & (NS) \\
\hline
\end{tabular}

Note: For all health and well-beling measures except "self-esteem", the smaller the mean, the greater the health and well-belng. For "self-esteem", the smaller the mean, the lower the "self-esteem."

Utllizatlon measures represent number of contacts per year for speclfle IIInesses. 
TABLE XV CONTINUED

Survey Measures

\begin{tabular}{|c|c|c|c|c|c|}
\hline \multicolumn{2}{|c|}{ Self-Esteom } & \multicolumn{2}{|c|}{$\begin{array}{c}\text { General Health } \\
\text { Status } \\
\end{array}$} & \multicolumn{2}{|c|}{$\begin{array}{c}\text { Mental Health } \\
\text { Status } \\
\end{array}$} \\
\hline Husbands & Wives & Husbands & WIves & Husb ands & Wives \\
\hline 2.77 & $\overline{2.61}$ & 1.77 & $\overline{1.77}$ & 1.39 & 2.38 \\
\hline 2.70 & 2.52 & 1.90 & 1.92 & 1.64 & 2.94 \\
\hline$(.028)$ & $(.006)$ & $(.013)$ & $(.003)$ & $(.057)$ & $(.001)$ \\
\hline
\end{tabular}

UtIllzation Measures

\begin{tabular}{|c|c|c|c|c|c|c|c|}
\hline \multicolumn{2}{|c|}{ Chronlc } & \multicolumn{2}{|c|}{ Trauma } & \multicolumn{2}{|c|}{ Acute } & \multicolumn{2}{|c|}{ Emotion-Rel ated } \\
\hline Husbands & WIves & Husb ands & Wives & Husbands & Wives & Husbands & Wives \\
\hline 1.33 & $\overline{1.49}$ & .88 & $\overline{1.11}$ & .68 & .52 & .71 & 1.13 \\
\hline 1.42 & 1.69 & .80 & 1.25 & .70 & .51 & .77 & 1.25 \\
\hline (NS) & (NS) & (NS) & (NS) & (NS) & (NS) & (NS) & (NS) \\
\hline
\end{tabular}

HIgh Group

Low Group

SIgnifl cance

(NS)

(NS)

(NS)

(NS)

(NS)

(NS)

(NS)

Survey Measures

\begin{tabular}{|c|c|c|c|c|c|}
\hline & & \multicolumn{2}{|c|}{ General Health } & \multicolumn{2}{|c|}{ Mental Health } \\
\hline \multicolumn{2}{|c|}{ Self-Esteem } & \multicolumn{2}{|c|}{ Status } & \multicolumn{2}{|c|}{ Status } \\
\hline Husbands & Wives & Husbands & WI ves & Husbands & WIves \\
\hline 2.71 & 2.59 & 1.83 & 1.82 & 1.51 & 2.48 \\
\hline 2.76 & 2.54 & 1.83 & 1.86 & 1.47 & 2.88 \\
\hline (NS) & (NS) & (NS) & (NS) & (NS) & $(.014)$ \\
\hline
\end{tabular}

Utillzation Measures

\begin{tabular}{|c|c|c|c|c|c|c|c|}
\hline \multicolumn{2}{|c|}{ Chronlc } & \multicolumn{2}{|c|}{ Trauma } & \multicolumn{2}{|c|}{ Acute } & \multicolumn{2}{|c|}{ Emotion-Related } \\
\hline Husbands & Wives & Husbands & Wives & Husbands & Wives & Husbands & WIves \\
\hline 1.47 & 1.68 & .63 & .52 & .85 & 1.18 & .80 & 1.15 \\
\hline 1.22 & 1.48 & .74 & .53 & .81 & 1.15 & .68 & 1.25 \\
\hline (NS) & (NS) & (NS) & (NS) & (NS) & (NS) & (NS) & (NS) \\
\hline
\end{tabular}


Comparison of Husbands and Wives With Respect to the Marriage/Health Relationship

Is the health and well-being of wives more likely to be affected by marital cohesion, companionship, cooperation, and consensus than the health and well-being of husbands?

Table XIII reveals that the marital interaction variables are present in the regression equations for the survey-related health measures for both husbands and wives. If the total variance explained by the marital variables for each health measure is compared between husbands and wives, it is seen that slightly more variance is explained by the marital variables for wives. The difference is less than one-half of one percent of the variance explained in the case of self-esteem and general health status and about one and one-half percent in the case of mental health status.

When the regressions for the utilization-related health measures in Table XIII are examined, there is a slight tendency for husbands to be affected by marital interaction in relationship to chronic and emotion-related diseases only, but the amount of variance in these health measures explained by the marital interaction variables involved is less than one-half of one percent in both cases. The marital variables enter none of the regressions for wives on these measures. 
In summary, there is very little difference between husbands and wives in terms of the effect of the marital variables on their health and well-being. Only on the basis of the number of different health measures affected by one or more of the marital variables can it be said that the health of husbands is affected more by marital interaction (five measures for husbands compared to three measures for wives).

A set of interesting questions emerged in the context of this analysis: Does the "couple" nature of our marital interaction measures make a difference in explaining individual spousal health and well-being? Also, do the measures of marital interaction of one spouse affect the health of the other?

In the description of how the marital interaction measures were constructed it was indicated that measures of cohesion, companionship, and cooperation were first developed for husbands and wives separately based upon their individual responses to survey items. Only then were husband and wife responses combined to create a "couple" measure for these interaction variables. To answer the first question another series of regressions were performed which are summarized in Table XVI. For the regressions on the husband's (wife's) health measures, only the marital variables for the wife (husband) (along with the socioeconomic variables) were entered as independent variables. If the 
TABLE XVI

STEPWISE REGRESSION OF SOCIODEMOGRAPHIC VARIABLES AND WIFE'S (HUSBAND'S) MARITAL INTERACTION MEASURES ON HUSBAND'S (WIFE'S)

HEALTH AND WELL-BEING VARIABLES

Regression Analysis

I. Health and Well-Being

Multiple R Rsq. Rsq. change Sig. Beta Sig.

Variables (Survey)

A. Self-Esteem

For Husbands

$\begin{array}{lllllll}\text { Cohesion (Wife) } & .137 & .0188 & .0188 & .000 & .147 & .000 \\ \text { Education } & .180 & .0323 & .0135 & .000 & -.123 & .000 \\ \begin{array}{l}\text { Childhood Health } \\ \text { or Wives }\end{array} & .190 & .0362 & .0039 & .050 & .063 & .050 \\ \begin{array}{l}\text { Cohesion (Husband) } \\ \text { Cohesion }\end{array} & .134 & .0178 & .0178 & .000 & .133 & .000\end{array}$

B. General Health Status

For Husbands

Age

Childhood Health

Education

Cohesion (Wife)

For Wives

Age

Childhood Health

Education

Cohesion (Husband)

.27

$$
.368
$$$$
.386
$$

.398

.1584

.0733

.0733

.000

$-.209$

.000

$.000 \quad .237 \quad .000$

$.000 \quad .115 \quad .000$

$.001 \quad .099 \quad .001$

.291

$.0846 \quad .0846$

C. Mental Health Status

For Husbands

Childhood Health

Cohesion (Wife)

For Wives

\begin{tabular}{|c|c|c|c|c|c|c|}
\hline Childhood Health & .154 & .0236 & .0236 & .000 & .150 & .000 \\
\hline Cohesion (Wife) & .185 & .0343 & .0107 & .002 & .104 & .002 \\
\hline \multicolumn{7}{|l|}{ or Wives } \\
\hline Childhood Health & .143 & .0204 & .0204 & .000 & .127 & .000 \\
\hline Cohesion (Husband) & .188 & .0352 & .0149 & .000 & .126 & .000 \\
\hline Education & .215 & .0462 & .0110 & .002 & .105 & .00 \\
\hline
\end{tabular}

.359

.393

.404

$.1291 \quad .0445$

$.1542 \quad .0251$

$.1635 \quad .0093$

$.000 \quad .150 \quad .000$

$\begin{array}{lll}.002 & .04 & .002\end{array}$

$\begin{array}{lll}.185 & .0343 \quad .0107\end{array}$

$\begin{array}{lll}.000 & -.216 \quad .000\end{array}$

$.000 \quad .200 \quad .000$

$.000 \quad .173 \quad .000$

$.001 \quad .097 \quad .001$ 
TABLE XVI, CONTINUED

Regression Analysis

Multiple R Rsq. Rsq. change Sig. Beta Sig.

II. Health Variables

(Utilization)

A. Chronic Disease

For Husbands

Age

Length of Marriage

Consensus

For Wives

Education

Childhood Health
.327

.336

.343

.229

.244

.067

$$
\begin{array}{ll}
.1072 & .1072 \\
.1128 & .0056 \\
.1177 & .0049 \\
.0523 & .0523 \\
.0594 & .0071 \\
.0663 & .0069
\end{array}
$$$$
.000
$$$$
.446 \quad .000
$$$$
\begin{array}{lll}
.015 & -.146 \quad .007
\end{array}
$$$$
.021
$$$$
.071 \quad .021
$$

.000

.008

$.256 \quad .000$

$\begin{array}{lll}.008 & -.083 \quad .008\end{array}$

B. Trauma

\section{$\frac{\text { For Husbands }}{\text { SES }}$}

Age

Cohesion (Wife)

For Wives

Childhood Health

Education

Cohesion (Husband)

Length of Marriage

$$
.143
$$

$$
.0205
$$$$
.0205
$$$$
.0442 \quad .0237
$$$$
.210
$$

.220

.0484

.0041

$$
\begin{array}{lll}
.000 & -.159 & .000 \\
.000 & -.156 & .000 \\
.042 & -.064 & .042
\end{array}
$$

.102

.0104

.0104

$\begin{array}{lll}.002 & -.096 & .003\end{array}$

.136

.018

.0080

.006

$-.115 \quad .001$

.155

.024

.0057

$.019 \quad-.074 \quad .023$

.169

.0286

.0044

.038

$-.071 \quad .038$

C. Acute

For Husbands

$$
\text { Age }
$$

For Wives

Childhood Health

$$
.098
$$

.0096

.0096

.002

.098

.002

.101

.0103

.0103

.002

$-.101$

.002

D. Emotion-Related

$\frac{\text { For Husbands }}{\text { Age }}$

$$
\text { Cohesion (Wife) }
$$

$$
.116
$$

$$
.0134
$$$$
.0134
$$$$
.000
$$$$
.115
$$$$
\begin{array}{lll}
.003 & -.095 & .003
\end{array}
$$

For Wives

$$
\text { Cohesion (Husband) }
$$

.150

.0225

.0091

.094

$$
.0089
$$

.0089

$\begin{array}{lll}.004 & -.087 \quad .008\end{array}$

Childhood Health

.0069

$.010 \quad-.083 \quad .010$ 
"couple" nature of the marital interaction measures makes no difference in explaining the health of either spouse, we would expect that the marital interaction measures of the opposite spouse would give the same results as those displayed in Table XIII. As Table XVI illustrates, this is precisely what happens. Evidently there is a great deal of "overlapping" information contained in the couple measures so that little information is lost when the marital variables of only one of the partners (in this case the opposite spouse) are utilized.

In an attempt to answer the question about whether the measures of marital interaction of one spouse influence the health of the other, additional regressions were performed. This time the separate marital variables for husbands and wives were entered together in all regressions on the health measures of both husbands and wives (along with the sociodemographic variables). Table XVII displays the results. In most cases the husband's marital interaction measures enter regressions explaining his health and wellbeing. Similarly, the wife's marital interaction measures enter regressions explaining her health and well-being. There are, however, some interesting exceptions. For emotion-related disease, it is the cohesion measure of one's partner which helps to account for variance in one's own health. In relationship to trauma, it is the husband's measure of cohesion which helps to account for variance in 
TABLE XVII

STEPWISE REGRESSION OF SOCIODEMOGRAPHIC VARIABLES AND BOTH HUSBAND'S AND WIFE'S MARITAL INTERACTION MEASURES ON HEALTH AND WELL-BEING

OF HUSBANDS AND WIVES

Regression Analysis

Multiple R Rsq. Rsq. change Sig. Beta Sig.

I. Health and Well-Being

Varlables (Survey)

A. Self-Esteem

For Husbands

$\begin{array}{lllllll}\text { Cohesion (Husband) } & .156 & .0244 & .0244 & .000 & .110 & .002 \\ \text { Education } & .184 & .0340 & .0095 & .002 & -.109 & .001 \\ \begin{array}{l}\text { Cohesion (Wife) } \\ \text { For Wives }\end{array} & .206 & .0423 & .0083 & .004 & .101 & .004 \\ \begin{array}{l}\text { Cohesion (Wife) } \\ \text { Cohesion (Husband) }\end{array} & .143 & .0205 & .0205 & .000 & .106 & .003 \\ \end{array}$

B. General Health Status

For Husbands

$\begin{array}{lllllll}\text { Age } & .271 & .0733 & .0733 & .000 & -.211 & .000 \\ \text { Childhood Health } & .368 & .1355 & .0622 & .000 & .227 & .000 \\ \begin{array}{l}\text { Cohesion (Husband) } \\ \text { Education }\end{array} & .395 & .1562 & .0207 & .000 & .148 & .000 \\ \begin{array}{l}\text { For Wives } \\ \text { Age }\end{array} & .412 & .1702 & .0140 & .000 & .129 & .000 \\ \text { Childhood Health } & .3593 & .1291 & .0445 & .000 & .208 & .000 \\ \begin{array}{l}\text { Education } \\ \text { Cohesion (Wife) }\end{array} & .3927 & .1542 & .0251 & .000 & .150 & .000 \\ \text { Companionship (Wife) } & .4184 & .1751 & .0076 & .003 & .090 & .003\end{array}$

C. Mental Health Status

For Husbands

\begin{tabular}{lllllll} 
Childhood Health & .154 & .0236 & .0236 & .000 & .143 & .000 \\
$\begin{array}{l}\text { Cohesion (Husband) } \\
\text { For Wives }\end{array}$ & .203 & .0413 & .0177 & .000 & .134 & .000 \\
\hline Cohesion (Wife) & .224 & .0499 & .0499 & .000 & .211 & .000 \\
Childhood Health & .261 & .0682 & .0183 & .000 & .132 & .000 \\
Education & .273 & .0747 & .0064 & .014 & .081 & .014
\end{tabular}


TABLE XVII, CONTINUED

Regression Analysis

Multiple R Rsq. Rsq. change Sig. Beta Sig.

II. Health Variables

(Utilization)

A. Chronic Disease

For Husbands

Age

.327

.1072

.1072

.000

$.446 \quad .000$

Length of Marriage

.336

.1128

.0056

$\begin{array}{lll}.015 & -.146 \quad .007\end{array}$

Consensus

.343

.1177

.0049

$.022 \quad .071 \quad .022$

$\frac{\text { For Wives }}{\text { Age }}$

Education

.229

.0523

.0523

$.000 \quad .256 \quad .000$

Childhood Health

.244

.0594

.0071

$.008 \quad .092 \quad .007$

.258

$.0663 \quad .0069$

$\begin{array}{lll}.008 & -.083 & .008\end{array}$

B. Trauma

$\frac{\text { For Husbands }}{\text { SES }}$

Age

.143

.0205

.0205

.000

$-.163$

.000

$.210 \quad .0445 \quad .0237$

$\begin{array}{lll}.000 & -.152 \quad .000\end{array}$

Cohesion (Husband)

.223

.0499

.0057

$\begin{array}{lll}.018 & -.075 & .018\end{array}$

For Wives

Childhood Health

.102

.0104

.0104

$\begin{array}{lll}.002 & -.096 \quad .003\end{array}$

Education

.136

.0184

.0080

.006

$-.115 \quad .001$

Cohesion (Husband)

.155

.0241

.0057

$\begin{array}{lll}.019 & -.074 \quad .023\end{array}$

Length of Marriage

.169

.0286

.0044

$\begin{array}{lll}.038 & -.071 \quad .038\end{array}$

C. Acute

For Husbands

$$
\text { Age }
$$

.0096

.0096

.003

.098

.003

For Wives

Childhood Health

.101

.0103

.0103

.002

$-.101$

.002

D. Emotion-Related

For Husbands

Age

.116

.0134

.0134

.000

$.115 \quad .000$

.150

.0225

.0091

$\begin{array}{lll}.003 & -.095 & .003\end{array}$

For Wives

Cohesion (Husband)

.094

.0089

.0089

$\begin{array}{lll}.004 & -.087 \quad .008\end{array}$

Childhood Health

$.0158 \quad .0069$

$.010 \quad-.083 \quad .010$ 
trauma experienced not only by himself but also by his wife. And, in terms of self-esteem, the measure of cohesion of one's spouse adds something to one's own measure of cohesion in explaining variation in one's feelings about oneself. 13

A comparison of the regression findings of Tables XIII, XVI, and XVII is more easily made in Figure 3 ( $p$. 107) which lists the independent variables in each column in their relative order of importance in explaining the various measures of health and well-being for husbands and wives for the various regressions.

Comparative Effects of the Marital Relationship on the Health and Well-Being Measures

Are diseases with a high emotional content more likely to reflect variation in marital cohesion, companionship, cooperation, and consensus than other types of illness?

In reviewing the regression tables presented thus far (Tables XIII, XVI, and XVII), it is observed that there is a slight tendency for variation in emotion-related disease and trauma to be more influenced by marital interaction

13 The separate cohesion measures for husbands and wives have a correlation of .421. For companionship and cooperation, the correlations are .410 and .207 respectively. This suggests that while the marital perceptions of husbands and wives are significantly related, there is enough divergence in perspective for the separate husband/ wife measures to operate somewhat independently (at least in a statistical sense). 
than chronic or acute disease for both husbands and wives. These differences among diseases measured by rates of utilization are not as great, however, as the differences between the impact of marital interaction on these measures of health and on the survey-related health measures. The contributions of the marital variables in accounting for variance in self-esteem and both general and mental health status for both husbands and wives is consistently greater than for the utilization-related health measures. Within the survey-related measures of health, the marital variables are more important (in terms of order of entry into regression equations) in explaining the well-being measures (self-esteem and mental health status) rather than general health status.

Summarizing these results, the evidence suggests that health measures most susceptible to the influence of the emotions, namely the well-being measures and emotionrelated disease and trauma, are most likely to reflect variation in the marital interaction variables.

The Direction of the Marriage/Health Relationship

Do marital cohesion, companionship, cooperation, and consensus influence health and well-being independent of 
the effect of health and well-being on these marital variables? 14

In pursuing this question of causal direction the approach used by Pratt (1976) who partialled out the effects of health on the marriage relationship by controlling for health in childhood will be followed. One must assume, of course, that childhood health is a relatively good indicator of pre-marital health status. As was true for Pratt, the data available offer no better alternative. The correlations of childhood health with the various measures of current health and the marital interaction variables are given in Table XVIII. Since childhood health is significantly associated with both health and marital interaction, it is wise to consider its effects in the analysis which follows.

Table XIX exhibits the results of a regression analysis in which childhood health has been forced to enter each regression equation first before proceeding with the stepwise procedure. If the marital variables enter a regression equation after childhood health has explained as much of the variance in health as it can, it can be said that they have an effect on health independent of childhood health. The magnitude of such an effect, if there is one,

$14^{T h e}$ literature refers to this question as the "selection" versus "protection" hypothesis. Do persons with apparently good health "select" each other for marriage? Or, does marriage "protect" spouses from illness? 
CORRELATIONS BETWEEN CHILDHOOD HEALTH AND THE MARITAL INTERACTION MEASURES AND HEALTH AND WELL-BEING MEASURES FOR HUSBANDS AND WIVES

Childhood Health

Marital Interaction Measures

Cohesion

Companionship

Cooperation

Consensus

Health and Well-Being Measures

Self-Esteem

General Health Status

Mental Health Status

Chronic Disease

Trauma

Acute Disease

Emotion-Related Disease
Husbands

$$
.067 *
$$$$
-.099 * *
$$$$
-.035
$$

.001

$$
.056 *
$$$$
.072 *
$$

$.267 * \star \star$

$$
.154 \star \star \star
$$

$-.026$

$-.030$

$-.039$

$-.038$
Wives $.068 *$

$-.037$

$-.027$

$-.057 *$
$.231 * * *$

$.143 * \star \star$

$-.098 * * *$

$-.102 * * *$

$-.101 * * *$

$-.091 * \star$

\footnotetext{
*SIgnificant at $p=.05$. **Significant at $\mathrm{p}=.01$. $\star * \star$ Significant at $p=.001$.
} 
TABLE XIX

STEPWISE REGRESSION OF SOCIODEMOGRAPHIC VARIABLES AND MARITAL INTERACTION MEASURES ON HEALTH AND WELL-BEING OF HUSBANDS AND WIVES

AFTER FORCING ENTRY OF CHILDHOOD HEALTH

$\underline{\text { Regression Analysis }}$

I. Health and We11-Being

Multiple R Rsq. Rsq. change Sig. Beta Sig.

Variables (Survey)

A. Self-Esteem

For Husbands

$\begin{array}{lllllll}\text { Childhood Health } & .056 & .0031 & .0031 & .089 & .058 & .074 \\ \text { Cohesion } & .151 & .0229 & .0198 & .000 & .147 & .000 \\ \text { Education } & .191 & .0365 & .0136 & .000 & -.117 & .000\end{array}$

For Wives

$\begin{array}{lllllll}\text { Childhood Health } & .072 & .0052 & .0052 & .028 & .067 & .039 \\ \text { Cohesion } & .157 & .0245 & .0194 & .000 & .125 & .000 \\ \text { Age } & .172 & .0294 & .0049 & .030 & .075 & .021 \\ \text { Cooperation } & .184 & .0339 & .0045 & .038 & .069 & .038\end{array}$

B. General Health Status

For Husbands

\begin{tabular}{lllllll} 
Childhood Health & .267 & .0713 & .0713 & .000 & .231 & .000 \\
Age & .368 & .1355 & .0642 & .000 & -.204 & .000 \\
Coheston & .394 & .1550 & .0196 & .000 & .135 & .000 \\
Education & .408 & .1668 & .0118 & .000 & .118 & .000 \\
For Wives & & & & & & \\
\hline Childhood Health & .231 & .0534 & .0534 & .000 & .200 & .000 \\
Age & .359 & .1291 & .0757 & .000 & -.210 & .000 \\
Education & .393 & .1542 & .0251 & .000 & .156 & .000 \\
Cohesion & .414 & .1709 & .0167 & .000 & .118 & .000 \\
Companionship & .419 & .1753 & .0043 & .027 & .067 & .027
\end{tabular}

C. Mental Health Status

For Husbands

$\begin{array}{lllllll}\text { Childhood Health } & .154 & .0236 & .0236 & .000 & .140 & .000 \\ \begin{array}{l}\text { Cohesion } \\ \text { Companionship }\end{array} & .189 & .0356 & .0120 & .000 & .097 & .004 \\ \begin{array}{l}\text { For Wives } \\ \text { Childhood Health }\end{array} & .202 & .0409 & .0053 & .000 & .074 & .029 \\ \text { Cohesion } & & & & & & \\ \text { Education } & .213 & .0204 & .0204 & .000 & .133 & .000 \\ \text { Age } & .231 & .0451 & .0248 & .000 & .154 & .000 \\ & .241 & .0581 & .0045 & .0042 & .072 & .042\end{array}$


TABLE XIX, CONTINUED

$\underline{\text { Regression Analysis }}$

Multiple R Rsq. Rsq. change Sig. Beta Sig.

II. Health Variables

(Utilization)

A. Chronic Disease

For Husbands

$\begin{array}{lllllrl}\text { Childhood Health } & .026 & .0007 & .0007 & .420 & -.000 & .928 \\ \text { Age } & .328 & .1072 & .1065 & .000 & .446 & .000 \\ \text { Length of Marriage } & .336 & .1128 & .0055 & .016 & -.146 & .007 \\ \text { Consensus } & .343 & .1177 & .0049 & .023 & .071 & .023 \\ \begin{array}{l}\text { For Wives } \\ \text { Childhood Health }\end{array} & .098 & .0097 & .0097 & .003 & -.083 & .009 \\ \text { Age } & .243 & .0590 & .0494 & .000 & .257 & .000 \\ \text { Education } & .258 & .0663 & .0073 & .007 & .092 & .007\end{array}$

B. Trauma

For Husbands

$\begin{array}{lllllll}\text { Childhood Health } & .030 & .0009 & .0009 & .364 & -.025 & .430 \\ \text { SES } & .144 & .0208 & .0199 & .000 & -.161 & .000 \\ \text { Age } & .212 & .0449 & .0241 & .000 & -.157 & .000\end{array}$

For Wives

$\begin{array}{lllllll}\text { Childhood Health } & .102 & .0104 & .0104 & .002 & -.103 & .002 \\ \text { Education } & .136 & .0184 & .0080 & .006 & -.113 & .001\end{array}$

$\begin{array}{lllllll}\text { Length of Marriage } & .152 & .0232 & .0048 & .033 & -.073 & .033\end{array}$

C. Acute

For Husbands

$\begin{array}{lllllll}\text { Childhood Health } & .039 & .0015 & .0015 & .235 & -.032 & .321\end{array}$ Age

.103

$.0106 \quad .0091$

$.003 \quad .096 \quad .003$

For Wives

$\begin{array}{lllllll}\text { Childhood Health } & .101 & .0103 & .0103 & .002 & -.101 & .002\end{array}$

D. Emotion-Related

For Husbands

Childhood Health

.038

.120

.0015

$\begin{array}{lll}.241 & -.026 & .417\end{array}$

Age

$.0144 \quad .0129$

$.000 \quad .112$

.001

Cohesion

.136

$.0186 \quad .0042$

$\begin{array}{lll}.045 & -.065 & .045\end{array}$

For Wives

$\begin{array}{lllllll}\text { Childhood Health } & .091 & .0084 & .0084 & .005 & -.091 & .005\end{array}$


is given by changes in R-square brought about by the addition of a marital variable. Table XIX reveals that such an effect exists for each marital variable which originally appeared in each regression (for both husbands and wives) in Table XIII. The changes in R-square for the marital variables are also very similar to those in Table XIII. Support is therefore given to the hypothesis that marriage helps to "protect" the health and well-being of husbands and wives i.e., that marital interaction influences health and well-being independent of the effect of health and well-being on marital interaction.

An alternative test of the "protection" hypothesis was performed by means of a regression analysis utilizing only those husbands and wives in the study population who experienced "excellent" health in childhood. Does marital interaction still make a difference when childhood health is controlled? Table $\mathrm{XX}$ indicates that most of the marital variables remain in the various regressions when compared to Table XIII. Notable exceptions, however, are that cohesion no longer helps to explain mental health status and emotion-related disease for husbands. For the case of trauma, however, cohesion is added to the regression. For wives, cohesion is removed from the explanation of general health status. These findings suggest that marital interaction does influence health and well-being but for the 
TABLE XX

STEPWISE REGRESSION OF SOCIODEMOGRAPHIC VARIABLES AND MARITAL INTERACTION MEASURES ON HEALTH AND WELL-BEING OF HUSBANDS AND WIVES WHO HAD EXCELLENT HEALTH DURING CHILDHOOD

I. Health and Well-Being

$\underline{\text { Regression Analysis }}$

Multiple R Rsq. Rsq. change Sig. Beta Sig. Variables (Survey)

A. Self-Esteem

For Husbands

Cohesion

Education

For Wives

Cohesion

.161

$.0260 \quad .0260$

.001

.165

.000

$.213 \quad .0453 \quad .0193$

$\begin{array}{lll}.003 & -.139 \quad .003\end{array}$

$\begin{array}{lll}.124 & .0152 \quad .0152\end{array}$

$.012 \quad .123 \quad .012$

B. General Health Status

For Husbands

$\begin{array}{lllllll}\text { Age } & .316 & .1000 & .1000 & .000 & -.309 & .000 \\ \begin{array}{l}\text { Cohesion } \\ \text { or Wives }\end{array} & .330 & .1091 & .0090 & .035 & .095 & .035 \\ \text { Age } & .296 & .0876 & .0876 & .000 & -.282 & .000 \\ \text { Companionship } & .324 & .1050 & .0174 & .005 & .128 & .006 \\ \text { SES } & .337 & .1135 & .0085 & .047 & .093 & .047\end{array}$

C. Mental Health Status

For Husbands

(No variables entered the equation)

For Wives

Cohesion

$.168 \quad .0283 \quad .0283$

$.001 \quad .168 \quad .001$

II. Health Variables

(Utilization)

A. Chronic Disease

For Husbands

Age

$.0799 \quad .0799$

$.000 \quad .283 \quad .000$

$\frac{\text { For Wives }}{\text { Age }}$

Education

$\begin{array}{llllll}.156 & .0242 & .0242 & .001 & .202 & .000 \\ .198 & .0390 & .0152 & .011 & .132 & .011\end{array}$


TABLE XX, CONTINUED

$\underline{\text { Regression Analysis }}$

Multiple R Rsq. Rsq. change Sig. Beta Sig.

B. Trauma

For Husbands

Cohesion

$\begin{array}{llllll}.127 & .0162 & .0162 & .007 & -.133 & .004\end{array}$

Age

$\begin{array}{llllll}.178 & .0315 & .0154 & .009 & -.151 & .002\end{array}$

SES

$.230 \quad .0530 \quad .021$

$.002 \quad-.149 \quad .002$

For Wives

SES

.09

$.0093 \quad .0093$

$.049 \quad-.096 \quad .049$

C. Acute

For Husbands

$\begin{array}{lllllll}\text { Length of Marriage } & .114 & .0129 & .0129 & .017 & .103 & .031 \\ \text { SES } & .151 & .0230 & .0099 & .035 & -.100 & .035\end{array}$

For Wives

(No variables entered the equation)

D. Emotion-Rélated

For Husbands Age

$$
.116 \quad .0134 \quad .0134
$$

$.015 \quad .116 \quad .015$

For Wives

(No variables entered the equation) 
(A)

Using Joint

Interaction

Measures - From

Table XIII
(B)

Using Interaction Measures of the Partner - From

Table XVI
(C)

Using Interaction

Measures of

Husband \& Wife

Simultaneously -

From Table XVII
(D)

Using Joint Interaction Measures but Selecting on Excellent for Childhood Health -

From Table XX

\begin{tabular}{|c|c|c|c|}
\hline \multicolumn{4}{|c|}{ SELF-ESTEEM } \\
\hline \multicolumn{4}{|c|}{ Husbands } \\
\hline $\begin{array}{l}\text { Cohesion (Joint) } \\
\text { Education }\end{array}$ & $\begin{array}{l}\text { Cohesion (Wife) } \\
\text { Education } \\
\text { Childhood Health }\end{array}$ & $\begin{array}{l}\text { Cohesion (Husband) } \\
\text { Education } \\
\text { Cohesion (Wife) }\end{array}$ & $\begin{array}{l}\text { Cohesion (Joint) } \\
\text { Education }\end{array}$ \\
\hline
\end{tabular}

\begin{tabular}{lll}
\hline & \multicolumn{3}{c}{ Wives } \\
\hline Cohesion (Joint) & Cohesion (Husband) & $\begin{array}{l}\text { Cohesion (Wife) } \\
\text { Cohesion (Husband) }\end{array}$ \\
Age & & \\
Cooperation & & \\
(Joint) & & \\
Childhood Health & &
\end{tabular}

GENERAL HEALTH STATUS

\begin{tabular}{|c|c|c|c|}
\hline \multicolumn{4}{|c|}{ Hus bands } \\
\hline $\begin{array}{l}\text { Age } \\
\text { Childhood Health } \\
\text { Cohesion (Joint) } \\
\text { Education }\end{array}$ & $\begin{array}{l}\text { Age } \\
\text { Childhood Health } \\
\text { Education } \\
\text { Cohesion (Wife) }\end{array}$ & $\begin{array}{l}\text { Age } \\
\text { Childhood Health } \\
\text { Cohesion (Husband) } \\
\text { Education }\end{array}$ & $\begin{array}{l}\text { Age } \\
\text { Cohesion (Joint) }\end{array}$ \\
\hline \multicolumn{4}{|c|}{ Wives } \\
\hline $\begin{array}{l}\text { Age } \\
\text { Childhood Health } \\
\text { Education } \\
\text { Cohesion (Joint) } \\
\text { Companionship } \\
\text { (Joint) }\end{array}$ & $\begin{array}{l}\text { Age } \\
\text { Childhood Health } \\
\text { Education } \\
\text { Cohesion (Husband) }\end{array}$ & $\begin{array}{l}\text { Age } \\
\text { Childhood Health } \\
\text { Education } \\
\text { Cohesion (Wife) } \\
\text { Companionship } \\
\quad \text { (Wife) }\end{array}$ & $\begin{array}{l}\text { Age } \\
\text { Companionship } \\
\text { (Joint) } \\
\text { SES }\end{array}$ \\
\hline \multicolumn{4}{|c|}{ MENTAL HEALTH STATUS } \\
\hline \multicolumn{4}{|c|}{ Husbands } \\
\hline $\begin{array}{l}\text { Childhood Health } \\
\text { Cohesion (Joint) } \\
\text { Companionship } \\
\text { (Jolnt) }\end{array}$ & $\begin{array}{l}\text { Childhood Health } \\
\text { Cohesion (Wife) }\end{array}$ & $\begin{array}{l}\text { Childhood Health } \\
\text { Cohesion (Husband) }\end{array}$ & -- \\
\hline
\end{tabular}

Figure 3. Comparison of regression analyses. 
Wives

$\begin{array}{llll}\text { Cohesion (Joint) } & \begin{array}{l}\text { Childhood Health } \\ \text { Cohesion (Husband) } \\ \text { Edildhood Health }\end{array} & \begin{array}{l}\text { Cohesion (Wife) } \\ \text { Childhood Health } \\ \text { Education }\end{array} & \begin{array}{l}\text { Education } \\ \text { Age }\end{array}\end{array}$

CHRONIC DISEASE

\begin{tabular}{|c|c|c|c|}
\hline \multicolumn{4}{|c|}{ Husbands } \\
\hline $\begin{array}{l}\text { Age } \\
\text { Length of Marriage } \\
\text { Consensus (Joint) }\end{array}$ & $\begin{array}{l}\text { Age } \\
\text { Length of Marriage } \\
\text { Consensus (Joint) }\end{array}$ & $\begin{array}{l}\text { Age } \\
\text { Length of Marriage } \\
\text { Consensus (Joint) }\end{array}$ & Age \\
\hline \multicolumn{4}{|c|}{ W1ves } \\
\hline $\begin{array}{l}\text { Age } \\
\text { Education } \\
\text { Childhood Health }\end{array}$ & $\begin{array}{l}\text { Age } \\
\text { Education } \\
\text { Childhood Health }\end{array}$ & $\begin{array}{l}\text { Age } \\
\text { Education } \\
\text { Childhood Health }\end{array}$ & $\begin{array}{l}\text { Age } \\
\text { Education }\end{array}$ \\
\hline \multicolumn{4}{|c|}{ TRAUMA } \\
\hline \multicolumn{4}{|c|}{ Husbands } \\
\hline $\begin{array}{l}\text { SES } \\
\text { Age }\end{array}$ & $\begin{array}{l}\text { SES } \\
\text { Age } \\
\text { Cohesion (Wife) }\end{array}$ & $\begin{array}{l}\text { SES } \\
\text { Age } \\
\text { Cohesion (Husband) }\end{array}$ & $\begin{array}{l}\text { Cohesion (Joint) } \\
\text { Age } \\
\text { SES }\end{array}$ \\
\hline \multicolumn{4}{|c|}{ Wives } \\
\hline $\begin{array}{l}\text { Childhood Health } \\
\text { Education } \\
\text { Length of Marriage }\end{array}$ & $\begin{array}{l}\text { Childhood Health } \\
\text { Education } \\
\text { Cohesion (Husband) } \\
\text { Length of Marriage }\end{array}$ & $\begin{array}{l}\text { Childhood Health } \\
\text { Education } \\
\text { Cohesion (Husband) } \\
\text { Length of Marriage }\end{array}$ & SES \\
\hline \multicolumn{4}{|c|}{ ACUTE DISEASE } \\
\hline \multicolumn{4}{|c|}{ Husbands } \\
\hline Age & Age & Age & $\begin{array}{l}\text { Length of Marriage } \\
\text { SES }\end{array}$ \\
\hline \multicolumn{4}{|c|}{ Wives } \\
\hline Childhood Health & Childhood Health & Childhood Health & -- \\
\hline \multicolumn{4}{|c|}{ EMOTION-RELATED DISEASE } \\
\hline \multicolumn{4}{|c|}{ Husbands } \\
\hline $\begin{array}{l}\text { Age } \\
\text { Cohesion (Joint) }\end{array}$ & $\begin{array}{l}\text { Age } \\
\text { Cohesion (Wife) }\end{array}$ & $\begin{array}{l}\text { Age } \\
\text { Cohesion (Wife) }\end{array}$ & Age \\
\hline \multicolumn{4}{|c|}{ Wives } \\
\hline Childhood Health & $\begin{array}{l}\text { Cohesion (Husband) } \\
\text { Childhood Health }\end{array}$ & $\begin{array}{l}\text { Cohesion (Husband) } \\
\text { Childhood Health }\end{array}$ & $-\quad-$ \\
\hline
\end{tabular}

Figure 3. (Continued) 
very healthy its influence is somewhat diminished for certain of the health measures. 
CHAPTER V

SUMMARY AND DISCUSSION

Although the amount of variance explained is small, the findings provide some support for the hypothesis that better health is associated with higher levels of marital interaction. In particular, the cohesion dimension of marital interaction appears as the most important in explaining health and well-being. There is some suggestion that marital interaction has a greater influence on the health of husbands than wives, but the difference is slight. Self-evaluated health and well-being is more sensitive to variation in the marital relationship than clinical data. Within this context measures of health and well-being which tend to be more affect-related (emotionrelated disease, trauma, self-esteem, and mental health status) are also those most likely to be influenced by the marital relationship. These are also the measures which are most affected by the spouse's perceptions of the marital relationship. The effect of marital interaction on health and well-being is independent of the health status one brings to a marriage.

What might account for the importance of cohesion? First, given the relatively high intercorrelations among 
cohesion, companionship, and cooperation (see Table VIII), it may be that companionable and cooperative activities within a marriage are the behaviors which help to produce cohesion. In effect, spouses who engage in more joint activities, especially during periods of leisure, may have greater opportunity to understand and appreciate each other and hence feel happy about their relationship. On the other hand, the reverse may also be true. The number and quality of joint activities may be a reflection of preexisting levels of cohesion (Orthner, 1976). In any case, as Table XXI reveals, the "happiness" aspect of marital cohesion in this study is, in fact, more strongly associated with companionship and cooperation than its other components (shared times of laughing, chatting, and worry about getting along with spouse). Cohesion may, therefore, be taking something of companionship and cooperation into account when it is regressed on the various health measures .

Second, given the importance of the "happiness" aspect of cohesion in marriage, it is possible that the measure of cohesion utilized in this study is only a part, but perhaps a very important part, of a much broader or more global measure of happiness and general well-being. If this is the case, and recent research suggests this is true (Glenn, 1981; Orden and Bradburn, 1973), marital cohesion may conceptually overlap with other subjective 
prominent in relation to survey-based (subjective) rather than utilization-based (objective) measures of health in this study.

\section{TABLE XXI}

CORRELATIONS BETWEEN COMPANIONSHIP AND COOPERATION AND THE COMPONENTS OF THE MARITAL COHESION INDEX (ZERO-ORDER PEARSON)

Marital Interaction Measures

Measures

Companionship

Cooperation
Components of Marital Cohesion Index

Communication

Happiness

Worry

(Chat/Laugh)

$$
.133 * \star \star \quad .001 \quad .063 *
$$

(For Wives)

$\begin{array}{lll}.188 * \star * & .071 * & .167 * \star \star \\ .164 * \star \star & .046 & .146 * \star \star\end{array}$

(For Wives)

$.130 * \star \star$

$.182 * \star *$

\footnotetext{
*Significant at $\mathrm{p}=.05$.

$\star \star$ Significant at $p=.01$.

$\star \star *$ Significant at $\mathrm{p}=.001$.
}

Third, factors which stimulate or contribute to the development of certain illnesses, such as emotion-related disease, may be more easily triggered by the absence of or weakness of the affective qualities of marital interaction as opposed to the cognitive or behavioral content of marital interaction. The findings suggest that spouses who 
enjoy higher levels of marital cohesion (an affective quality) may experience higher levels of health and wellbeing even though they may not share a high degree of consensus (a cognitive quality).

Why was consensus not helpful in explaining health in this study? It is likely that the measure of consensus used here is too limited. Religious homogeneity probably reflects not so much the conscious integration of world views on the part of spouses but rather a by-product of homogeneity with respect to other elements of homogamy in spouse selection, e.g.. SES, race, age, education, etc. Since consensus is significantly related to length of marriage, consensus as operationalized here may reflect spouse selection during an earlier time period when religious homogeneity was more highly valued than it is today. A more valid measure of consensus would tap agreement on a wider range of basic norms, beliefs, attitudes, and values. Constructing such a measure is likely to be difficult, however, if consensus means something different at different stages of the marital career.

While generally women have been regarded to need greater closeness and intimacy (Wright, 1972), to be more impacted by socioemotional factors (Hawkens, 1968), and to have a greater emotional investment in marriage (Bell, 1972); our findings suggest that some of these assumptions 
may not be accurate, or no longer apply, if indeed, they ever did. At the very least, the present findings suggest that interaction in marriage is as important to the health and well-being of husbands as it is to wives.

The Midtown Manhattan Study found few differences in the mental health of married men and women and explained that the strains of career and work may be as disturbing to a man as the strains of marriage are disturbing to a woman. The Midtown researchers were, therefore, unwilling to "assume as yet that the married state has in itself like mental health consequences for the two sex groups" (Srole et al., 1978:215).

Major differences between the Midtown Study and the present research are that specific dimensions of the marital relationship have been the focus of the present study and these have been examined in relationship to other health measures in addition to mental health status. The purpose here has also not been to examine the marriage relationship as a source of stress in comparison to other potential environmental stressors such as career and work. Rather, in accord with the theoretical model presented earlier, the focus here is on the mechanisms by which marriage serves as a buffer against stressors regardless of their origin. It is in this respect that marital interaction in the present research appears to be as important to husbands as to wives. 
Perhaps the meaning attached to marriage by both husbands and wives may be changing over time. The past decade has witnessed a great deal of shifting in the distribution of power and the allocation of roles within and outside of marriage (e.g., working wives) which may in part account for the greater equality between husbands and wives in terms of the effect of the marital relationship on health.

If the marital relationship really does have more significance for the emotional health of husbands, it may be because husbands have fewer close friends and less intimate relationships outside of marriage than their wives. They may therefore depend more on marriage for the satisfaction of their emotional needs. If marriage fails to satisfy these needs, there is greater risk of experiencing lower levels of health and well-being.

A question related to that of whose health is affected more by the marital relationship is: "Whose perceptions of the relationship are more likely to influence one's health--one's own or those of one's partner?" It has been shown that for certain emotionsensitive health measures (self-esteem, trauma, and emotion-related disease) it is the perception of one's spouse which partially accounts for one's own health.17 Why does this occur?

17 This "crossover" effect, however, is not true for the measure of mental health status. 
Since American culture places such a high value on "success" in marriage, married persons are not only motivated to make their own contribution to a "successful" marriage but are, in a sense, obligated to do so. Each partner's perceptions regarding the "success" of the marital relationship are more or less directly communicated to the other. If a married person becomes aware of the fact that his or her spouse perceives marital interaction as negative or as less positive than desired, he or she may feel a sense of failure or inadequacy which, in turn, affects his or her self-esteem and emotional health. One's own perception of marital quality is certainly important, but to evaluate "success" objectively one needs the kind of significant external criterion provided by a spouse. It is easy for one to feel a sense of inadequacy even though one's spouse perceives marital quality to be good, but it is difficult to maintain a good feeling about one's marriage when one's spouse perceives the relationship to be less than desirable.

If there is interest in studying the relative contributions of husband and wife to one another's health and well-being, it is important to collect data from both husbands and wives as has been done here. The merits of this type of data collection are well-documented (Spanier and Lewis, 1980; Scanzoni, 1970; Feldman, 1964). On the other hand, if one's purpose is to determine the relative 
importance of various dimensions of the marital relationship in explaining health, it has been demonstrated that the results obtained are essentially the same if one interviews only one rather than both of the marriage partners. Age for husbands and childhood health for wives are the factors external to the marriage relationship which are the most important determinants of health. Age is the primary or secondary factor in explaining health for husbands defined by utilization of medical services for each of the four disease classes. As men age, they are at greater risk of health impairment. Illness for wives, on the other hand, may to a greater degree than for husbands represent a behavior pattern learned early in life which tends to persist in adulthood. Remarkably, childhood health appears as a factor in the explanation of all seven measures of health and well-being for wives in this study (compared to only two measures, mental and general health status, for husbands) .

SUGGESTIONS FOR FUTURE RESEARCH

The findings of this study encourage further research in an attempt to better understand marriage-health linkages. Suggestions for continuing the work reported here include both the addition of new variables and the refinement of some of those variables which have been utilized. 
On one level, as was already noted, a wider range of norms beliefs, attitudes, and values should be used in constructing a consensus measure. But, if consensus for many couples actually means "agreeing to disagree", this would represent a type of consensus on an entirely different level. At this level it would be possible for a husband and wife to hold different values (e.g.. one a Republican and the other a Democrat) and still be in "consensus" regarding the acceptability of the differences. It would be a challenge to design a measure that would take this type of consensus into account.

Other improvements might include subdividing marital activities into "joint" and "parallel" rather than into companionship and cooperation; using separate social status measures (education, occupation, and perceived social class) for husbands and wives rather than using one measure for the household, i.e., the male head (Hornung, 1981; Langner and Michael, 1963); and studying the effect of marriage on specific diseases within some of the disease classes which have been utilized.

In addition to improving upon the measures used in this study, other elements of marriage might be taken into account to refine and extend the present findings. For example, does the distribution of power or the allocation of roles within marriage enhance or diminish the importance of the marital interaction variables we have selected to 
explain health? Evidence from other studies indicates the desirability of pursuing this question (Pratt, 1976).

While the wife's employment status has been unrelated to marital satisfaction in previous studies (Blood and Wolfe, 1960; Orden and Bradburn, 1974), it should be considered in relationship to the association shown here between marital interaction and health.

Although the number of years a couple has been married is an indirect indicator of stage in the family life cycle, such factors as family size and the number of children and their ages need to be more explicitly taken into account. The presence of children has a great deal of effect, often negative according to many studies (Scheuch, 1960; Spanier and Lewis, 1980; Burke and Weir, 1977; Feldman, 1964; Luckey, 1966), on the quality of interaction between a husband and wife. Does one's relationship with one's children account for much of the effect on one's health and well-being which has been attributed here to one's relationship with one's spouse?

Most of the family literature in sociology, as is true of this study, tends to ignore negative socioemotional interaction and its consequences (Hawkens, 1968). In one study, for example, measures of hostility and tension accounted for more variance in marital satisfaction than companionship (Barnett and Nietzel, 1979). Negative socioemotional experiences would seem to be particularly useful 
in studies using emotionally sensitive health and wellbeing measures. Gurin and his colleagues (1960) remind us that "happiness" in marriage needs to be considered along with feelings of "inadequacy" and an awareness of "problems" in order to achieve a more complete understanding of the marital relationship.

In order to have greater assurance that the marriage relationship does affect health independent of health and well-being prior to marriage, it would be desirable to use additional direct or indirect measures of health and wellbeing which antedate marriage. One of these might be the emotional environment of one's home of origin (Gurin et al., 1960; Goetting, 198I).

A final suggestion for future research would be to mention the benefit of a followup survey of this study population. Although costly, it would provide a "one-group pretest-posttest experimental design" (Campbell and Stanley, 1963). Such a design would offer valuable opportunities to observe changes in marital status and marital perceptions in relationship to changes in health status over time.

To the extent that marital interaction affects health, the identification of those factors which contribute to higher levels of marital interaction has practical implications for the promotion of health, if spouses can be taught to incorporate these factors into their marriage. 
Intervention to improve health status, especially for wives, might involve educational efforts to help couples become more aware of how their health behavior is conditioned by social factors (e.g., childhood socialization) and is therefore at least somewhat amenable to change. At least one health insurance carrier has used measures of cohesion and companionship in designing a "Wellness Kit" for its customers (Aid Association for Lutherans, 1979). The kit provides a scale for family members to rate their life together in terms of these measures and others. Then, on the basis of the results, the family is encouraged, by means of a planning guide also included in the kit, to consider behavioral changes which will result in greater family togetherness and ultimately, it is hoped, improved health and well-being.

Given the ubiquity of stressors in contemporary life and an increasing interest in behaviors which preserve health, studies such as this one should provide additional motivation for strengthening the social support inherent in the marital bond. 
REFERENCES

Aid Association for Lutherans.

1979 The Wellness Kit. Appleton, Wisconsin.

Antonovsky, Aaron

1979 Health, Stress, and Coping. San Francisco: Jossey-Bass.

Aved, Barbara $M$.

1976 "An analysis of the relationship between physical

health status and marital satisfaction among married couples." Dissertation Abstracts International $37(6) \mathrm{A}: 3436$.

Axelson, Leland $J$.

1963 "The marital adjustment and marital role definitions of husbands of working and nonworking wives."

Marriage and Family Living 25:189-195.

Barker, Paul (ed.)

1972 A Sociological Portrait. Baltimore: Penguin Books.

Barnett, Linda $R$. and Michael $T$. Nietzel

1979 "Relationship of instrumental and affectional behaviors and self-esteem to marital satisfaction in distressed and nondistressed couples." Journal of Consulting and Clinical Psychology 47:946-957.

Bel1, Colin

1972 "Marital status." In Paul Barker (ed.), A Sociological Portrait. Baltimore: Penguin Books.

Benson, Purnell

1952 "The interests of happily married couples." Marriage and Family Living 14:276-280.

Berkman, Paul L.

1969 "Spouseless motherhood, psychological stress, and physical morbidity." Journal of Health and Social Behavior 10:323-334.

Berkson, Joseph

1962 "Mortality and marital status." American Journal of Public Health 52:1318-1329.

Bernard, Jessie

1964 "Developmental tasks of the NCFA - 1963-1988." Journal of Marriage and the Family 26:29-38.

1972 The Future of Marriage. New York: Bantam. 
Blalock, Hubert M., Jr.

1972 Social Statistics (Second Edition). New York: McGraw-Hill.

Blood, Robert 0., Jr. and Donald M. Wolfe

1960 Husbands and Wives. Glencoe: Free Press.

Blumenthal, M.D.

1967 "Mental health among the divorced: a field study of divorced and never divorced persons." Archives of General Psychiatry 16:603-608.

Bossard, James H.S. and Eleanor S. Boll

1955 "Marital unhappiness in the life cycle." Marriage and Family Living 17:10-14.

Bradburn, Norman and David Caplovitz

1965 Reports on Happiness. Chicago: Aldine.

1969 The Structure of Psychological Well-Being. Chicago: Aldine.

Brown, George W., Maire Ni Bhrolchain, and Tirril Harris

1975 "Social class and psychiatric disturbance among women in an urban population." Sociology 9:225-254.

Burgess, E.W. and L.S. Cottrell

1939 Predicting Success or Failure in Marriage. New York: Prentice-Hall.

Burgess, E.W. and Paul Wallin

1944 "Predicting adjustment in marriage from adjustment in engagement." American Journal of Sociology $49: 324-330$.

Burgess, E.W., Harvey J. Locke, and Mary Margaret Thomes

1963 The Family: From Institution to Companionship (Third Edition). New York: American Book Company.

Burke, Ronald J. and Tamara Weir

1977 "Husband-wife helpng relationships: the 'mental hygiene' function in marriage." Psychological Reports 40:911-925.

1977 "Marital helping relationships: the moderators between stress and well-being." The Journal of Psychology 95:121-130. 
Burr, Wesley R.

1970 "Satisfaction with various aspects of marriage over the life cycle: a random middle-class sample." Journal of Marriage and the Family 32:29-37.

Campbell, Angus, Phillip E. Converse, and Willard L. Rodgers 1975 The Perceived Quality of Life. New York: Russell Sage.

Campbel1, Donald and Donald Fiske

1959 "Convergent and discriminant validation by the multitrait, multimethod matrix." Psychological Bulletin 56:81-105.

Campbell, Donald T. and Julian C. Stanley

1963 Experimental and Quasi-Experimental Designs for Research. Chicago: Rand McNally.

Carisse, Collette B.

1975 "Family and leisure: a set of contradictions." Family Coordinator 24:191-197.

Cassel, John

1976 "The contribution of the social environment to host resistance." American Journal of Epidemiology 104:107-123.

Chafetz, Janet $\mathbf{S}$.

1978 A Primer on the Construction and Testing of Theories in Sociology. Itasca, Illinois: F.E. Peacock.

Charon, Joel $M$.

1979 Symbolic Interactionism. Englewood Cliffs: Prentice-Hall.

Chien, Agnes and Lawrence J. Schneiderman

1975 "A comparison of health care utilization by husbands and wives." Journal of Community Health l:118-126.

Cobb, Sidney, Stanislav Kasl, John R.P. French, and Guttorm Norstebo

1969 "Why do wives with rheumatoid arthritis have husbands with peptic ulcer?" Journal of Chronic Diseases $22: 279-293$.

Crandell, Dewitt L., and Bruce P. Dohrenwend

1967 "Some relations among psychiatric symptoms, organic illness, and social class." American Journal of Psychiatry 123:1527-1537. 
Cuber, John F. and Peggy B. Harroff

1965 The Significant Americans. New York: Appleton-Century.

Cunningham, Kenneth R. and Theodore B. Johannis, Jr.

1960 "Research on the family and leisure: a review and critique of selected studies." Family life

Coordinator 9:25-32.

Dentler, Robet $A$. and Peter C. Pineo

1960 "Sexual adjustment, marital adjustment, and personal growth of husbands." Marriage and Family Living $22: 45-48$.

Dizard, Jan

1968 Social Change in the Family. Chicago: University of Chicago.

Dohrenwend, B.P. and B.S. Dohrenwend

1965 "The problem of validity in field studies of psychological disorder." International Journal of Psychiatry 1:585-610.

Donald, Marjorie N. and Robert J. Havighurst

1959 "The meanings of leisure." Social Forces 37:355-360.

Downes, Jean

1947 "Chronic disease among spouses." The Milbank Memorial Fund Quarterly 25:334-358.

Dumazedier, Joffre

1967 Toward a Society of Leisure. New York: Free Press.

Edwards, John N.

1967 "The future of the family revisited." Journal of Marriage and the Family 29:505-511.

Elinson, Jack and Ray E. Trussell

1957 "Some factors relating to degree of correspondence for diagnostic information as obtained by household interviews and clinical examinations." American Journal of Public Health 47:311-321.

Feldman, Harold

1964 Development of the Husband-Wife Relationship. Ithaca: Cornell University.

Freeborn, Donald K., Clyde R. Pope, Maradee A. Davis, and John P. Mullooly

1977 "Health status, socioeconomic status, and utilization of outpatient services for members of a prepaid group practice." Medical Care 15:115-128. 
Freeborn, Donald $K$. and Clyde R. Pope

1981 "Health status, utilization, and satisfaction among enrollees in three types of private insurance plans." Presented at the Annual Meeting of the American Public Health Association, Los Angeles, California.

Fried, Marc

1969 "Social differences in mental health." In John Kosa, Aaron Antonovsky, and Irving K. Zola (eds.), Poverty and Health. Cambridge: Harvard University.

Geismar, Ludwig L.

1973555 Families. New Brunswick: Transaction.

Gerson, Walter

1960 "Leisure and marital satisfaction of college married couples." Marriage and Family Living 22:360-361.

Glenn, Norval D.

1975 "The contribution of marriage to the psychological well-being of males and females." Journal of Marriage and the Family 37:594-601.

Glenn, Norval D. and Charles $N$. Weaver

1981 "The contribution of marital happiness to global happiness." Journal of Marriage and the Family 43:161-168.

Glick, Bruce R.

1976 "Self-esteem, the perception of support during marital conflict, and marital satisfaction." Dissertation Abstracts International 37(5) B:2504-2505.

Goetting, Ann

1981 "Divorce outcome research: issues and perspectives." Journal of Family Issues 2:350-378.

Gove, Walter R.

1972 "The relationship between sex roles, marital status, and mental illness." Social Forces 51:34-44.

1973 "Sex, marital status, and mortality." American Journal of Sociology 79:45-67.

Graham, Saxon

1963 "Social factors in relationship to chronic illnesses." In Howard E. Freeman, Sol Levine, and Leo G. Reeder (eds.). Handbook of Medical Sociology. Englewood Cliffs: Prentice-Hall.

Greenberg, Joel

1981 "Study says remarriage boosts lifespan." The Oregonian, August 4. 
Grey, Alan L.

1970 Man, Woman, and Marriage. New York: Atherton Press.

Gurin, Gerald, Joseph Veroff, and Sheila Feld

1960 Americans View Their Mental Health. New York: Basic Books.

Handel, Gerald (ed.)

1967 The Psychosocial Interior of the Family. Chicago: Aldine.

Hare, E.H. and G.K. Shaw

1965 "A study in family health: health in relation to family size." British Journal of Psychology 11l:461.

Hawkens, James L.

1968 "Associatioans between companionship, hostility, and marital satisfaction." Journal of Marriage and the Family 30:647-650.

Hawkins, Harold and James Walters

1952 "Family recreational activities." Journal of Home Economics $44: 623-626$.

Hawkins, James L, and Kathryn Johnsen

1969 "Perception of behavioral conformity, imputation of consensus, and marital satisfaction." Journal of Marriage and the Family 31:507-511.

Heer, David M.

1962 "Husband and wife perceptions of family power structure." Journal of Marriage and the Family $24: 65-67$.

Henry, Frank

1982 "Multivariate analysis and ordinal data." American Sociological Review 47:299-304.

Hicks, Mary W. and Mairlyn Platt

1970 "Marital happiness and stability: a review of the research in the sixties." Journal of Marriage and the Family 32:553-566.

Hobart, Charles W.

1963 "Commitment, value conflict, and the future of the family." Marriage and Family Living 25:405-412.

Hollingshead, August B. and Frederick C. Redlich

1953 "Social stratification and psychiatric disorders." American Sociological Review 18:163-169. 
Homans, George C.

1950 The Human Group. New York: Harcourt, Brace and World.

1961 Social Behavior: Its Elementary Forms. New York: Harcourt, Brace and World.

Hornung, Carlton A. and B. Claire McCullough

1981 "Status relationships in dual-employment marriages: consequences for psychological well-being." Journal of Marriage and the Family 43:125-141.

Hurtado, Arnold V. and Merwyn R. Greenlick

1971 "A disease classification system for analysis of medical care utilization, with a note on symptom classification." Health Services Research 6:235-250.

Insel, Paul M. and Rudolf H. Moos (eds.)

1974 Health and the Social Environment. Lexington: D.C. Heath.

Jordan, John R.

1976 "Marital adjustment and satisfaction: the role of companionship." Dissertation Abstracts International 37 ( 3 ) B : $1436-1437$.

Kaiser-Permanente Health Services Research Center.

1980 Kaiser-Permanente Medical Care Program: A Description of the Health Services Research Center. Portland, Oregon.

Kaplan, Berton H., John C. Cassel, and Susan Gore

1977 "Social support and health." Medical Care 15:47-58.

Kaplan, Max

1960 Leisure in America: A Social Inquiry. New York: Wiley.

Kasl, Stanislav V. and Sidney Cobb

1966 "Health behavior, illness behavior." Archives of Environmental Health 12:246-266.

Kellner, R.

1963 Family Ill Health: An Investigation in General Practice. Springfield: C.C. Thomas.

Kerckhoff, A.

1966 "Family patterns and morale in retirement." In I. Simpson and J. McKinney (eds.), Social Aspects of Aging. Durham: Duke University. 
Kim, Jae-On

1980 "Factor analysis and the construction of factor scales: procedure factor." In Norman H. Nie, C. Hadlai Hull, Mark N. Franklin, Jean G. Jenkins, Keith J. Sours, Marija J. Norusis, and Viann Beadle, SCSs: A User's Guide to the SCSS Conversational System. New York: McGraw-Hill.

Klausner, W.J.

1968 "An experiment in leisure." Science Journal 4:81-85.

Kobrin, F.E. and G.E. Hendershot

1977 "Do family ties reduce mortality? Evidence from the United States, 1966-1968." Journal of Marriage and the Family 39:737-745.

Komarovsky, Mirra

1962 Blue Collar Marriage. New York: Random House.

Koos, Earl

1954 The Health of Regionville. New York: Columbia University.

Kraus, Arthur S. and Abraham M. Lilienfeld

1959 "Some epidemiologic aspects of the high mortality rate in the young widowed group." Journal of Chronic Diseases 10:207-217.

Kraus, Richard

1971 Recreation and Leisure in Modern Society. New York: Appleton-Century-Crofts.

Kreitman, Norman

1964 "The patient's spouse." British Journal of Psychiatry 110:159-173.

Krueger, Dean E.

1957 "Measurement of prevalence of chronic disease by household interview and clinical evaluations." American Journal of Public Health 47:953-960.

Kuhn, Thomas

1970 The Structure of Scientific Revolutions. Chicago: University of Chicago.

Langner, Thomas $\mathbf{s}$.

1962 "A twenty-two item screening score of psychiatric symptoms indicating impairment." Journal of Health and Human Behavior 3:269-276.

Langner, Thomas S. and Stanley M. Michael

1963 Life Stress and Mental Health. Glencoe: The Free Press. 
Lattorgue, Zeva

1960 "Morbidity and marital status." Journal of Diseases $12: 476-498$.

Lawrence, P.S.

1948 "Chronic illness and socioeconomic status." Public Health Reports 63:1507-1521.

Lehman, E.W.

1967 "Social class and coronary heart disease: a sociological assessment of the medical literature." Journal of Chronic Diseases 20:381-391.

Leighton, A.H., John A. Clausen, and Robert N. Wilson

1957 Explorations in Social Psychiatry. New York: Basic Books.

Lerner, Monroe

1969 "Social differences in physical health." In John Kosa, Aaron Antonovsky, and Irving K. Zola (eds.), Poverty and Health. Cambridge: Harvard University.

Levinger, George

1964 "Task and social behavior in marriage." Sociometry $27: 433-448$.

1965 "Marital cohesiveness and dissolution: an integrative review." Journal of Marriage and the Family 27:19-28.

Levinger, George and James Breedlove

1966 "Interpersonal attraction and agreement: a study of marriage partners." Journal of Personality and Social Psychology $3: 367-372$.

Lilienfeld, Abraham M.

1956 "Variation in mortality from heart disease." Public Health Reports 71:545-552.

Litman, Theodor J.

1974 "The family as a basic unit in health and medical care: a socio-behavioral overview." Social Science and Medicine 8:495-519.

Litman, Theodor J. and Maureen Venters

1979 "Research on health care and the family: a methodological overview." Social Science and Medicine $13 \mathrm{~A}: 379-385$.

Locke, Harvey J.

1951 Predicting Adjustment in Marriage. New York: Henry Holt. 
Luckey, Eleanor Braun

1959 "An investigation of the concepts of the self, mate, parents, and ideal in relation to degree of marital satisfaction." Dissertation Abstracts International $29(1): 396$.

1960 "Marital satisfaction and congruent self-spouse concepts." Social Forces 39:153-157.

1964 "Measures of marital satisfaction: a correlation study of three instruments." Journal of Home Economics 56:593-598.

1966 "Number of years married as related to personality perception and marital satisfaction." Journal of Marriage and the Family 28:44-48.

Luckey, Eleanor Braun and Joyce K. Bain

1970 "Children: a factor in marital satisfaction." Journal of Marriage and the Family 32:43-44.

Mancini, Jay A.

1979 "Family relationships and morale among people 65 years of age and older." American Journal of Orthopsychiatry 49:292-300.

Mangus, A.R.

1957 "Family impacts on mental health." Marriage and Family Living 19:256-262.

Mauksch, Hans 0 .

1974 "A social science basis for conceptualizing family health." Social Science and Medicine 8:521-528.

McDonald, Gerald w.

1980 "Family power: the assessment of a decade of theory and research, 1970-1979." Journal of Marriage and the Family 42:841-854.

McEwan, Peter J.M.

1974 "The social approach to family health studies." Social Science and Medicine 8:487-493.

McKinley, Donald G.

1964 Social Class and Family Life. Glencoe: The Free Press.

Mechanic, David

1959 "Illness and social disability: some problems in analysis." Pacific Sociological Review 2:37-41. 
Mechanic, David

1962 "The concept of illness behavior." Journal of Chronic Diseases 15:189-194.

1965 "Some problems in the analysis of morbidity data." Journal of Chronic Diseases 18:569-580.

1966 "Response factors in illness: the study of illness behavior." Social Psychiatry 1:11-20.

Meissner, W.W.

1966 "Family dynamics and psychosomatic processes." Family Process 5:142-161.

Meyers, J.K. and L. Schaffer

1954 "Social stratification and psychiatric practice." American Sociological Review 19:307-310.

Nast, Evelyn C.

1979 "The relationship between value systems and marital satisfaction." Dissertation Abstracts International $39(8)$ B : 4046 .

Neumeyer, Martin H. and Esther S. Neumeyer

1958 Leisure and Recreation: A Study of Leisure and Recreation in their Sociological Aspects (Third Edition). New York: Ronald Press.

Olson, David H. and Carolyn Rabunsky

1972 "Validity of our measures of family power." Journal of Marriage and the Family 34:224-234.

Orden, Susan R. and Norman Bradburn

1973 "Dimensions of marriage happiness." American Journal of Sociology 73:715-731.

1974 "Working wives and marriage happiness." American Journal of Sociology 74:392-407.

Orthner, Dennis K.

1974 "Leisure activity patterns and marital interaction." Dissertation Abstracts International 35(2)A:1256-1257.

1975 "Leisure activity patterns and marital satisfaction over the marital career." Journal of Marriage and the Family 37:91-102.

1976 "Patterns of leisure and marital interaction." Journal of Leisure Research 8:98-111. 
Paris, Bethel L. and Eleanor B. Luckey

1966 "A longitudinal study of marital satisfaction." Sociology and Social Research 50:212-223.

Parsons, Talcott

1972 "Definitions of health and illness in the light of American values and social structure." In E.J. Jaco (ed.), Patients, Physicians and Illness. New York: The Free Press.

Parsons, Talcott and Robert F. Bales

1955 Family, Socialization, and Interaction Process. Glencoe: The Free Press.

Parsons, Talcott and Renee Fox

1952 "Illness, therapy and the modern urban American family." Journal of Social Issues $8: 31-44$.

Pearlin, L.I. and J.S. Johnson

1977 "Marital status, life strains, and depression." American Sociological Review 42:704-715.

Petroni, Frank A.

1969a "Significant others and illness behavior: a much neglected sick role contingency." The Sociological Quarterly 10:32-41.

1969b "Social class, family size, and the sick role." Journal of Marriage and the Family 31:728-735.

Picken, Bruce and George Ireland

1969 "Possible influences of family size, role, and social class on illness behavior." Journal of Chronic Diseases 22:181-191.

Pilisuk, Marc and Charles Froland

1978 "Kinship, social networks, social support and health." Social Science and Medicine 12B:273-280.

Pineo, Peter C.

1961 "Disenchantment in the later years of marriage." Marriage and Family Living 23:3-11.

Pope, C.R., D.K. Freeborn, and M.R. Greenlick

1972 "Use of outside physicians by members of a group practice prepayment plan." Presented at the 100th Annual Meeting of the American Public Health Association, Atlantic City, New Jersey.

Pratt, Lois

1972 "Conjugal organization and health." Journal of Marriage and the Family 34:85-94. 
Pratt, Lois

1976 Family Structure and Effective Health Behavior. Boston: Houghton Mifflin.

Radioff, L.

1975 "Sex differences in depression: the effects of occupation and marital status." Sex Roles 1:249-265.

Rainwater, Lee

1968 "The lower class: health, illness, and medical institutions." In Irwin Deutscher and Elizabeth J. Thompson (eds.), Among the People: Encounters with the Poor. New York: Basic Books.

Raush, Harold

1977 Close Relationships: Perspectives on the Meaning of Intimacy. Boston: University of Massachusetts.

Raush, Harold, William Barry, Richard Hertel, and Mary Ann Swain

1974 Communication, Conflict and Marriage. San Francisco: Jossey-Bass.

Raymond, Jonathan S., Deborah L. Rhoads, and R. Irene Raymond

1980 "The relative impact of family and social involvement on Chicano mental health." American Journal of Community Psychology 8:557-569.

Renne, Karen $S$.

1971 "Health and marital experience in an urban population." Journal of Marriage and the Family $23: 338-350$.

1974 "Measurement of social health in a general population survey." Social Science Research 3:25-44.

Rennie, Thomas A.C., Leo Srole, Marvin K. Opler, and Thomas S. Langner

1957 "Urban life and mental health: socioeconomic status and mental disorder in the metropolis." American Journal of Psychiatry 113:831-837.

Richardson, William C.

1972 "Poverty, illness, and the use of health services in the United States." In E.G. Jaco (ed.), Patients, Physicians and Illness. New York: Free Press.

Rico-Velasco, J. and L. Mynko

1973 "Suicide and marital status: a changing relationship." Journal of Marriage and the Family $35: 239-244$. 
Rogers, Lawrence S., Harl H. Young, Irwin H. Cohen, Jack Dworin, and Milton E. Lipetz

1970 "Marital stability, mental health, and marital satisfaction." Journal of Consulting and Clinical Psychology 35:342-348.

Rollins, Boyd C. and Harold Feldman

1970 "Marital satisfaction over the family life cycle." Journal of Marriage and the Family 32:20-28.

Rollins, Boyd $C$. and Kenneth L. Cannon

1974 "Marital satisfaction over the family life cycle: a re-evaluation." Journal of Marriage and the Family $36: 271-283$.

The Roper Organization, Inc.

1974 The Virginia Slims American Women's Opinion Poll, Volume III.

Rosenstock, Irwin M.

1966 "Why people use health services." Milbank Memorial Fund Quarterly 44:94-127.

Roth, Julius and Robert F. Peck

1951 "Social class and social mobility factors related to marital adjustment." American Sociological Review $16: 478-487$.

Rummel, R.J.

1967 "Understanding factor analysis." The Journal of Conflict Resolution 11:444-480.

Sanders, Barkev S.

1962 "Have morbidity surveys been oversold?" American Journal of Public Health 52:1648-1659.

Scanzoni, John H.

1970 Opportunity and the Family. New York: The Free Press.

Scheuch, Erwin K.

1960 "Family cohesion in leisure time." The Sociological Review 8:37-61.

Seiler, L.

1973 "The 22-item scale used in field studies of mental illness: a question of method, a question of substance, and a question of theory. Journal of Health and Social Behavior 14:252. 
Sheps, Mindel C.

1961 "Marriage and mortality." American Journal of Public Health 51:547-555.

Shostak, Arthur B. and William Gomberg

1964 Blue Collar World. Englewood Cliffs: Prentice-Hall.

Shostak, Arthur B.

1969 Blue Collar Life. New York: Random House.

Smith, H.W.

1975 Strategies of Social Research. Englewood Cliffs: Prentice-Hall.

Spanier, Graham B., Robert A. Lewis, and Charles L. Cole

1975 "Marital adjustment over the family life cycle: the issue of curvilinearity." Journal of Marriage and the Family 37:263-275.

Spanier, Graham B, and Robert A. Lewis

1980 "Marital quality: a review of the seventies." Journal of Marriage and the Family 42:825-839.

Spaulding, J.A. and G. Simpson, trans.

1951 Suicide. By E. Durkheim. Glencoe: The Free Press.

Srole, Leo, Thomas S. Langner, Stanley T. Michael, Price

Kirkpatrick, Marvin K. Opler, Thomas A. Rennie

1978 Mental Health in the Metropolis: The Midtown

Manhattan Study. New York: New York University.

Stinnett, N., L. Carter, and J. Montgomery

1972 "Older persons' perceptions of their marriages." Journal of Marriage and the Family 34:665-670.

Stuckert, Robert P.

1963 "Role perception and marital satisfaction - a configurational approach." Marriage and Family Living $25: 415-419$.

Suchman, Edward A., Bernard S. Phillips, and Gordon F. Streib

1958 "An analysis of the validity of health questionnaires." Social Forces 36:23-232.

Terman, Lewis

1938 Psychological Factors in Marital Happiness. New York: McGraw-Hill. 
Terman, Lewis and Melita Oden

1947 The Gifted Child Grows Up: Twenty-Five Years of Following a Superior Group. Stanford: Stanford University.

Trussell, R.E. and J. Elinson

1959 Chronic Illness in a Rural Area. Cambridge: Harvard University.

Turner, Jonathan $\mathrm{H}$.

1974 The Structure of Sociological Theory. Homewood, Illinois: The Dorsey press.

Udry, Richard J., Harold A. Nelson, and Ruth Nelson

1961 "An empirical investigation of some widely held beliefs about marital interaction." Marriage and Family Living 23:388-390.

Verbrugge, Lois $M$.

1979 "Marital status and health." Journal of Marriage and the Family 41:267-285.

Veroff, Joseph and Sheila Field

1970 Marriage and Work in America. New York: Van Nostrand-Reinhold.

Weiss, Robert L. and Barbara M. Aved

1978 "Marital satisfaction and depression as predictors of physical health status." Journal of Consulting and clinical Psychology 44:1379-1384.

Williams, Ann Marie

1978 "The quantity and quality of marital interaction related to marital satisfaction: a behavioral analysis." Dissertation Abstracts International $38(7)$ B : 3424 .

Winch, Robert F.

1963 The Modern Family. New York: Holt, Rinehart and Winston.

Wright, Derek

1972 "Sex differences." In Paul Barker (ed.), A Sociological Portrait. Baltimore: Penguin Books.

Zaleski, Zbigniew

1978 "Neuroticism and marital satisfaction." Behavior Research and Therapy 16:285-286.

Zalocar, Julia B.

1960 "Marital satisfaction and major causes of death in women." Journal of Chronic Diseases 11:50-60. 


\section{APPENDIX}

\begin{tabular}{|c|c|c|}
\hline \multicolumn{3}{|c|}{$\begin{array}{l}\text { WEDICAL CARE UTILIZATION STUDY-FORM A } \\
\text { IMEDICAL SERVICE RECORD FORM }\end{array}$} \\
\hline & \multirow{3}{*}{$\begin{array}{l}\text { A. MORBIDITY } \\
\text { NAME } \\
\text { ICDA NO. }\end{array}$} & \multirow[b]{3}{*}{ (Card 01/37-40) 口 inapp. } \\
\hline \multirow{2}{*}{$(1-3) \quad 101$} & & \\
\hline & & \\
\hline $\begin{array}{l}\text { Card Code } \\
(10-19)\end{array}$ & $\begin{array}{l}\text { B. STATUS OF } \\
\text { DIAGNOSIS }\end{array}$ & $\begin{array}{ll}\text { (41) } 1 \square \text { unknown } & 3 \text { Destablished } \\
2 \square \text { tentative } & 9 \text { Q inapplicable }\end{array}$ \\
\hline$(10-19) \quad$ H.P.1.D. & EPISODE & (46) 1 Dinitial visit 35 \\
\hline 1. $(20-25)$ OATE OF SERVICE & $\begin{array}{c}\text { Punch g's } \\
\text { if blank }\end{array}$ & \\
\hline Honth & \multirow{2}{*}{\multicolumn{2}{|c|}{ 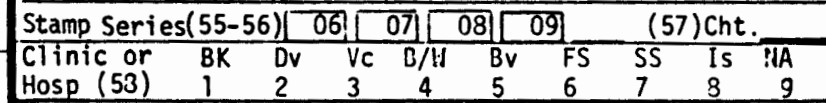 }} \\
\hline \multirow{2}{*}{ 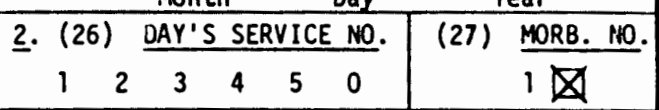 } & & \\
\hline & \multirow{3}{*}{$\begin{array}{l}\text { D. MAJOR } \\
\text { PRESENTING } \\
\text { SYMPTOMS }\end{array}$} & \multirow{2}{*}{ 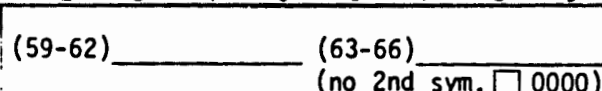 } \\
\hline 3. (28) DAY OF SERVICE & & \\
\hline $\begin{array}{lllllll}S & \text { in } & T & W & \text { Th } & F & S \\
7 & 1 & 2 & 3 & 4 & 5 & 6\end{array}$ & & 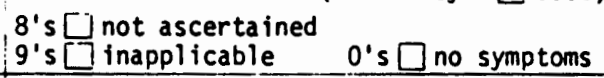 \\
\hline 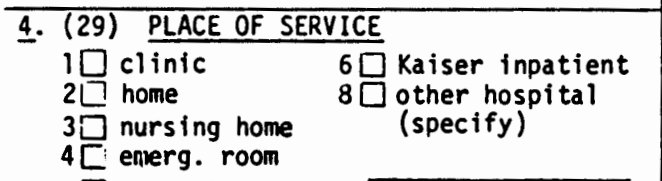 & \multirow[t]{2}{*}{$\begin{array}{l}\text { E. DURATION } \\
\text { OF MAJOR } \\
\text { PRESENTING } \\
\text { SY:IPTOMS }\end{array}$} & $\begin{array}{l}\text { days }(67-69), 666 \square \text { vague, less } \\
\text { than à year } \\
000 \square \text { less than } 1 \text { day } \\
998 \square \text { not ascertained } 777 \square \text { than a year } \\
999 \square \text { inapplicable }, 888 \square \text { since birth }\end{array}$ \\
\hline $\begin{array}{l}5 \square \text { phone/letter } 9 \text { Joutside N.0. } \\
\text { o[ other (specify) }\end{array}$ & & $\begin{array}{l}\text { (70) Assoc. Horb. for Hosp. Adms. } \\
\text { Referred by: } \quad(71-73) \text { stamp }(74-78)\end{array}$ \\
\hline \multirow{2}{*}{ 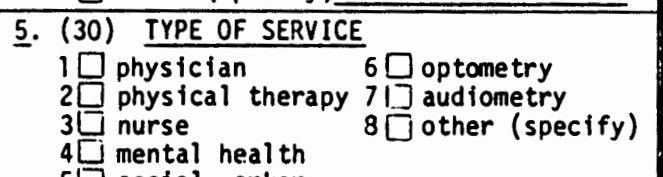 } & \multirow{3}{*}{$\begin{array}{l}\text { F. PROCEDURES } \\
\text { RENDERED } \\
\begin{array}{l}\text { Punch } 9^{\prime} s \\
\text { in blank } \\
\text { fields }\end{array} \\
\end{array}$} & \multirow{3}{*}{$\begin{array}{l}\left(\frac{1}{(c .02 / 29-32)}{ }^{2} \cdot \frac{}{(33-36)}{ }^{3} \cdot \frac{}{(37-40)}\right. \\
4_{(41-44)}^{5} \cdot \frac{}{(45-48)}\end{array}$} \\
\hline & & \\
\hline \multirow{2}{*}{$\begin{array}{l}\text { 6. (31) TIME OF SERVICE } \\
1 \square \text { during clinic hours } 90 \text { inapplicable } \\
=\square \text { not during } \\
=\square \text { clinic hours }\end{array}$} & & \\
\hline & \multirow{2}{*}{$\begin{array}{l}\text { G. TYPE OF } \\
\text { SCHEDULED } \\
\text { RETURN } \\
\text { VISIT }\end{array}$} & \multirow{2}{*}{$\begin{array}{l}\text { (53) RETURN VISIT: } \\
1 \square \text { Scheduled....... } 54-76 \text { SEE BELON } \\
8 \square \text { Not scheduled.. } 54-76 \text { punch } 8 \text { 's } \\
9 \square \text { inapplicable... } 54 \text { 54-76 punch } 9 \text { 's }\end{array}$} \\
\hline $\begin{array}{ll}\text { (32) TYPE OF APPOINTMENT } \\
1 \square \text { regular scheduled } 4 \square \text { phone/letter } \\
2 \square \text { walk-in } & 50 \text { other (specify) }\end{array}$ & & \\
\hline $\begin{array}{l}3 \square \text { emergency room } \\
7 \square \text { walk-in/after clinic hours }\end{array}$ & & \multirow{2}{*}{ 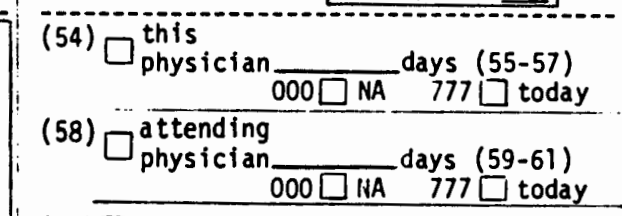 } \\
\hline $\begin{array}{l}\text { 8. }(33-35) \frac{\text { PKYSICIAN OR OTHER PROFESSIORAL }}{\text { RENDERIHG OR ORDERING SERVICE }} \\
\text { REE }\end{array}$ & & \\
\hline \multirow{2}{*}{$\begin{array}{l}\text { 9. (36) STATUS OF PHYSICIAN } \\
1 \square \text { attending } \quad 5 \square \text { other (specify) }\end{array}$} & & \multirow{3}{*}{ 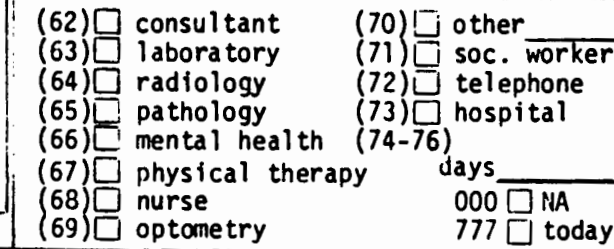 } \\
\hline & $\begin{array}{l}h \text { g's } \\
\text { each } \\
\text { d } \\
\text { ox }\end{array}$ & \\
\hline $3 \square$ consul tant--referred by: & & \\
\hline $\begin{array}{l}\text { Clerk: } \\
\cdots, 1,1\end{array}$ & Tech: & (77) No. of Associated itor \\
\hline
\end{tabular}


12. Associated Horbidity

13. Associated Horbidity

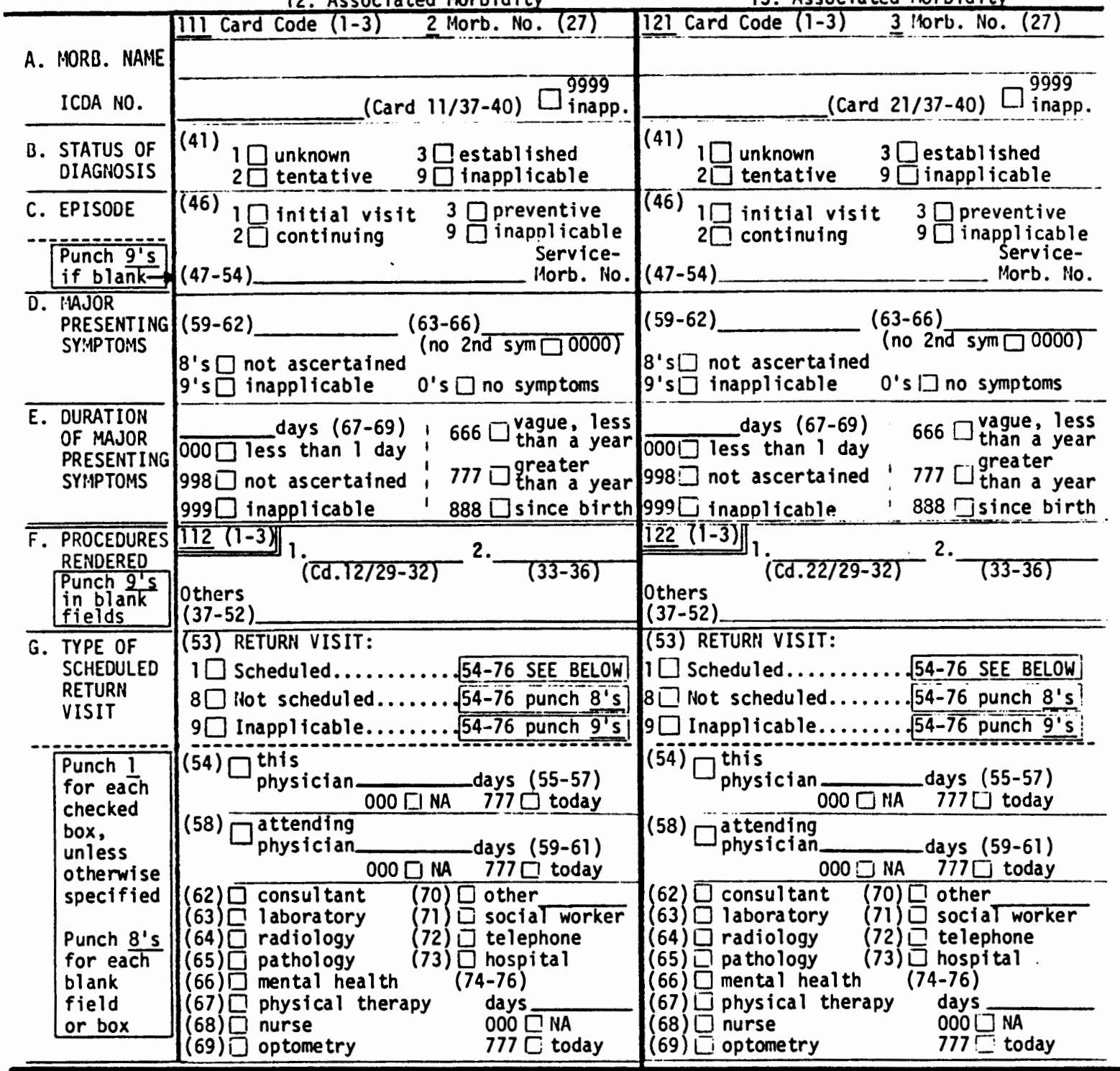

$104(1-3)$ dup. cols. 4-26, 28 पDRUGS OROERED $\square$ IMMUNIZATIONS $\square$ NONE ORDEREO $\square$ INAPPLICABLE

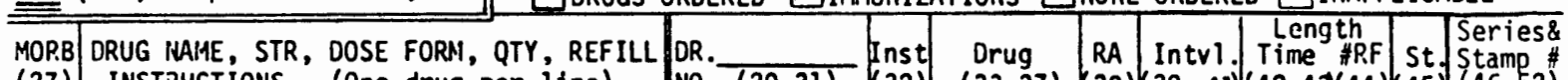
(27) INSTRUCTIONS (One drug per i ine) NO. (29-31) $(32)(33-37)(38)(39-41)(42-43)(44)(45)(46-52)$

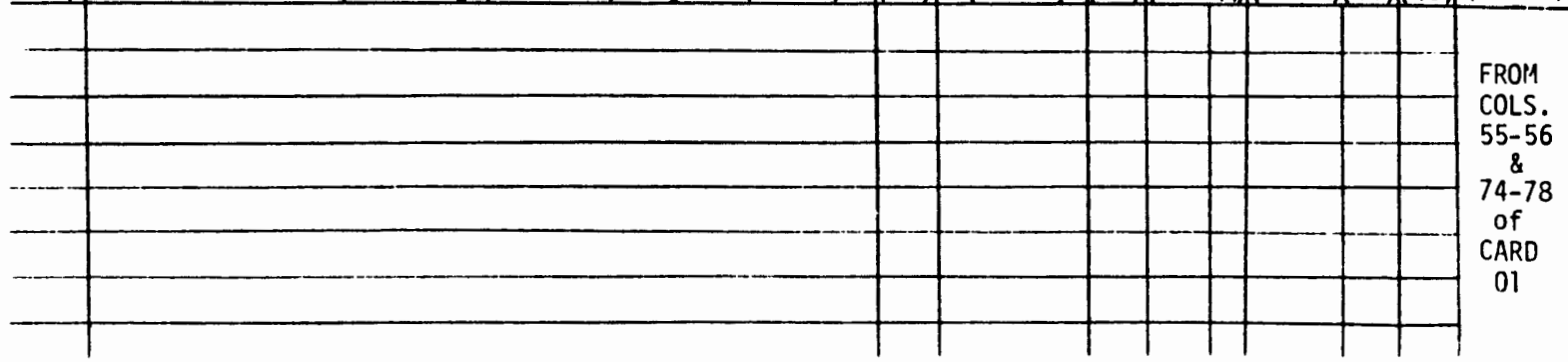




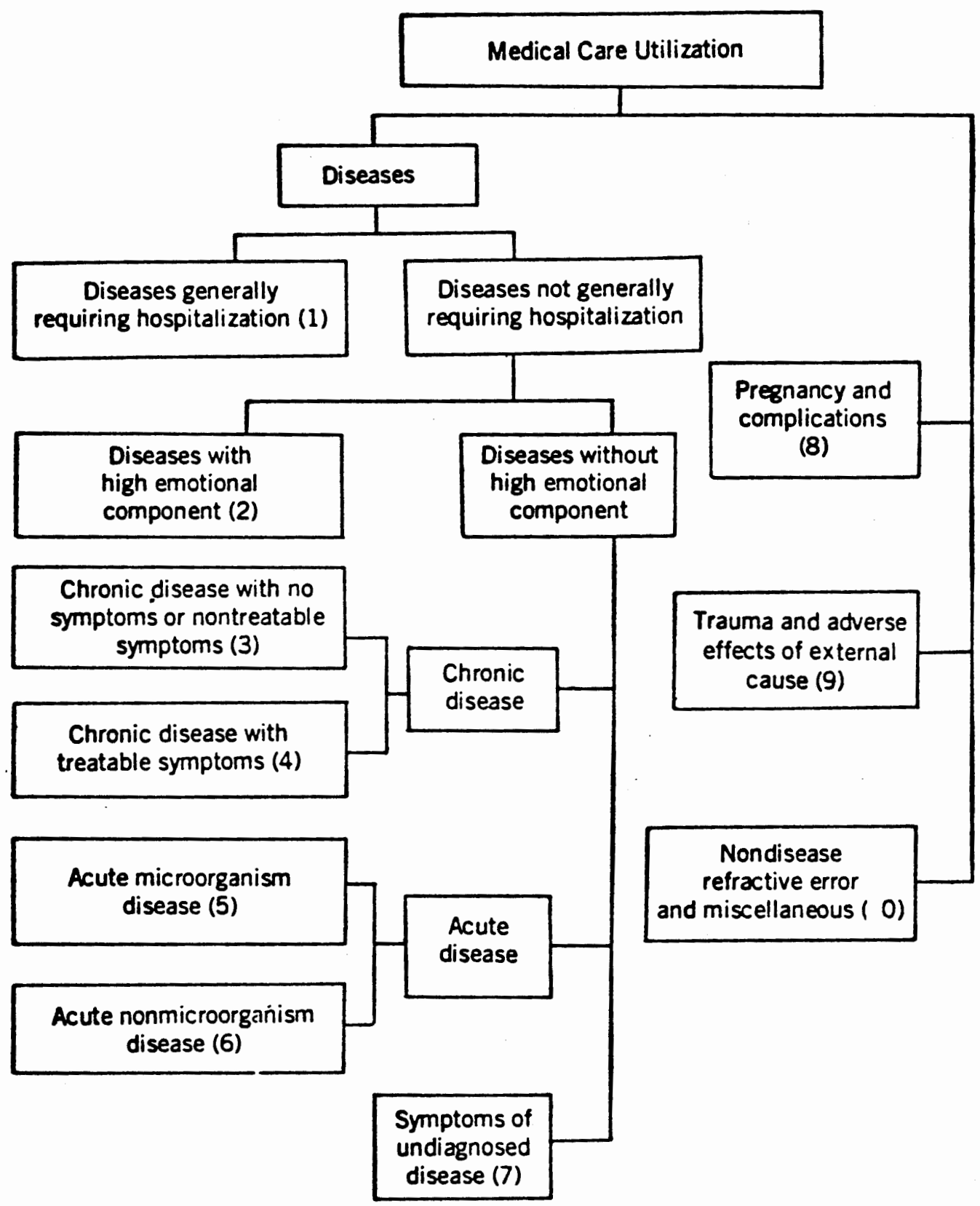

Basic structure of the Kaiser Clinical-Behavioral Classification System. 